\title{
Oil Mist Compliance
}

Federal Manufacturing \& Technologies

\author{
L.J. Lazarus
}

KCP-613-8544s

Published January 2009

\section{Final Report}

Approved for public release; distribution is unlimited.

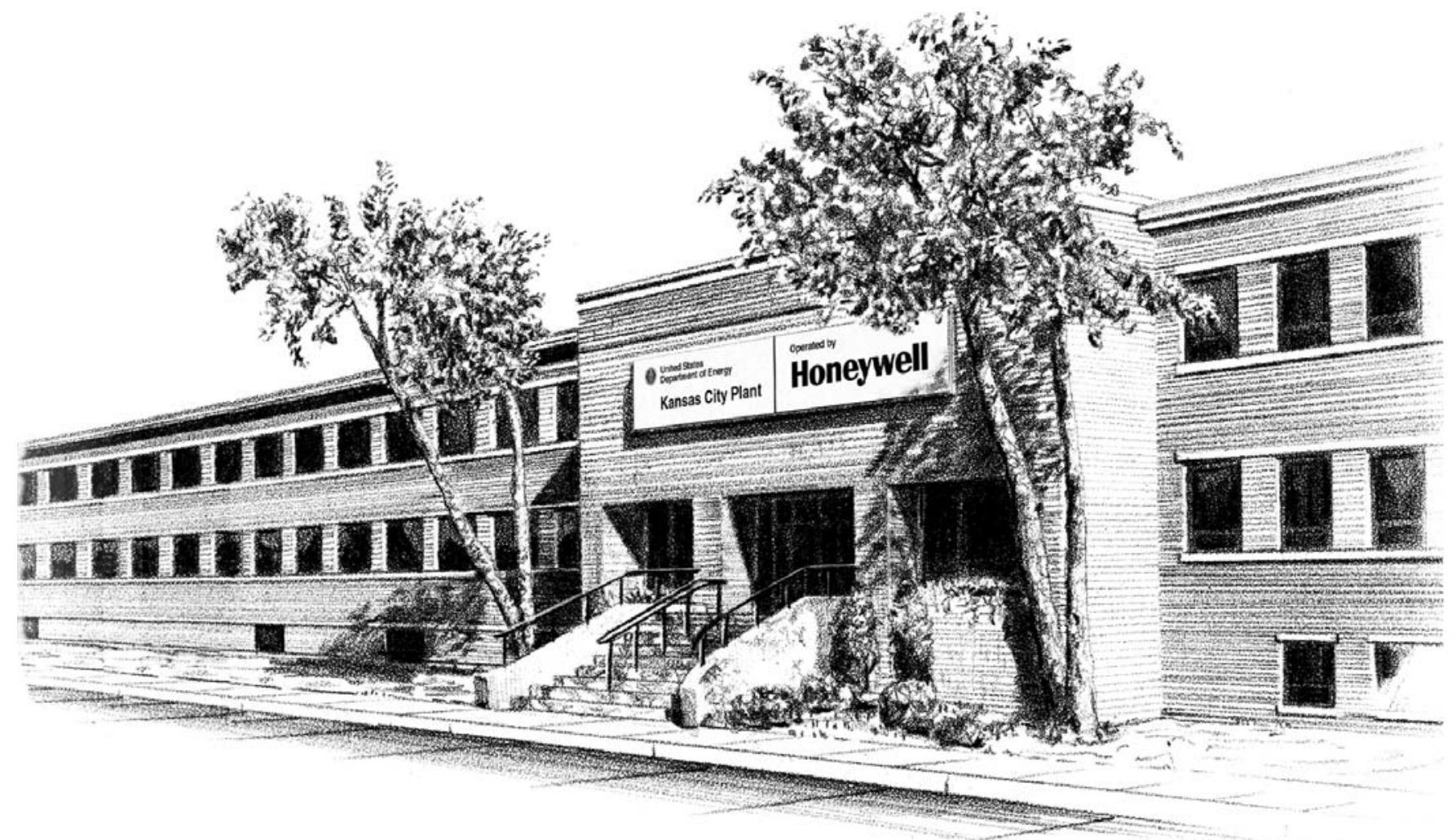

Prepared under prime contract DE-ACO4-01AL66850 for the United States Department of Energy 


\section{DISCLAIMER}

This report was prepared as an account of work sponsored by an agency of the United States Government. Neither the United States Government nor any agency thereof, nor any of their employees, makes any warranty, express or implied, or assumes any legal liability or responsibility for the accuracy, completeness, or usefulness of any information, apparatus, product, or process disclosed, or represents that its use would not infringe privately owned rights. Reference herein to any specific commercial product, process or service by trade names, trademark, manufacturer, or otherwise, does not necessarily constitute or imply its endorsement, recommendation or favoring by the United States Government or any agency thereof. The views and opinions of authors expressed herein do not necessarily state or reflect those of the United States Government or any agency thereof.

All data prepared, analyzed and presented has been developed in a specific context of work and was prepared for internal evaluation and use pursuant to that work authorized under the reference contract. Reference herein to any specific commercial product, process or service by trade name, trademark, manufacturer, or otherwise, does not necessarily constitute or imply its endorsement, recommendation or favoring by the United States Government, any agency thereof or Honeywell Federal Manufacturing \& Technologies, LLC.

Printed in the United States of America.

This report has been reproduced from the best available copy.

Available to DOE and DOE contractors from the Office of Scientific and Technical Information, P.O. Box 62, Oak Ridge, Tennessee 37831; prices available from (865) 576-8401, FTS 626-8401.

Available to the public from the National Technical Information Service, U.S. Department of Commerce, 5285 Port Royal, Rd., Springfield, Virginia 22161, (703) 487-4650.

A prime contractor with the United States Department of Energy under prime contract DE-ACO4-01AL66850.
Honeywell Federal Manufacturing \& Technologies

P. O. Box 419159

Kansas City, Missouri 64141-6159 
KCP-613-8544

Distribution Category UC-42

Approved for public release; distribution is unlimited.

Oil Mist Compliance

L.J. Lazarus

Published January 2009

Final Report

L.J. Lazarus, Project Leader 


\section{Contents}

Section Page

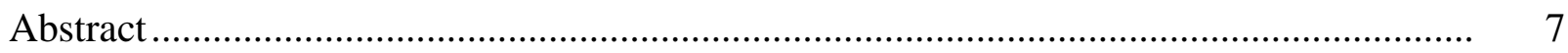

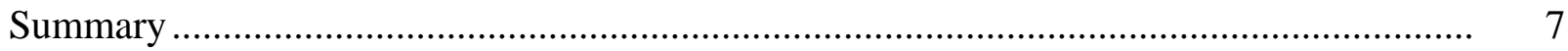

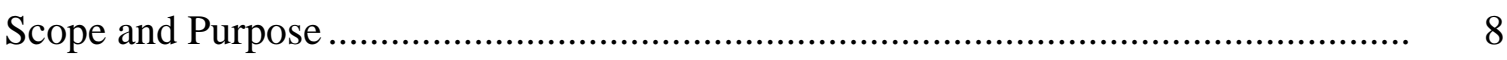

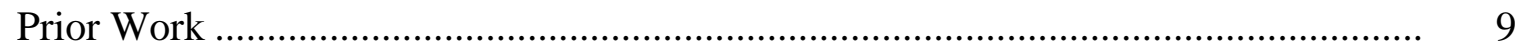

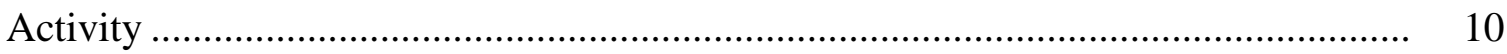

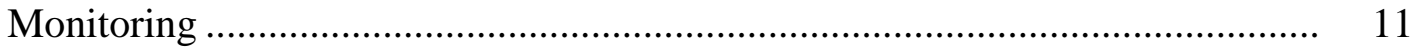

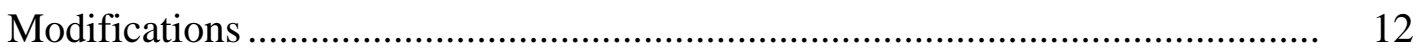

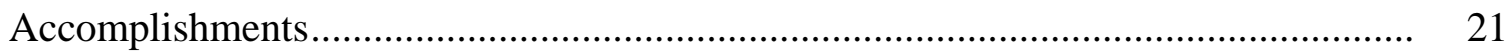

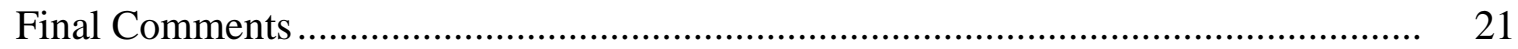

Appendices

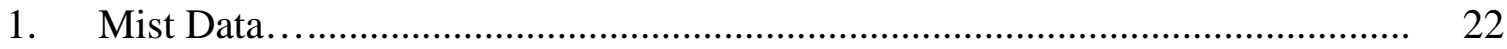

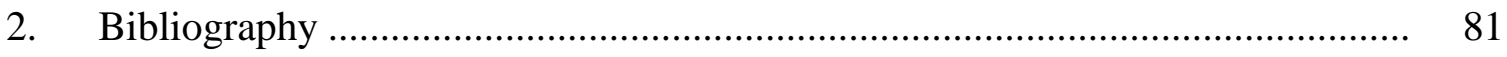

3. Supplier Technical Data on MIE Personal

Data Ram and Mist Collectors.................................................................. 84 


\section{Illustrations}

Figure Page

1 Monarch VMC-75........................................................................................ 10

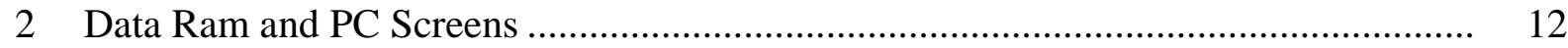

3 Monarch Machining Center ...................................................................................... 13

4 Bostomatic Machining Center ........................................................................ 13

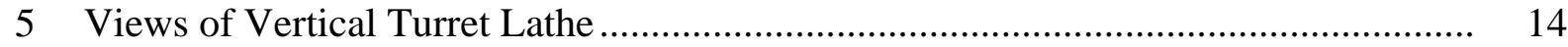

6 Large American Lathe ................................................................................. 15

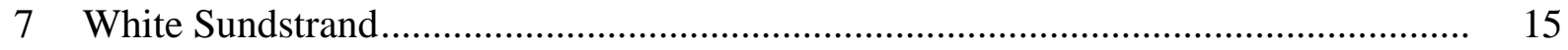

8 Large Portable Mist \& Fume Collector ............................................................... 16

9 Comparative Mist Data-Large American Lathe .................................................. 17

10 Typical Installation on a T-Bed lathe using redeployed mist collectors \& splash shield ...................................................................... 17

11 Hardinge CHNC4 with HEPA smoke and mist collector installed .......................... 18

12 Secondary mist collector installed on exhaust of Smog Hog ................................... 19

13 Redeployed mist collector installed downstream from Smog Hogs ......................... 20

14 Nagel-TB 3 Axis Gun Drill.......................................................................... 21 


\begin{abstract}
This report summarizes activities at the KCP related to evaluating and modifying machine tools in order to be in compliance with Section 23 of DOE 10 CFR 851, Worker Safety and Health Program. Section 851.23 (a) states that "Contractors must comply with the following safety and health standards that are applicable to the hazards in their covered workplace", and subsection 9 contains the following applicable standard: "American Congress of Governmental Industrial Hygienists (ACGIH), 'Threshold Limit Values for Chemical Substances and Physical Agents and Biological Exposure Indices,' (2005) (incorporated by reference, see \$851.27) when the ACGIH Threshold Limit Values are lower (more protective) than permissible exposure limits in 29 CFR 1910." In the 2005 ACGIH - Threshold Limit Value book a Notice of Change was issued for exposure to mineral oil mist used in metalworking fluids (MWFs). The effects of planning for the new facility and which machine tools would be making the transition to the new facility affected which machine tools were modified.
\end{abstract}

\title{
Summary
}

Two actions that happened almost simultaneously defined this project. First, DOE issued 10 CFR 851 the Worker Safety and Health Program. Section 851.23 (a) states that "Contractors must comply with the following safety and health standards that are applicable to the hazards in their covered workplace”, and subsection 9 contains the following applicable standard: "American Congress of Governmental Industrial Hygienists (ACGIH), 'Threshold Limit Values for Chemical Substances and Physical Agents and Biological Exposure Indices,' (2005) (incorporated by reference, see §851.27) when the ACGIH Threshold Limit Values are lower (more protective) than permissible exposure limits in 29 CFR 1910.” OSHA had been struggling with new mist requirements for metalworking fluids (MWFs), but when OSHA left the mist requirement the same (5.0 mg/M3) and just issued a best practice guide the American Congress of Governmental Industrial Hygienists (ACGIH) felt they had to take action. During 2004, ACGIH asked for comments on a proposed change to their Threshold Limit Value for mineral oil mist. In 2005, ACGIH issued their Notice of Change for mineral oil mist used in MWFs.

In order to be proactive and determine the scope of the possible problem at the KCP this study was commissioned. Machine tools were evaluated in the main machining (chip making) departments. Many of the large machine tools had been purchased in the early 1980s when OSHA Guarding requirements were minimal. Most machine tools had no enclosure and no mist control equipment. Today replacement equipment of this size costs upward of $\$ 1,000,000$. Ways of utilizing the splash shield along with adding temporary enclosures with mist collectors were evaluated. Methods of modification were tried and some proved successful in lowering employee exposure to the proposed mist requirements.

At the same time, the DOE also changed its quality standards to commercial quality so that part of its manufacturing could go to Outside Vendors (OSV). This allowed NNSA and Senior FM\&T management to consider downsizing the KC Plant. During the second year of this project KCRIMS became a reality and the technical staff was downsizing the manufacturing 
department based on needs. This factor, combined with reductions because of treaties and the future of weapons production, lead to giving up a significant amount of machining capability. The equipment this project addressed kept changing. From the final KCRIMS equipment list the project team was able to identify machine tools that would make the transition to the new facility. These were the machine tools the project addressed. Solutions to the mist levels over the proposed ACGIH TLV were accomplished and mist collection equipment was installed on machine tools. By utilizing mist collection equipment installed as part of SMRI project a number of machine tools were modified without purchasing additional mist collectors.

The following was accomplished during this project:

- Mist Collectors installed:

- 5 Cortland VMC-75B Machining Centers

- 5 American lathes w/partial enclosures

- 4 Bostomatic Machining Centers - Not transition - KCRIMS

- 1 transferred with mist collector

- 1 collector redeployed to another department, Grinder \& Bostomatic excessed

- 2 other currently in use

- 4 Hardinge CNC lathes

- 3 Plunge Form Grinders (3 redeployed collectors)

- 3 T-Bed lathes (with redeployed mist collectors)

- 1 Centerless Grinder

- $\quad$ Evaluated 9 machine tools \& determined they did not need collectors (TBT Gun Drill (2) , Okuma (2), White, (1), Hermle (2))

- Evaluated 5 machine tools before it was decided not to move them to the new facility and were dropped from list (2 VTL’s, Center Drive Lathe, Hollow Spindle Lathe, Tracer lathe).

- Prototyped particle collector for jig grinder

- Measured mist level during MQL Testing included in MQL report

\section{Scope \& Purpose}

On February 9, 2006 the Department of Energy published the final rules in the Federal Register for 10 CFR 850 \& 851. 10 CFR 851 is the Worker Safety and Health Program. In section 851.23 subsection (a) declares that "Contractors must comply with the following safety and health standards that are applicable to the hazards in their covered workplace", and subsection 9 contains the following applicable standard: "American Congress of Governmental Industrial Hygienists (ACGIH), 'Threshold Limit Values for Chemical Substances and Physical Agents and Biological Exposure Indices,' (2005) (incorporated by reference, see §851.27) when the ACGIH Threshold Limit Values are lower (more protective) than permissible exposure limits in 29 CFR 1910.” In the ACGIH 2005 Annual Report the Committees on Threshold Limit Values (TLVs) and Biological Exposure Indices (BEIs) issued the notice of Intended Change (NIC) pertaining to Mineral Oil used in Metalworking Fluids lowering the exposure limit from $5 \mathrm{mg} / \mathrm{M} 3$ to $0.2 \mathrm{mg} / \mathrm{M} 3$. Mineral oil is the primary component of all oil based metalworking fluid and soluble oil and semi synthetic water-based metal working fluids. These DOE and ACGIH actions, in combination, affected all machining 
operations that used metalworking fluids in all DOE facilities. This project was planned to start in the fall of 2005 to evaluate the impact of this proposed new rule at the KCP, develop a plan of action, and then implement that plan.

\section{Prior Work}

There are two primary types of metalworking fluids (MWFs); oil and water based. Waterbased MWFs are broken up into three groups:

- Soluble oil which is a mix of 4 to $10 \%$ oil, emulsifiers, buffers, biocides, rust inhibitors and the balance is water.

- Semi-Synthetics in which the oil component is replaced with a mix of oils and synthetic lubricants. The additional additive package is modified.

- Synthetic in which the oil component is replaced with synthetic lubricants. The additive package is tailored to the synthetic lubricants.

Employee mist exposure and possible heath effects have been a constant topic since the 1980s. Since metalworking fluids are primarily mixtures of multiple components, formulators have removed ingredients that have been designated as possible cancer causing agents. In the past, polyaromatic hydrocarbons (PAHs) and nitrosamine forming agents were removed from metalworking fluids. At the KCP, all mineral oils that are not high and severely refined (severely hydro treated or severely solvent refined) are not allowed to be used and stocked in stores. If one is allowed, a carcinogen plan must be issued for the department using the material. Presently all MWF and lubricants used in the machining departments are severely hydro treated and/or severely solvent refined.

Prior to 1993, the United Autoworkers signed collective bargaining agreements with the big three US Automobile Manufacturers (Chrysler, Ford, GM) to limit the exposure of MWF mists to the bargaining unit employees of less than $0.5 \mathrm{mg} / \mathrm{M} 3$. The automobile manufacturers and the UAW sponsored research and funded cancer studies on the effects of MWF on employee health.

In December of 1993 the UAW petitioned OSHA to reduce MWF exposure for all workers to $0.5 \mathrm{mg} / \mathrm{M} 3$. OSHA and NIOSH were funded to evaluate the MWF issues. In February 1996 OSHA made Coolant/Metalworking Fluids a targeted item, and in January 1998 NIOSH issued the criteria document "Criteria for a Recommended Standard - Occupational Exposure to Metalworking Fluids”. OSHA formed the Standards Advisory Committee in May 1997 to make recommendations for a new rule. Michigan's state wide OSHA type program fined a cutting tool manufacturer based on Michigan statues in May 1999 based on the proposed NIOSH REL. In July 1999 the OSHA Standards Advisory Committee issued their recommendation of $0.5 \mathrm{mg} / \mathrm{M} 3$. The UAW again sued OSHA in 2001 for not issuing a mist exposure standard. In December 2001, OSHA issued their Best Practice Guide.

During these years, industry and professional organizations were not ignoring the issues related to MWFs. There were many thrust activities that included the National Center for Manufacturing Sciences (NCMS) - Metalworking Fluids Project, Organizational Resources 
Counselors (ORC) - Metal Removal Fluids Task Force (also sponsored by ILMAIndependent Lubricant Manufacturers Association, American Automotive Manufacturers Association) and the Society of Manufacturing Engineers' Specialty Conferences. Two symposiums were held in Dearborn on the Industrial Metalworking Environment. Many of the publications of these organizations were quoted in the OSHA Best Practice Guide. ASTM, the American Automotive Manufacturers Association, and the Society of Automotive Engineers published standards that affect MWFs or their uses. OSHA included whole sections from the ORC guide in their document. The author has served on the MCMS Metalworking Fluids Project and the ORC MRF Task Force and the amount of literature published during this period is vey large.

Today the Society of Tribologists and Lubrication Engineers (STLE) has a rigorous Certified Metalworking Fluid Specialist certification program with requirements of a Bachelor of Science Degrees, five years of experience in working with MWF, and an eight hour Certification Exam. The Society of Manufacturing Engineers has a Metalworking Fluids Community with its own web page that is up-dated twice a month with information on the metalworking fluid environment. STLE and SME also cosponsor A Metalworking Fluid Certificate Program that includes three days of classes. This program is offered at least twice per year.

Despite the vast amount of study and research, scientists can not find a smoking gun that trigger the body's response to metalworking fluids. MWF are a mixture of many components that are constantly changing from the time they are added to the machine sump until used up and replaced. They are influenced by internal house keeping practices, hydraulic and way oil leaks, water hardness and purity, air borne bacteria and mold spoors, and many other factors. It is the synergistic effects of the materials, time, and contamination that trigger the body's response. Since all humans are different each person reacts differently to the exposure.

\section{Activity}

At the start of this project the KCP had many machine tools purchased before 1990 (Photo 1). These machines had no enclosures or mist collection accessories. Starting in the ' 90 s machine tool manufacturers started to manufacture machine tools with enclosures.

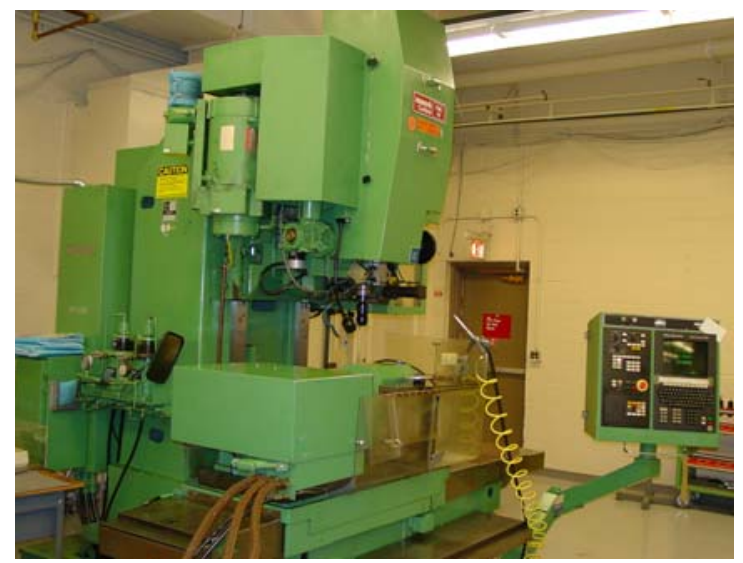

Figure 1. Monarch VMC-75- At one time KCP had 19 of these machine tools 
As the use of high pressure (1000 psi) coolant (MWF) spread, all machine tool manufacturers started making machines with enclosures. The problem with these designs was that they didn't include mist collectors to draw the mist out of the enclosure. When a machinist opens the enclosure to change or check a part he is being exposed to the mist that exists in the cavity. Since the TLV has been reduced to only $4 \%$ of what was legal before, the exposure from changing a part can raise the employee 8 hour exposure above the TLV.

\section{Monitoring}

All mist monitoring performed on this project was done with a Thermo Anderson Personal Data Ram (Photo 2). The literature on this instrument is included in Appendix 3 of this report. Unlike the standard requirement, the monitor was mounted between the controls of the CNC machine and where the operator worked when loading parts or observing the operation. In this way it was known what the machinist would be exposed to if he stayed at the machine. Over the course of the day the operator leaves the machine to perform other work duties. During this period, the operator is away from the operation zone where the mist levels are the highest. The machinist can still watch what is going on but the exposure will be less. Some machinists sit away from the machine to reduce their noise exposure. The pictures on the following page show where the monitor was mounted while data was being taken. All jobs monitored were being worked on production or development PIDS and product. Production jobs were run at the programmed speeds and feeds. One must also consider the type of MWF being used when evaluating the data. The requirement is on mineral oil mist. Therefore, when we are measuring the exposure on oil based MWF the instrument is reading directly. However, when we are measuring a water-based MWF, which is $6 \%$ oil, then the true exposure to mineral oil mist is $6 \%$ of the reading. The members of this project believe this would be unacceptable to our employees, and have diligently tried to limit the total exposure to $0.2 \mathrm{mg} / \mathrm{M} 3$.

Even though the unit is compact, it still is fairly large and heavy. Operators objected to its weight. In one case, when an operator wore the unit, there was a problem. This operator was a smoker. During his smoke brakes the unit recorded very high readings that over shadowed the rest of the data. The calculated TLV the instrument recorded was incorrect and an order of magnitude too high.

The unit was always started in the Process and Machining Evaluation Lab so that an idea of the machining department's background level could be established. Usually this represents less than 5 minutes of the data run. In most instances the monitor ran by the machine tool for 6 hours. Data files were down loaded from the Data Ram and plotted in Excel. The photographs on the following page show the screen available when the monitor is connected to the PC. A sampling rate of 5 points/min was used and provided approximately 6 hours of data. 


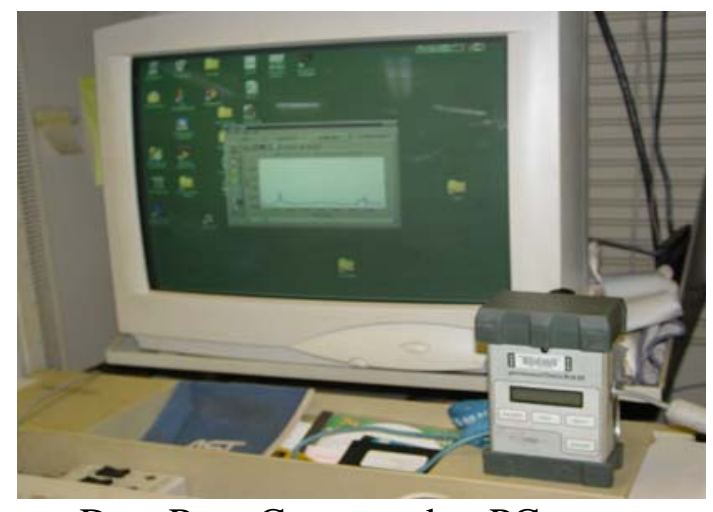

Data Ram Connected to PC

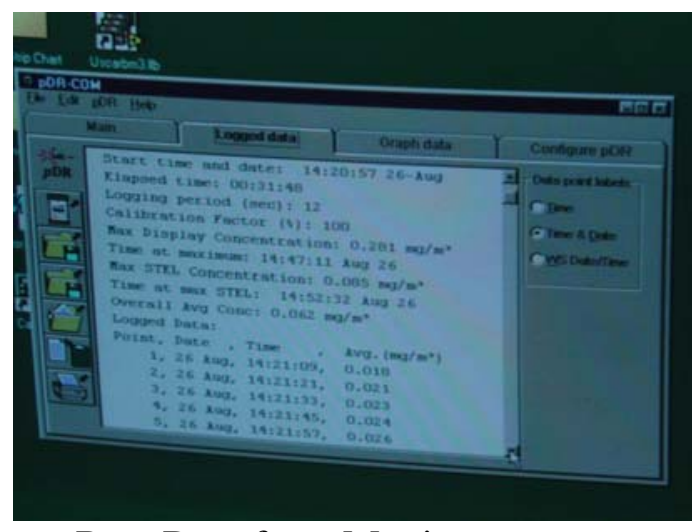

Raw Data from Monitor

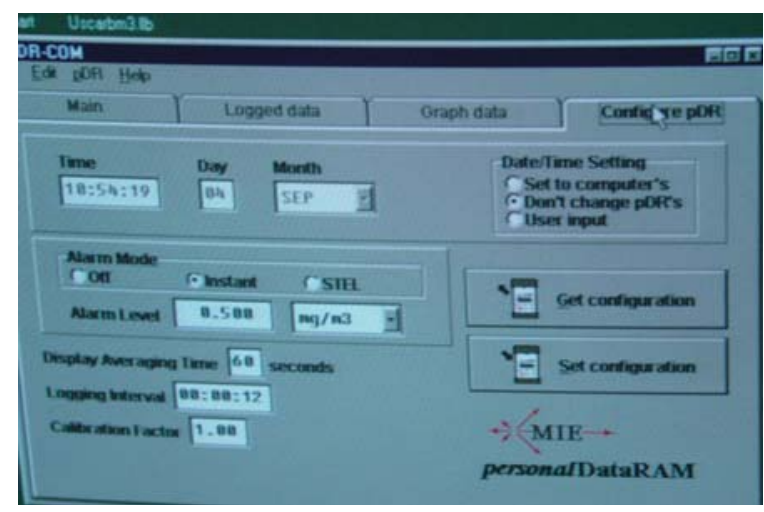

Instrument Set-up Screen

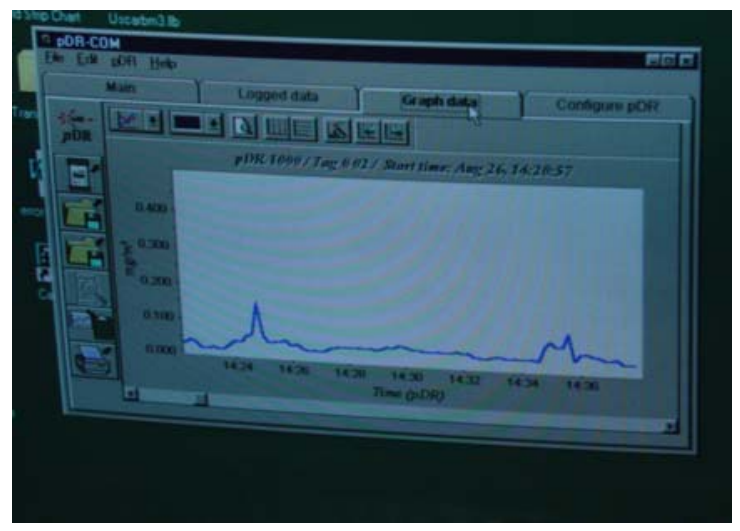

Graph of Raw Data

Figure 2. Data Ram and PC Screens

\section{Modifications}

The first items addressed were the new Bostomatic and Monarch VMC-75B and VMC-175B machining centers that had been purchased in the previous four years. Centrifugal Mist Collectors with HEPA filter on the exhaust were purchased and installed on these machine tools. These units have an operating flow rate of 900 cubic feet/minute. The HEPA filter also eliminates smoke particles that are generated when oil based MWFs are used.

Installation was modeled on the installation of a unit in the Reservoir production area. This unit was added after the exhaust mist began affecting the welding process occurring in the next work cell. In the case of both types of machine tools the manufacturer had designed the machine tool for installation of a mist collector but it was only included as an optional accessory. Since there was no driver, no one included the mist collector in the specification. Mist collection equipment was added to ten machine tools to bring them into compliance with the ACGIH TLV requirements. Examples of this installation are shown in Figures 3 and 4. 


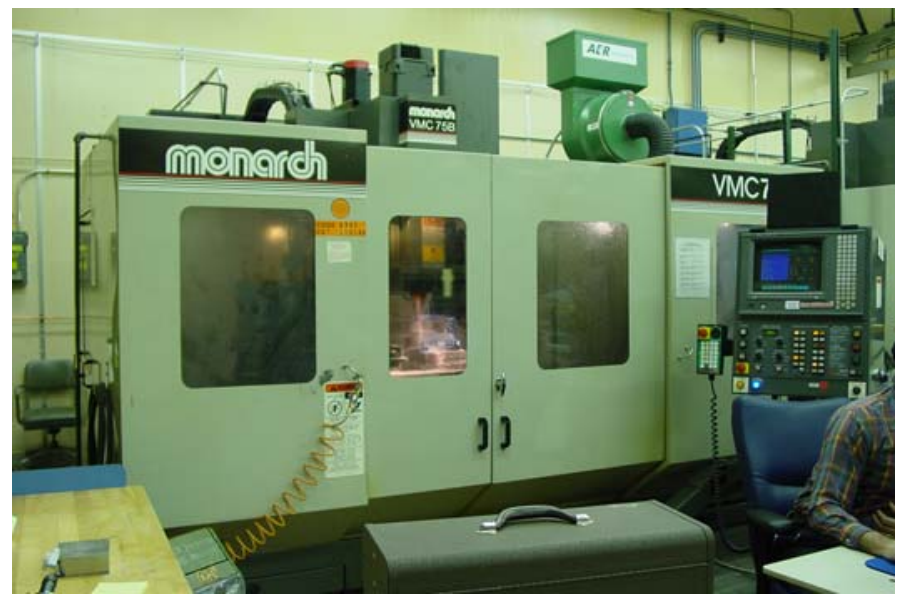

Cortland VMC-75B 4 Axis Machining Center with Mist Collector

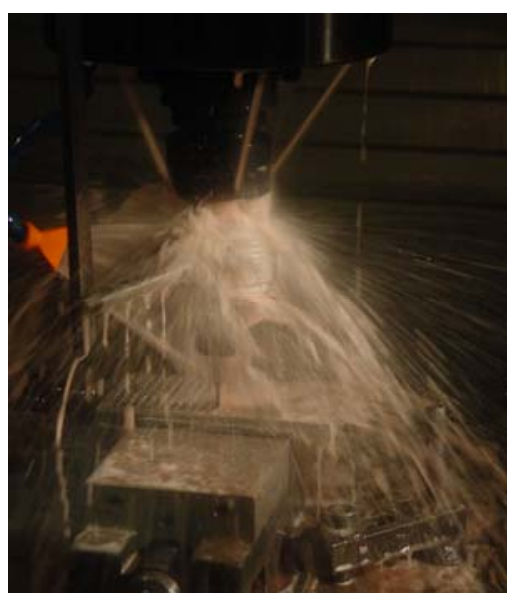

Detail of Drilling Operation in previous picture

Figure 3. Monarch Machining Center

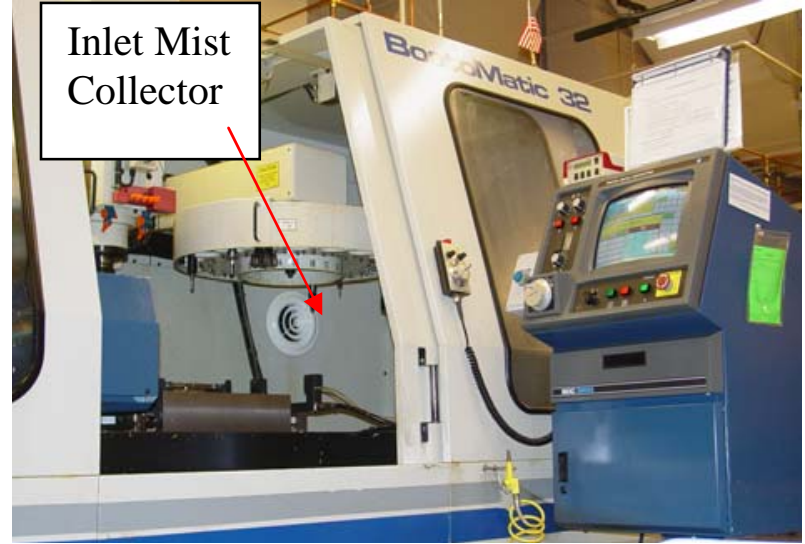

Bostomatic Installation

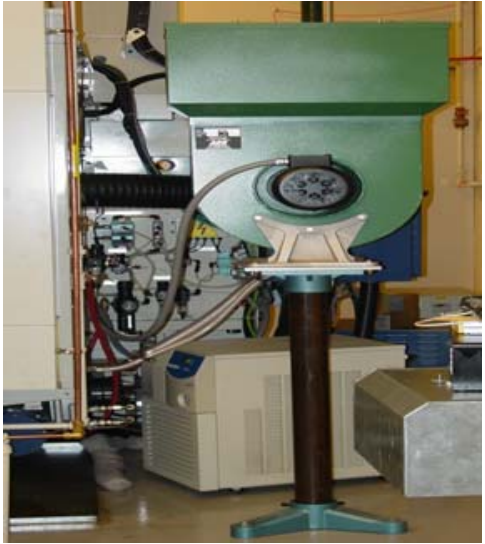

Mist collector in back of machine tool

Figure 4. Bostomatic Machining Center.

The next target was the large older machine tools that include Vertical Turret Lathes (2 machines), the large American Lathes (6 machines), and large 5 axis Machining Centers (3 machines). These machine tools were manufactured before enclosures were offered for machine tools. All of these machines were installed in the 1980s. They have no mist collection equipment associated with them. These machine tools were typical of what was produced during World War II when the environment, safety, and health were not considered as part of machine tool design. OSHA machine guarding requirements did not exist and the environment inside of plants included rainbows when a machinist looked up at the lights (a rainbow is visible when looking up at the lights when water-based MWF is used and the mist levels are above $3.5 \mathrm{mg} / \mathrm{M} 3$ ). Floors were wet and slippery. Example pictures of the problems at KCP are shown on the following page. 

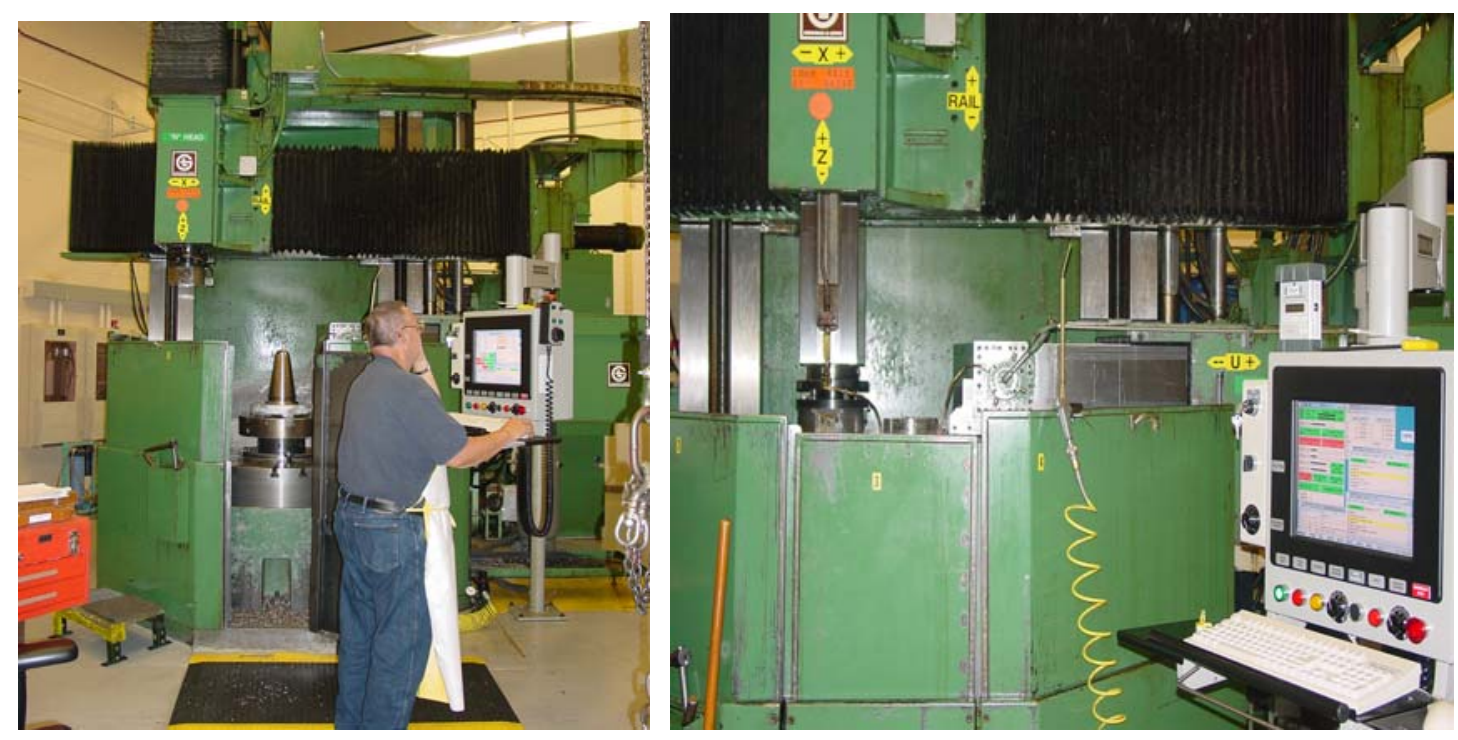

Overall view -Vertical Turret Lathe (VTL) Mist Monitor on Operator Console VTL
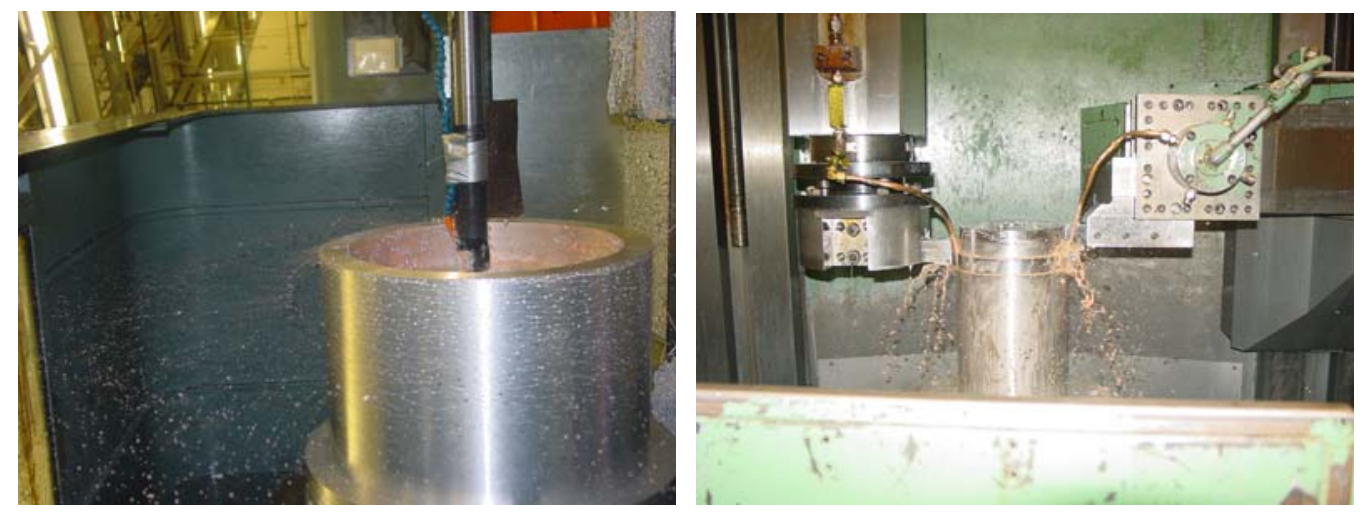

Typical VTL Operations - Note the large pink droplets of MWF

Figure 5. Views of Vertical Turret Lathe

During SMRI the VTL's were moved from Heavy Machining, which was a large open area of approximately 20,000 square feet to just a room of approximately 1200 square feet. This former stores area did not have adequate air exchanges; nor was the air large enough to dilute the mist and levels continued to increase during all day operations. Monitoring showed that during the latter part of the shift, mist levels exceeded current OSHA mist exposure levels. Temporary fixes included increasing the number of air changes and opening the 12 foot sliding door to the aisle.

Plans were being made to address the situation, including: adding add clear plastic extensions on the splash shield, adding clear vinyl strip curtains (similar to a shower curtain) and connecting them to the horizontal cross head, and adding two mist collectors (one for each turret). At this time the decision concerning heavy machining was made. The product scheduled on these machine tools was unclassified and it was decided to out-source this work. 
Since that time only four short duration jobs have been run on these machine tools and the temporary solution has proved adequate. One of the VTLs has been placed in cold storage and FM\&T plans to excess these machines in the next two years. No additional work has been done on these machine tools.

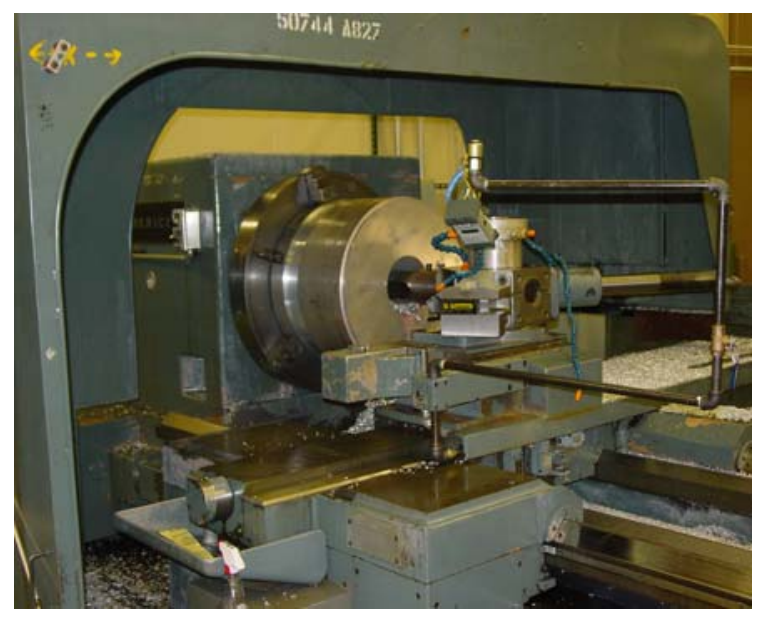

American Lathe - Mist Monitor Hanging from MWF Line

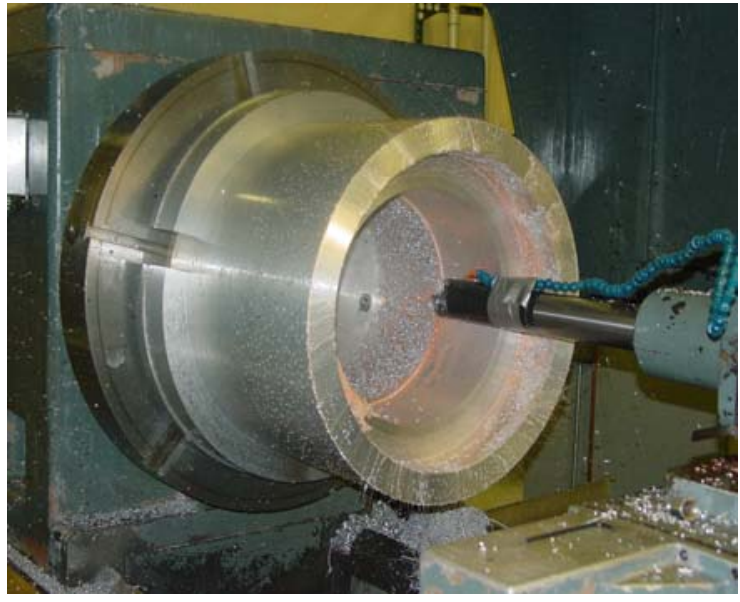

Typical Boring Operation on American Lathe - note the droplets

Figure 6. Large American Lathe

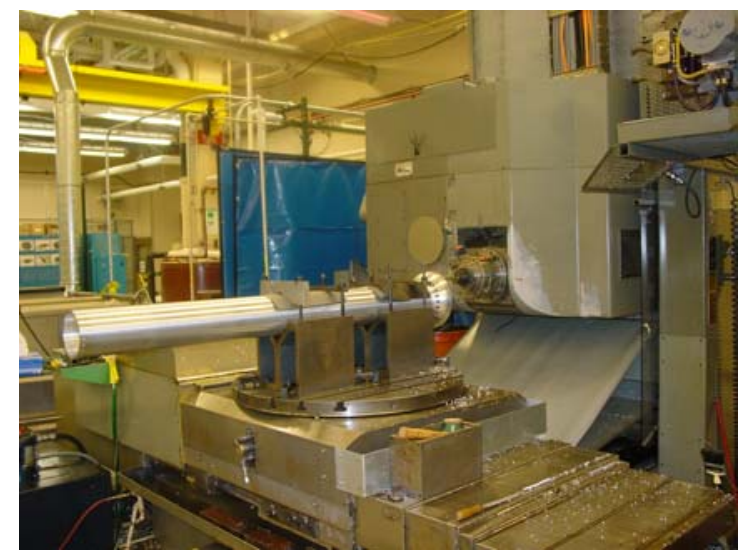

White Sundstrand Large 5 Axis

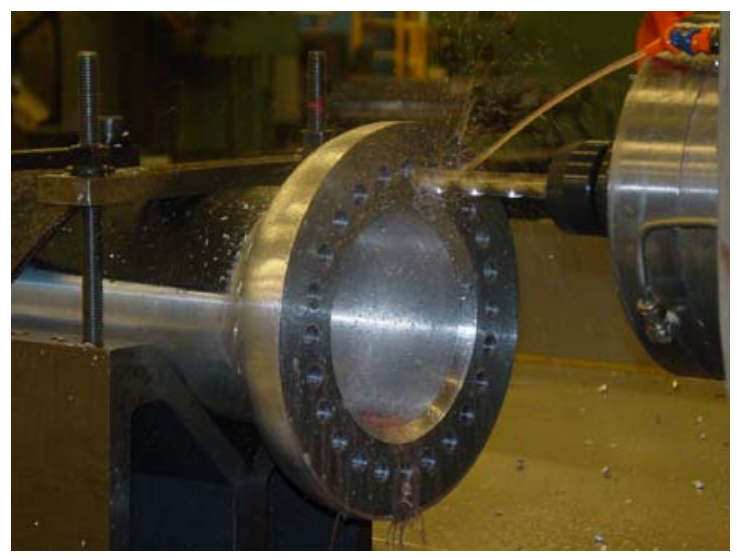

Detail of Drilling Operation - Note the droplets

Figure 7. White Sundstrand - Large 5 Axis Machining Center

Monitoring of the other machine tools had started as well. The decisions were being made as to which capabilities and machine tools would be included in KCRIMS. At that time it was decided that heavy machining would not be moving to the new facility. This eliminated the large 5 Axis Machining Centers, hollow spindle, large tracer and center-drive lathes, and large radial drill press from consideration. 
The unclassified work scheduled for these machines was decreasing and management decided to move this work to OSV (Outside Vendors). These machine tools presented major problems in controlling mist. Most large parts are made from aluminum alloys that require high cutting speeds that sling the MWF from the rotating part or cutting tool. The large droplets seen in the pictures are not breathable, but when they hit chips they break apart into smaller size droplets that can be breathable. In addition, there are small droplets (not seen in the pictures) that are sheared away as the larger droplets are formed, and these droplets are the particles of concern in mist formation.

These machines would need some type of temporary enclosure to contain the mist so that a collector could be effective. In the case of the White Sundstrand a large portable snorkel HEPA filter combination could be used for temporary setup. We have successfully used this type of unit but metal removal rates have to be reduced to match the capacity of the unit.
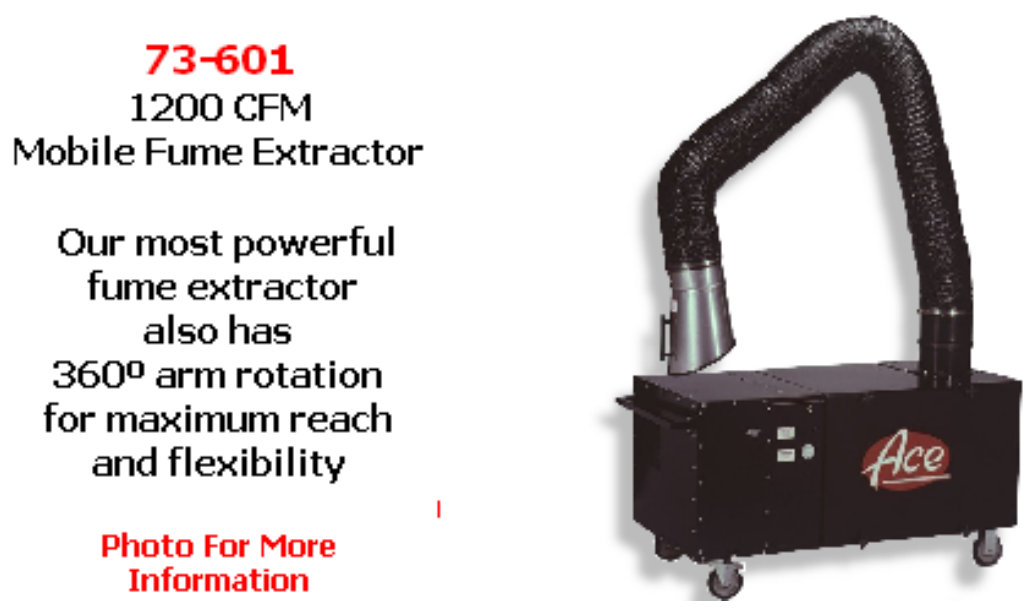

Figure 8. Large Portable Mist \& Fume Collector

The American Lathes were going to the new building and would require a solution. The American lathes have large and wide splash shields that can be locked to the saddle and will move with the cross slide as it moves down the length of the part. By utilizing clear strip curtains to form a partial enclosure around the saddle where the turret, cutting tool, and MWF come together and generate mist the splash shield now becomes a partial enclosure and can be connected to the saddle so that the enclosure moves with the cutting tool for long parts. The figure on the following page shows a comparison of the before and after data following the installation of the strip curtain and centrifugal mist collector. The mist collector has a 900 CFM (cubic feet/minute) capability and is adequate for most operations; however, there has been some trouble with some leaded brass turning operations. The small chips come off the parts in high speed streams of small chips that impact the strip curtain and force it open allowing some mist to escape. The only way to correct the problem is to slow the cutting process down. Fortunately, it is away from the operator station and mist levels are only slightly above the $0.2 \mathrm{mg} / \mathrm{M} 3$ for eight hours. The machinist running the job did not feel the levels were bothersome and did not notify anyone. Total run time was under three days. The operation occurs once per year and we will monitor it next year and make modifications. 

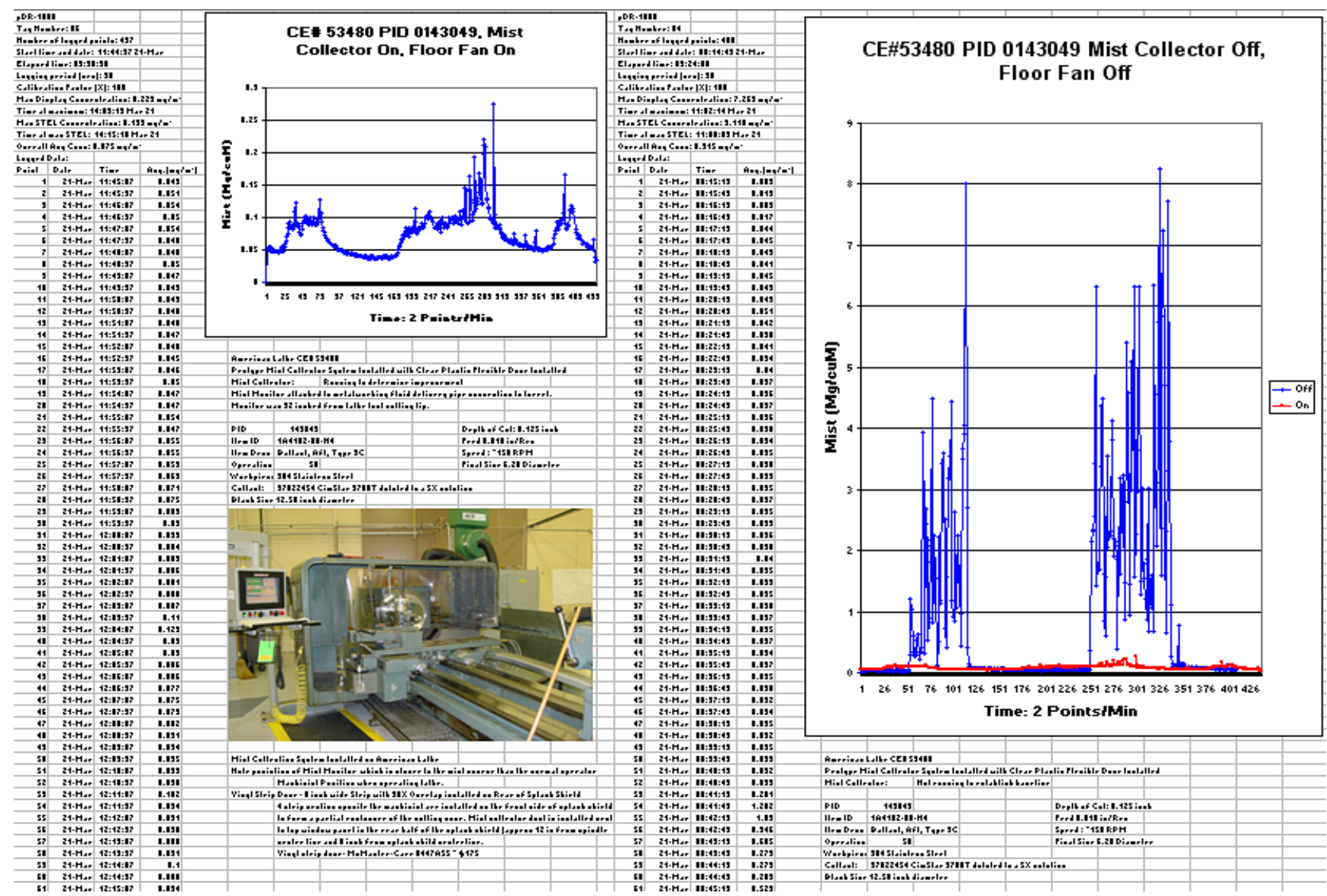

Figure 9. Comparative Mist Data - Large American Lathe

The same approach was used with the T-Bed lathes (1- Model Shop and 2-Tool Room). Again, the splash shield was connected to the mist collector. The air flow comes into the area where the cutting tools, MWF, and part come together and mist is formed. The configuration again proved successful.

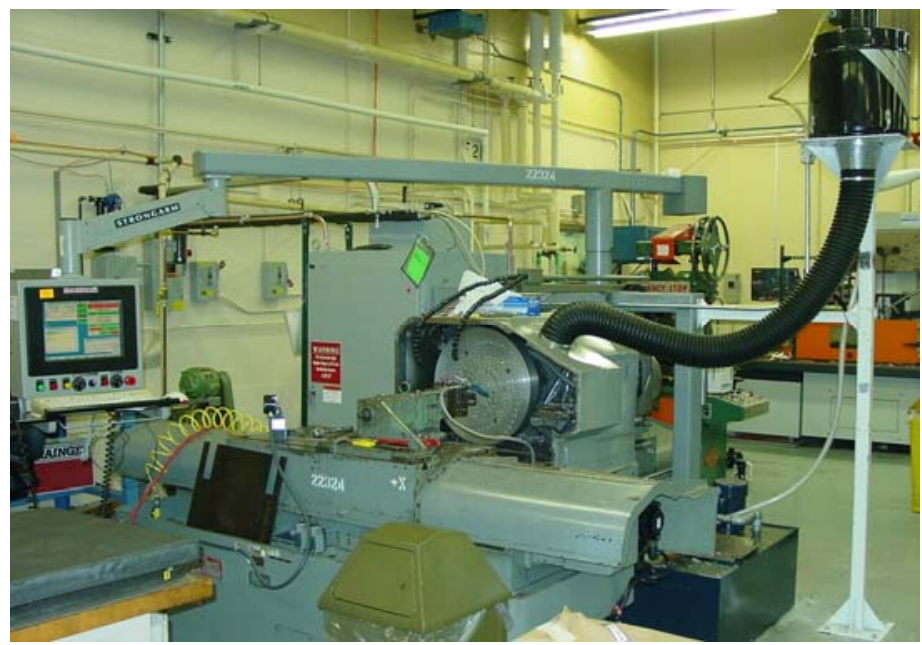

Figure 10. Typical Installation on a T-Bed lathe using redeployed mist collectors \& splash shield 
The final types of lathe addressed were the Hardinge CHNC \& CHNC4 lathes. The difference between these lathes is the spindle capacity (5C vs. $16 \mathrm{C}$ collets) and the configuration of the enclosure. An Ace Portable HEPA filter was utilized to control the mist and smoke generated within the machining cavity. On the CHNC4 the portable HEPA filter is mounted on the top of the enclosure. In the case of the CHNC the portable HEPA filter is set on the floor. Oil separators were installed between the enclosure and the HEPA filter so that large droplets would be purged from the air stream and not foul the HEPA filter element.
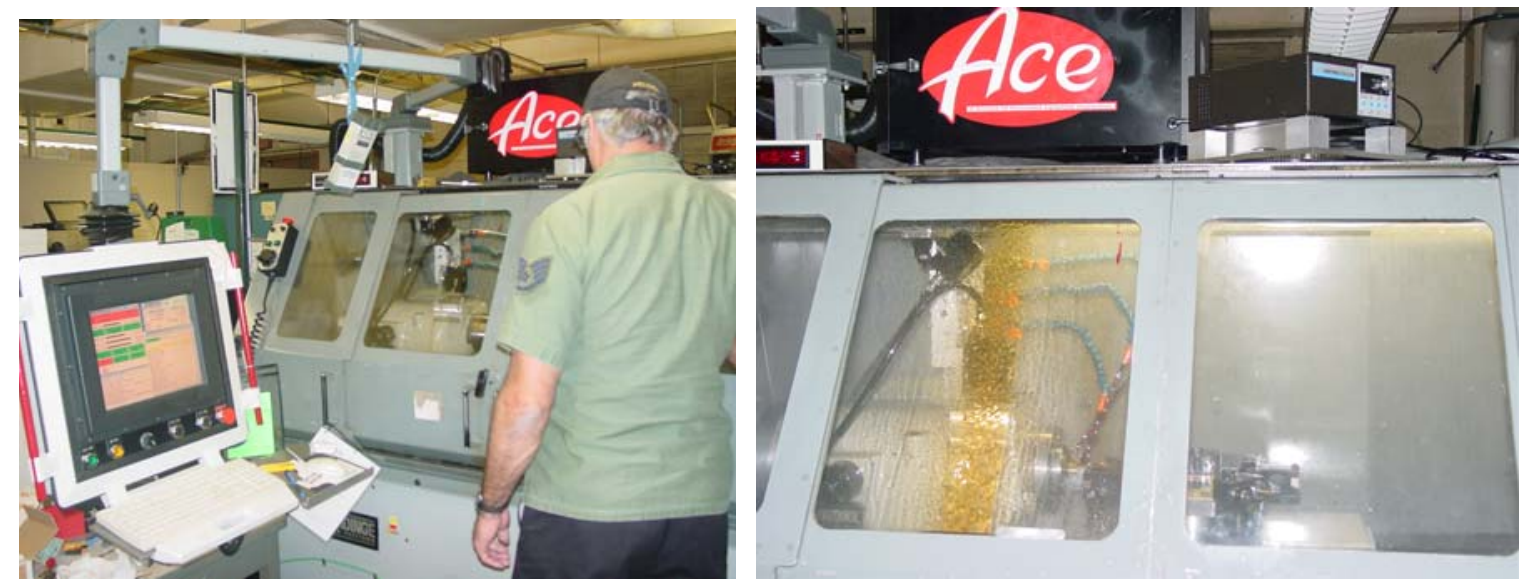

Figure 11. Hardinge CHNC4 with HEPA smoke and mist collector installed

The large Okuma lathes were monitored and we found the combination of splash and spindle shields were very effective. Monitoring was done during the final turning of the outside of the W80 case. Levels were below the ACGIH TLV and no further action was taken.

Subsequently, this program was cancelled and these lathes were dropped from the equipment list going to the new building.

In total, eleven lathes that were designated to be moved to the new building in the KCRIMS plan were modified for mist collectors. Manual lathes were evaluated for the generation of mist. In production areas the manual lathes are used for deburring, polishing, and rework. These operations are usually performed dry and in these cases a portable HEPA filter can be used to control the particulate generated. In the case of the manual lathes used in the model shop and tool room these jobs are development jobs that usually run once. These machines are not enclosed and the tool makers do not like to be splashed. They use only enough MWF to cool the tool and they minimize splash. The monitoring that was done showed higher levels during cutting, but the jobs were never run for over an hour before they went on to a different operation. In these cases the TLV for eight hours was not exceeded. It would be a rare case when the model maker was exposed to levels above the TLV.

Another area investigated was the Sheffield Plunge Form Grinders in Reservoir Manufacturing and the training area. Three of these machine tools are used in production. All three machines are made by the same manufacturer. All have enclosures and are equipped with a Smog Hog, which is an electro static mist collector. After the new grinder was installed in the training area complaints were received from the tool room. The tool makers complained of an odor problem. 
Monitoring revealed the mist was drifting across the hallway because the walls were not full height. The exhaust from the Smog Hog was above the mist TLVs. Many changes were made in the ducting trying to decrease the mist levels in the air flow. A supplemental mist collector had to be installed on the exhaust port so that it could be brought below TLV requirements.

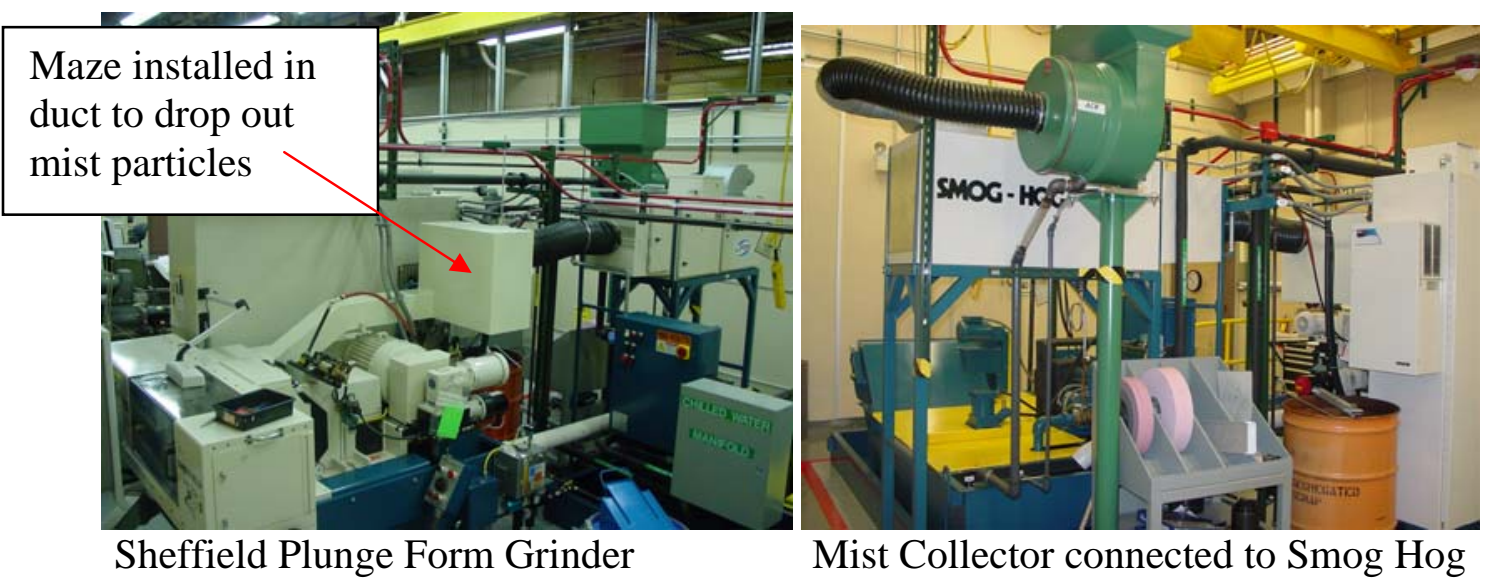

Figure 12. Secondary mist collector installed on exhaust of Smog Hog

Previous testing conducted by the HSE department had shown that the mist levels at the operator's station were within the TLV for the plunge form grinders. Both grinders had a baffle at 90 degrees to exhaust where the machinist and/or labors place pig mat to absorb the oil in the air stream. When the back of the machine tool was monitored it was found that exhaust from the Smog Hog was also above the TLV.

A maze was added in the duct between the grinding head and the Smog Hog, but it proved to be ineffective in reducing the mist levels. Grinding operations with oils also generate aerosols with smaller particles that are caused by the condensing of oil vapor formed in the grinding process. These particles are an order of magnitude smaller than mechanically formed mist particles. Since the maze was upstream from the mist collector they might not have condensed and coalesced until after they exited from the maze. A redeployed mist collector was installed and ducting from the mist collectors run to it. This additional duct length with reduced air flow to the collector allowed the aerosol to coalesce into a mist that could be removed.

After new operating parameters were established for newer products, a second redeployed mist collector was installed because of the higher mist load. It was beneficial that these problems were discovered at an early stage because this obscure problem would have shown up in the new building where the plunge form grinders will be installed in line, and mist levels at the operating station would have been affected by the exhaust from an adjacent grinder. 


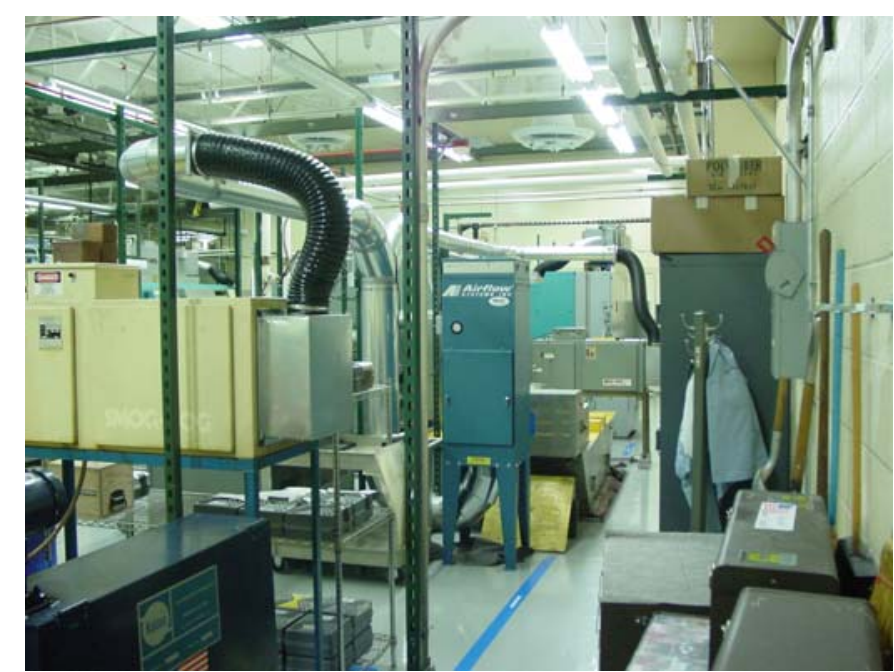

Figure 13. Redeployed Mist Collector installed downstream from Smog Hogs

Other grinders without mist collectors were examined and a FX1200 Royal Filtermist unit was redeployed and installed on the Cincinnati Milacron centerless grinder. This was the only grinder that did not have mist collection equipment installed. Approximately ten months ago the decision was made to only purchase centerless ground stock and this grinder was surplused. It was decided to redeploy this mist collector to the new plunge EDM machine. Provisions have been made by Charmiles to pull all fumes generated by the electrode up the rotating spindle. It was felt with the high efficiency supplemental filter that this unit would meet the requirement.

Gun drill operations were also monitored. One department had recently installed three Nagel TBT Gun Drills. Two of the units were twin spindle gun drills and the third was a three axis unit. All units are completely enclosed. When the part is drilled, the guide bushing presses against the piece part, forming a pressure cavity. On the dual spindle machines, when the drill breaks through the opposite side of the part, the flow and mist is trapped in the counter rotating spindle. Monitoring found low mist levels in the monitoring cavity and the 8 hour TLV was well under the $0.2 \mathrm{mg} / \mathrm{M} 3$ limit.

There was a complaint about the three axis TBT gun drill and it was monitored and found to be below the ACGIH requirement. After a backing block was put behind the work piece and the drilling was stopped while in the backing block, mist levels and odor problems disappeared. 


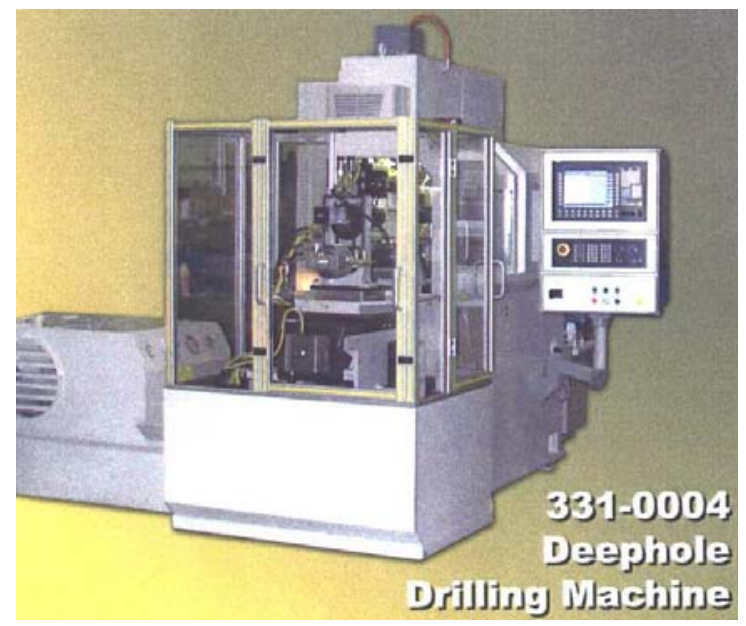

Figure 14. Nagel - TB 3 Axis Gun Drill

\section{Accomplishments}

All NC machine tools that are designated as going to the new building have been monitored and are compliant to the new ACGIH mist TLV. Many more machines were monitored before decisions were made as to which machine tools would be moving as part of the KCRIMS project.

Manual machine tools are used for development projects and for the fabrication of tools, jigs and fixtures. Every setup is unique and the operating parameters are different. Portable HEPA filters are available to control mist in these circumstances. Monitoring will be done on a periodic basis to assure compliance with DOE rules.

\section{Final Comments}

Only the Department of Energy has made the ACGIH TLV a rule. OSHA still has a mist level of $5.0 \mathrm{mg} / \mathrm{M} 3$. The collective bargaining agreement between the United Autoworkers and Chrysler, Ford and General Motors is still at $0.5 \mathrm{mg} / \mathrm{M} 3$. The ACIH has changed their Notice of Change every year since first issued and has yet to adopt a final rule. It is expected that the final mist level approved could be between 0.2 and $0.5 \mathrm{mg} / \mathrm{M} 3$.

Machine tool builders supply mist collectors with their equipment. Some are standard equipment and some are optional accessories. Be aware that the mist collectors supplied will meet the OSHA rule and not the DOE and ACGIH TLV. The mist collector required to meet this requirement is much larger and more expensive. This project showed that secondary mist collectors had to be added to meet the new rule. Staff writing specifications for machine tools must specify the ACGIH propose mist level of $0.2 \mathrm{mg} / \mathrm{M}$, in order to be assured that the equipment manufacturer is supplying collection equipment that meets this requirement. 


\section{Appendix 1 Mist Data}

Note on the files included in this appendix:

Graphs are for all tabular data in run.

Calculated values in header are for all data in run.

Only the first page of individual data points is shown. Files can contain up to 1000 individual data points. Complete files can be supplied upon request 


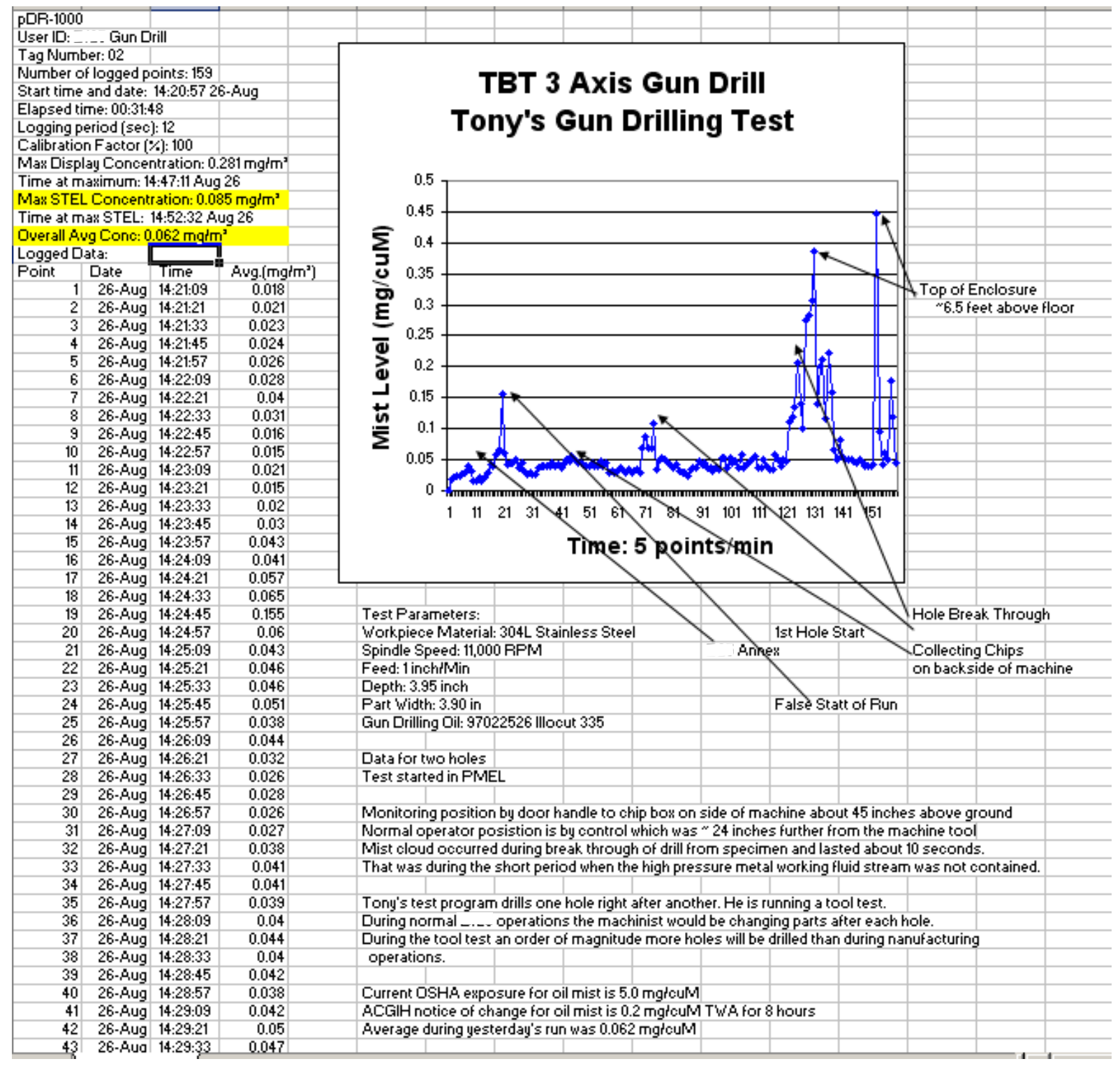




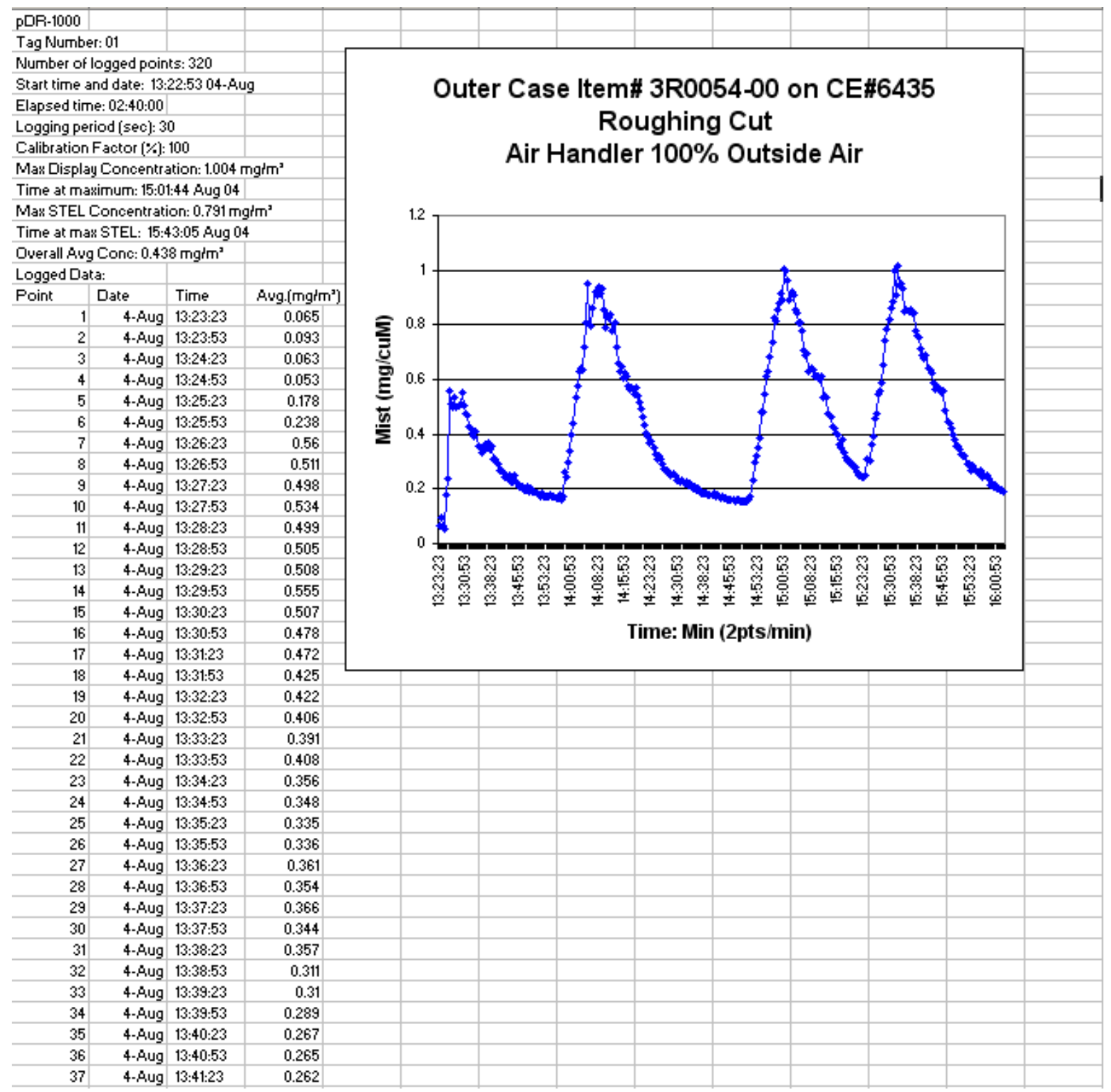




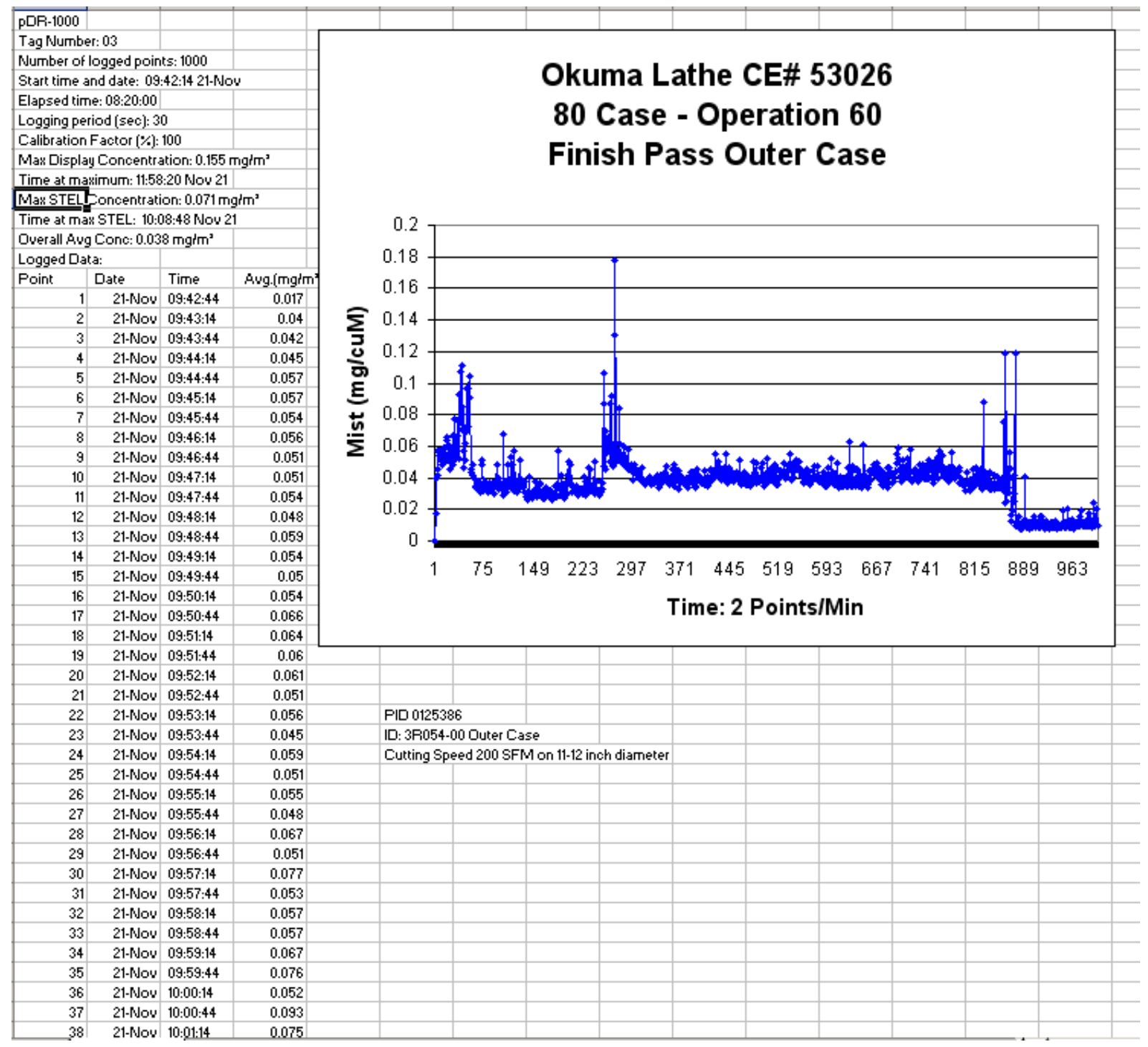




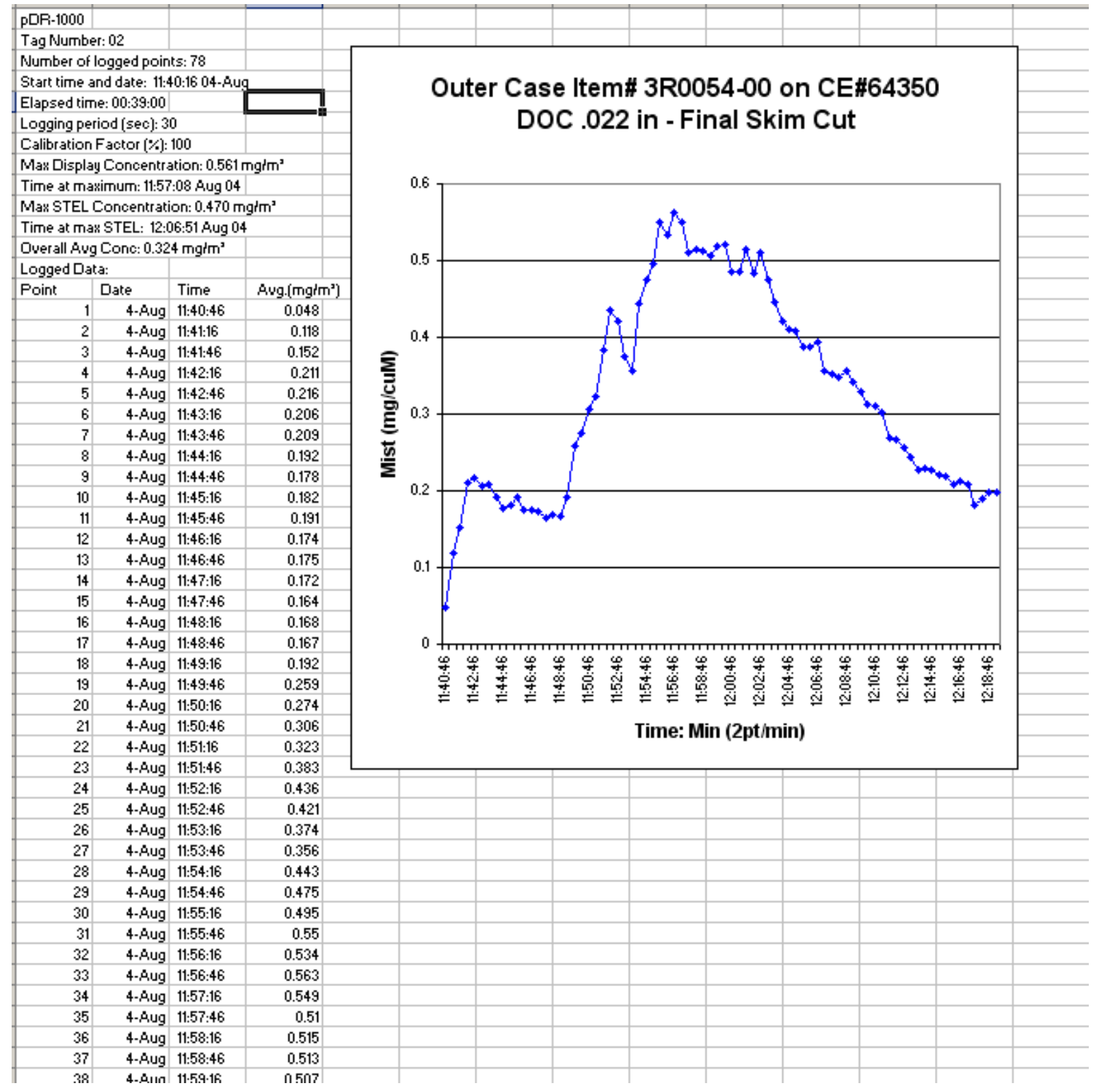




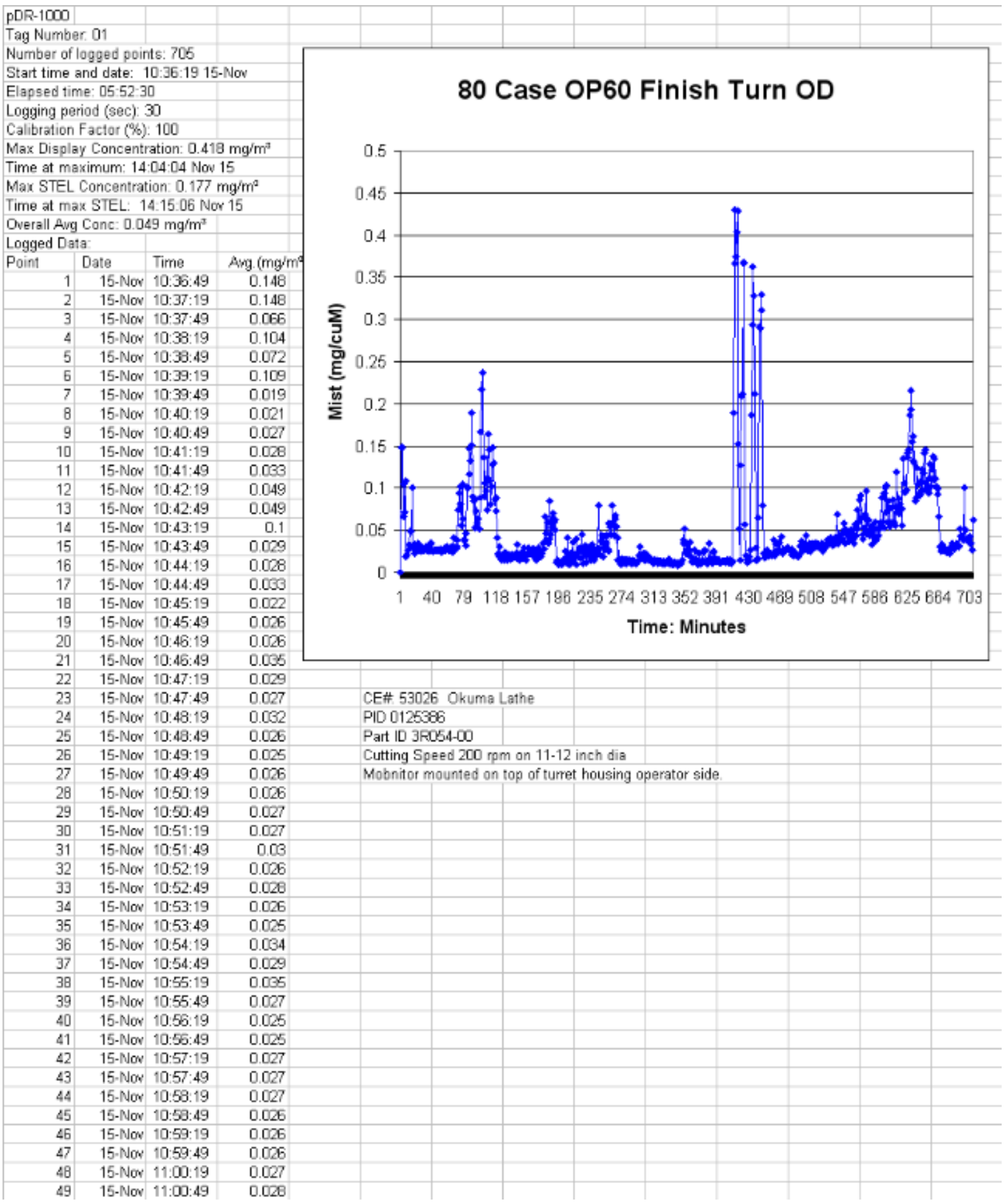




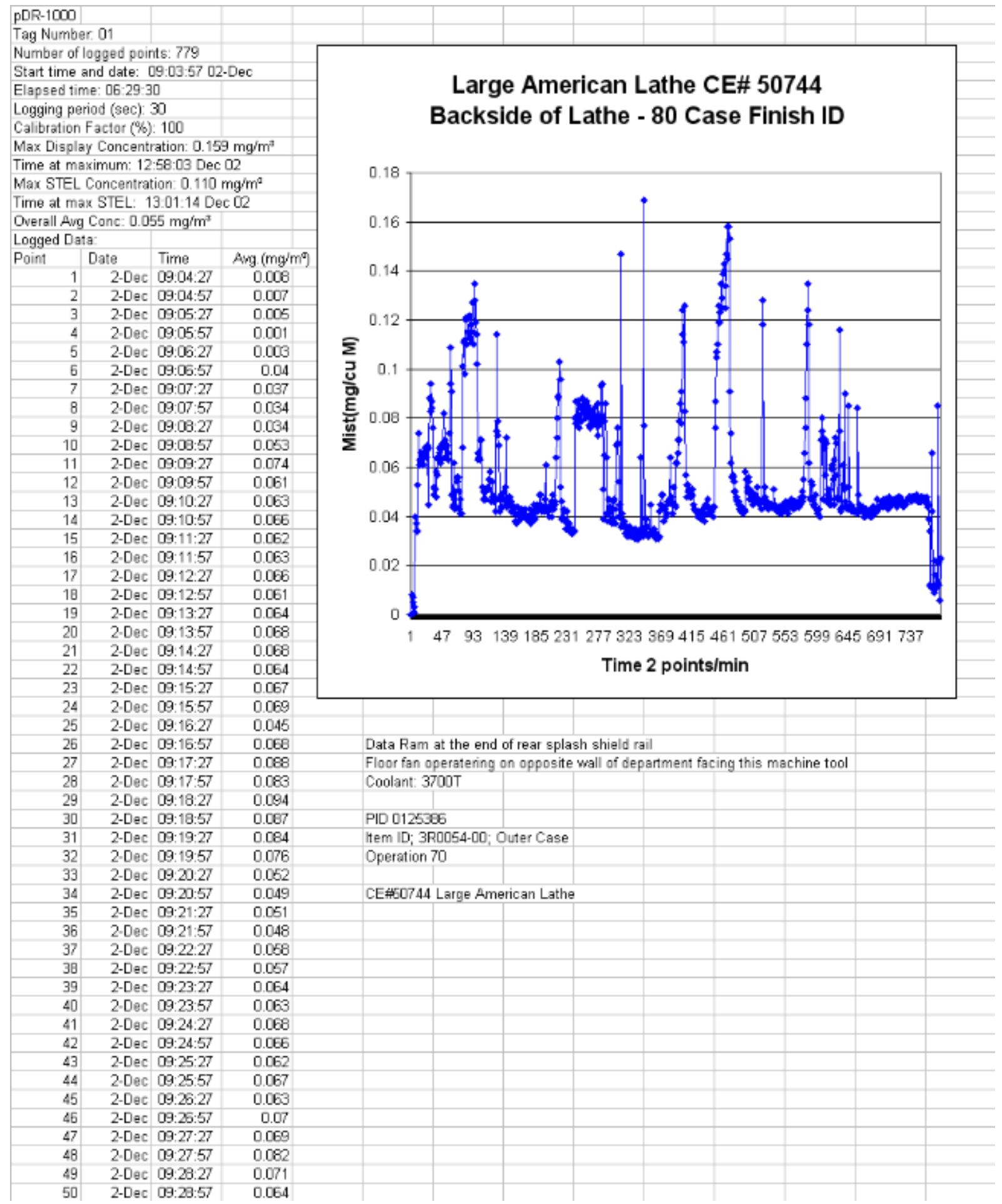




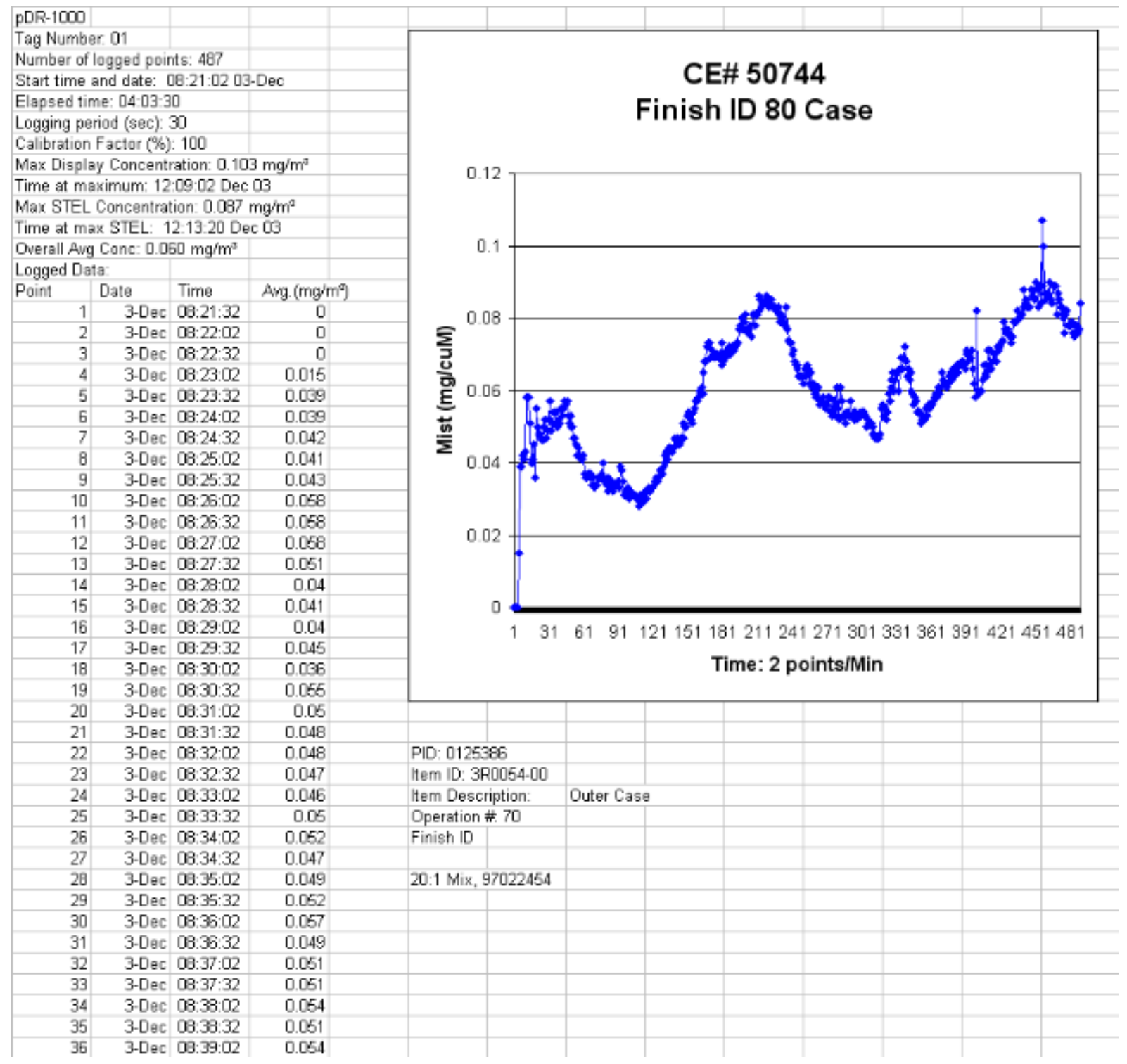




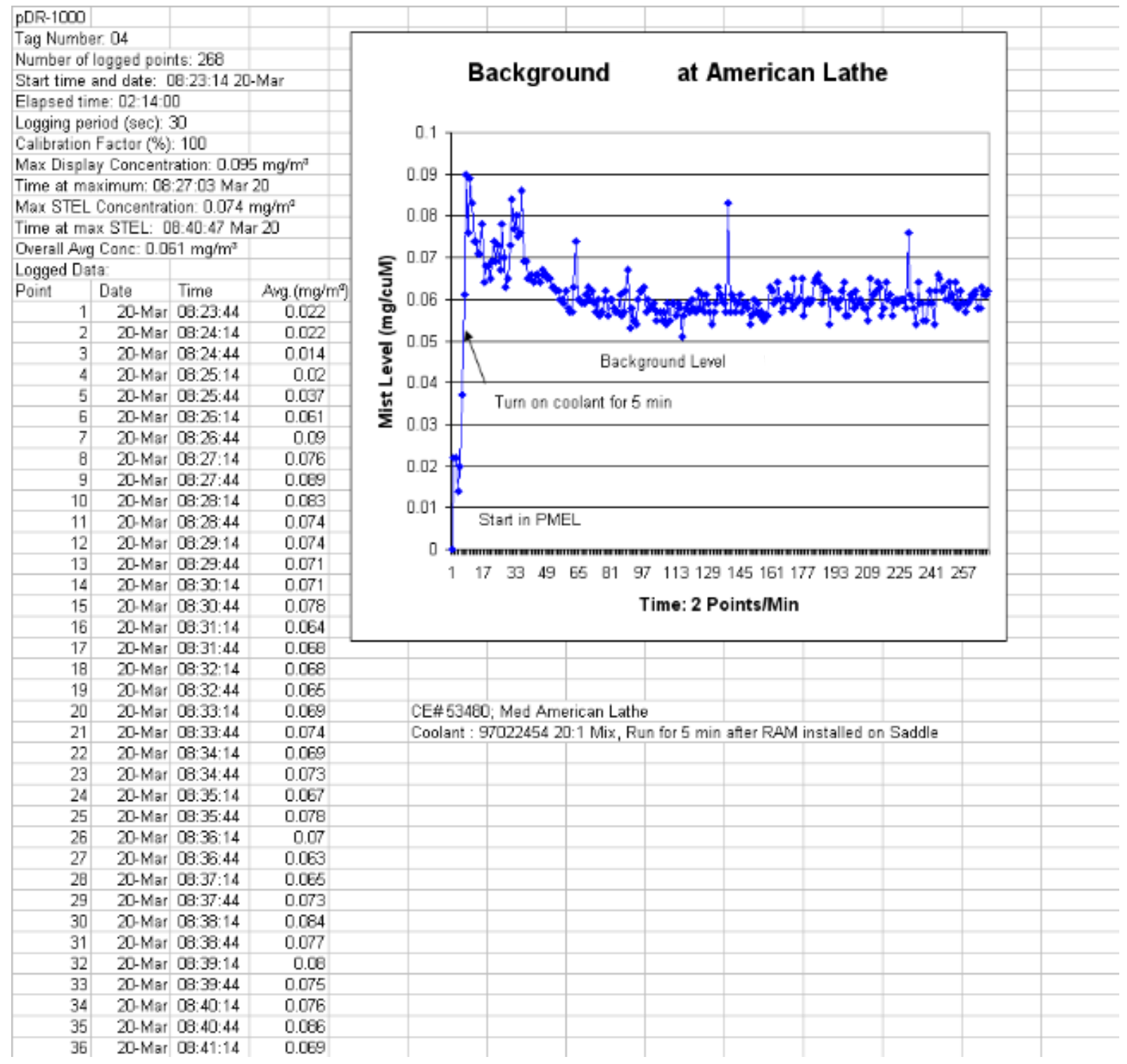




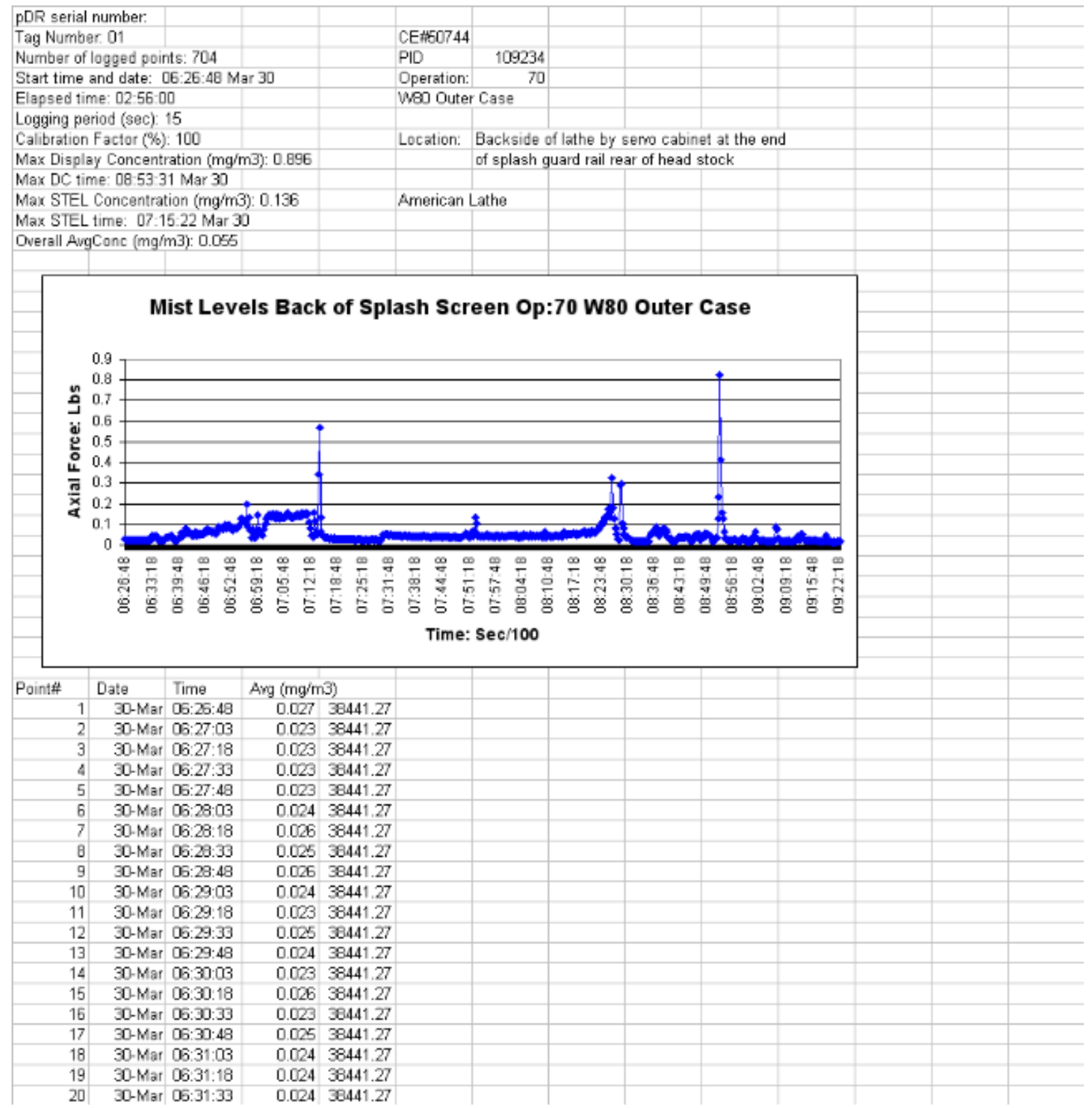




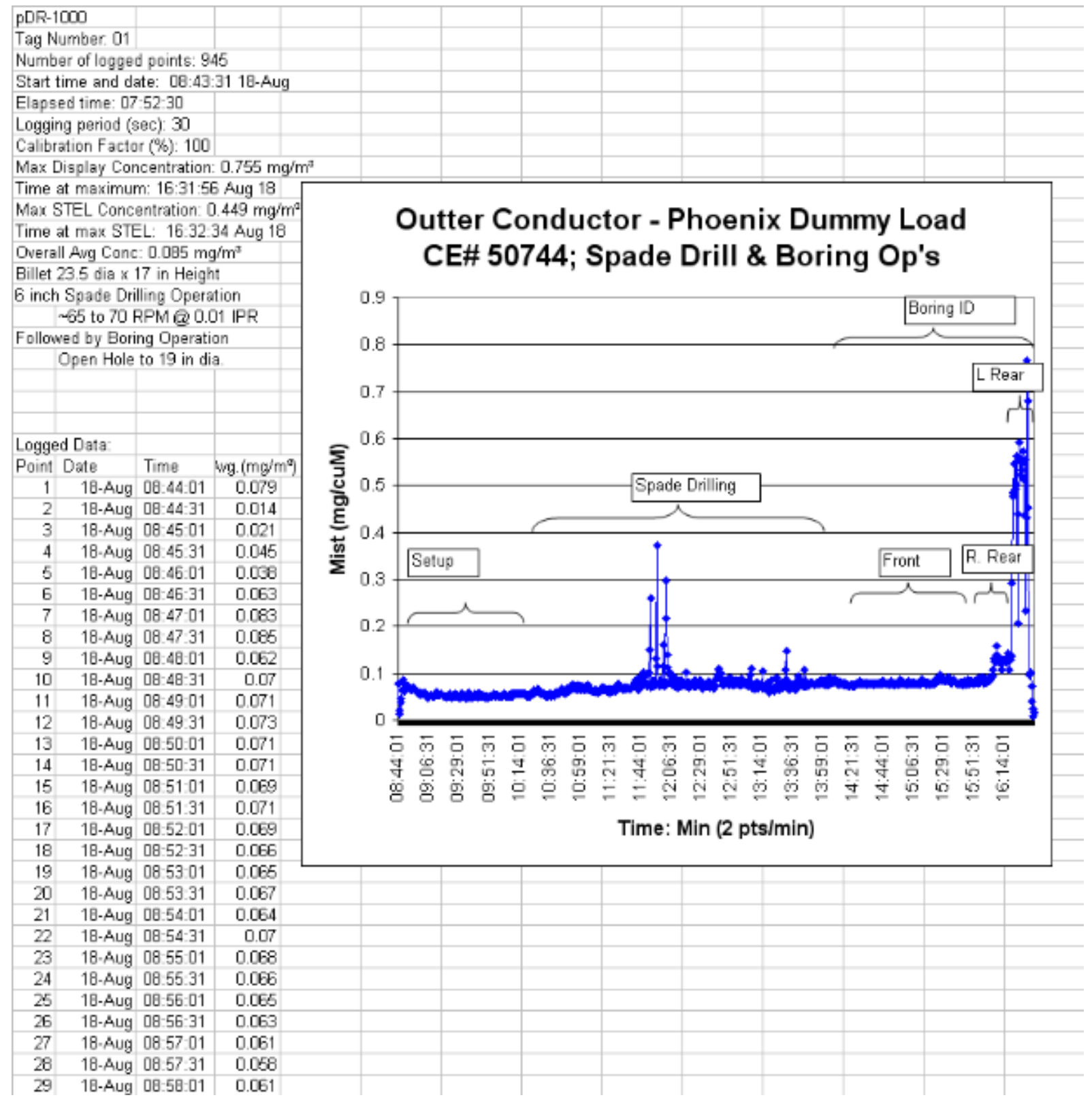




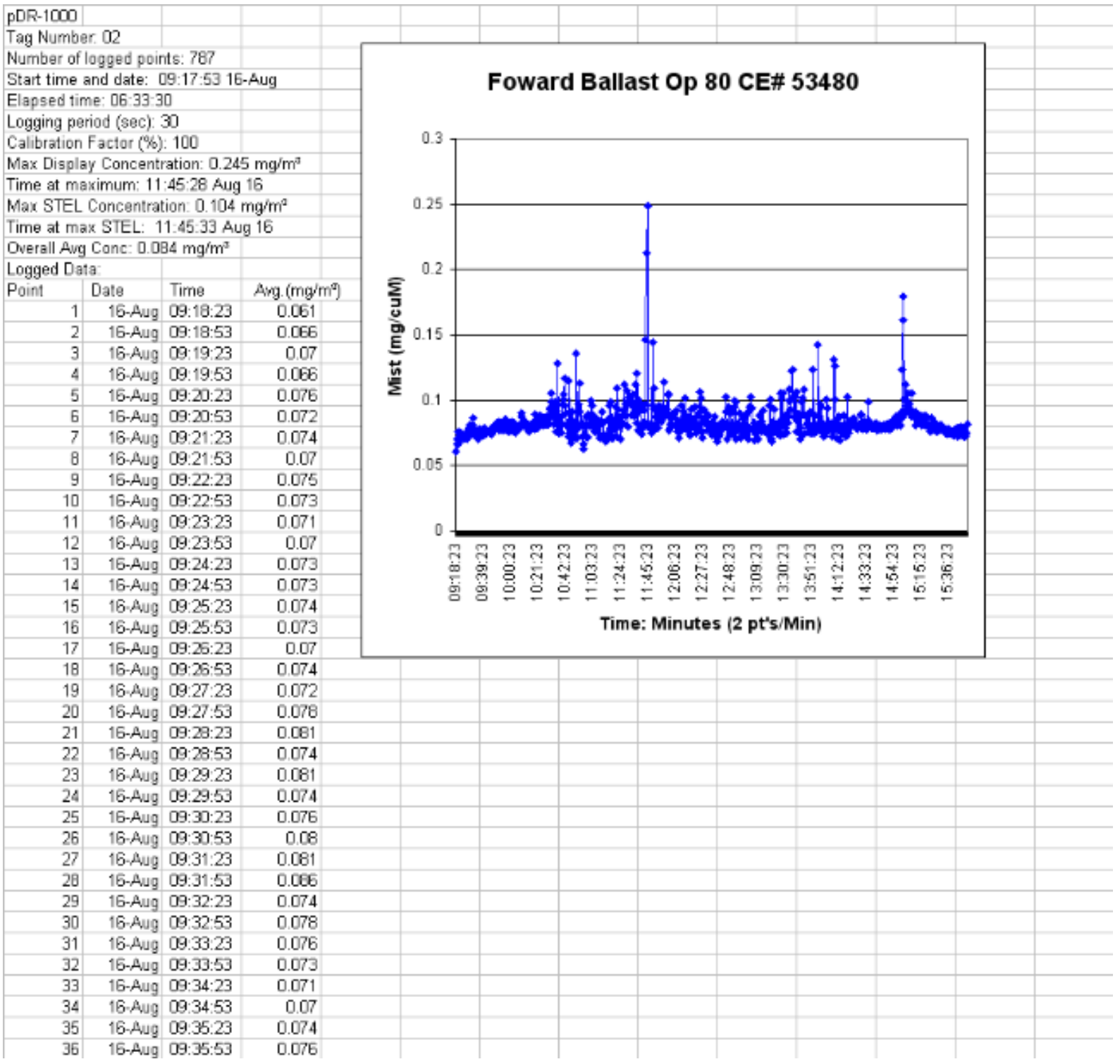


pDR-1000

Tag Number. 08

Number of logged points: 283

Start time and date: 10:28:59 26-Apr

Elapsed time: 02:21:30

Logging period (sec): 30

Calibration Factor (\%): 100

Max Display Concentration: $0.092 \mathrm{mg} / \mathrm{m}^{3}$

Time at maximum: 11:06:49 Apr 26

Max STEL Concentration: $0.047 \mathrm{mg} / \mathrm{m}^{\mathrm{a}}$

Time at max STEL: 11:41:38 Apr 26

Overall Avg Conc: 0.035 mg/m ${ }^{3}$

Logged Data

\begin{tabular}{|c|c|c|}
\hline \\
\hline Point & Date & Time \\
\hline 1 & 26-Apr & $10: 29: 29$ \\
\hline 2 & 26-Apr & $10: 29: 59$ \\
\hline 3 & 26-Apr & $10: 30: 29$ \\
\hline 4 & 26-Apr & 10.30 .59 \\
\hline 5 & $26-A p r$ & $10: 31: 29$ \\
\hline 6 & 26-Apr & $10: 31: 59$ \\
\hline 7 & 26-Apr & $10: 32: 29$ \\
\hline 8 & 26-Apr & 10.32 .59 \\
\hline 9 & $26-A p r$ & $10: 33: 29$ \\
\hline 10 & 26-Apr & $10: 33: 59$ \\
\hline 11 & 26-Apr & $10: 34: 29$ \\
\hline 12 & 26-Apr & $10: 34.59$ \\
\hline 13 & 25-Apr & $10: 35: 29$ \\
\hline 14 & 26-Apr & $10: 35: 59$ \\
\hline 15 & 26-Apr & $10: 36: 29$ \\
\hline 16 & 26-Apr & 10.36 .59 \\
\hline 17 & 26-Apr & $10: 37: 29$ \\
\hline 18 & $26-\mathrm{Apr}$ & $10: 37: 59$ \\
\hline 19 & 26-Apr & $10: 38: 29$ \\
\hline 20 & 26-Apr & $10: 33.59$ \\
\hline 21 & $26-\mathrm{Apr}$ & $10: 39: 29$ \\
\hline 22 & 26-Apr & $10: 39: 59$ \\
\hline 23 & 26-Apr & $10: 40: 29$ \\
\hline 24 & $26-\mathrm{Apr}$ & $10: 40: 59$ \\
\hline 25 & 26-Apr & $10: 41: 29$ \\
\hline 26 & 26-Apr & $10: 41: 59$ \\
\hline 27 & 26-Apr & $10: 42: 29$ \\
\hline 28 & $26-A p r$ & $10: 42: 59$ \\
\hline 29 & 26-Apr & $10: 43: 29$ \\
\hline 30 & 26-Apr & $10: 43: 59$ \\
\hline 31 & 26-Apr & $10.44: 29$ \\
\hline 32 & 25-Apr & $10: 44: 59$ \\
\hline 33 & 26-Apr & $10: 45: 29$ \\
\hline 34 & 26-Apr & $10: 45: 59$ \\
\hline 35 & 26-Apr & $10.46: 29$ \\
\hline 36 & 26-Apr & $10: 46: 59$ \\
\hline
\end{tabular}

Ang. $\left(m g / m^{2}\right)$

0.018

0.017

0.017

0.016

0.014

0.015

0.017

0.015

0.015

0.015

0.016

0.016

0.018

0.022

0.014

0.015

0.018

0.015

0.017

0.018

0.039

0.027

0.049

0.037

0.033

0.032

0.005

0.047

0.034

0,032

0.04

0.030

0.031

0.033

0.031

0.032
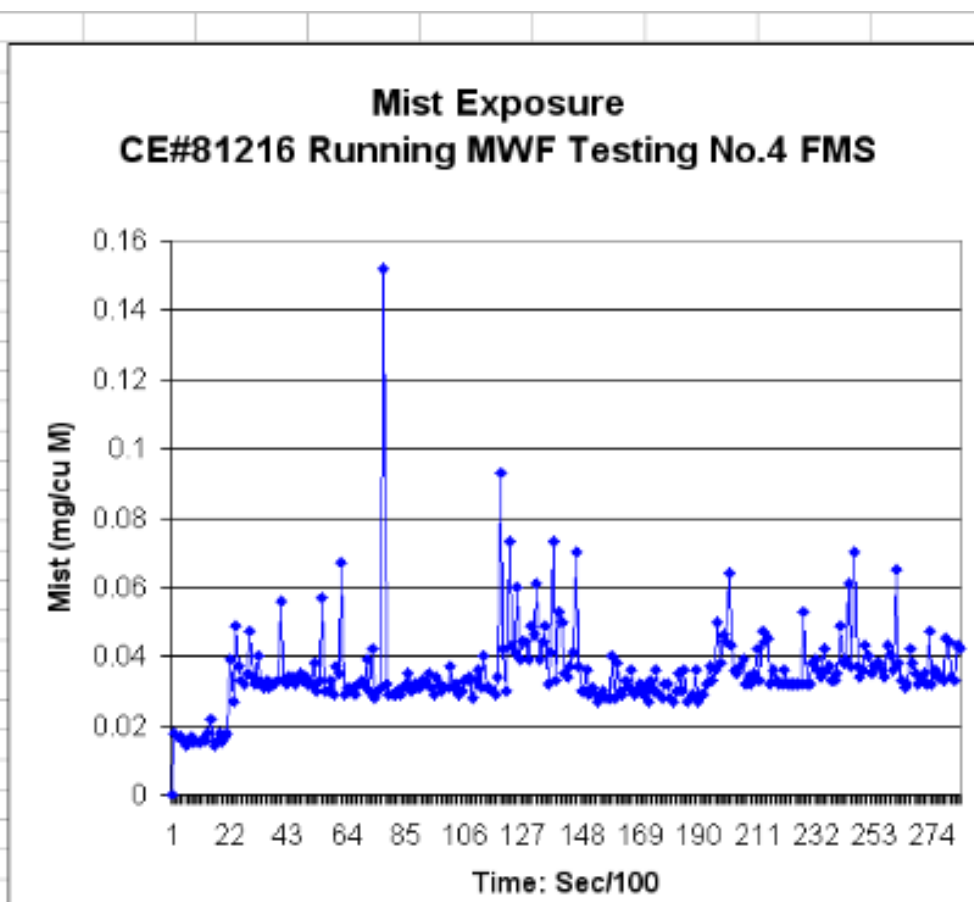

Fluid: 97022466 - $6 \%$ in Water

Running Adv Metalworking Fluids ADAPT Project Testing

Drilling 304 SS with 38 Diameter Jobber Length Drill in Dynamometer

Orion 2200 Horizontal Spindle Machining Center 


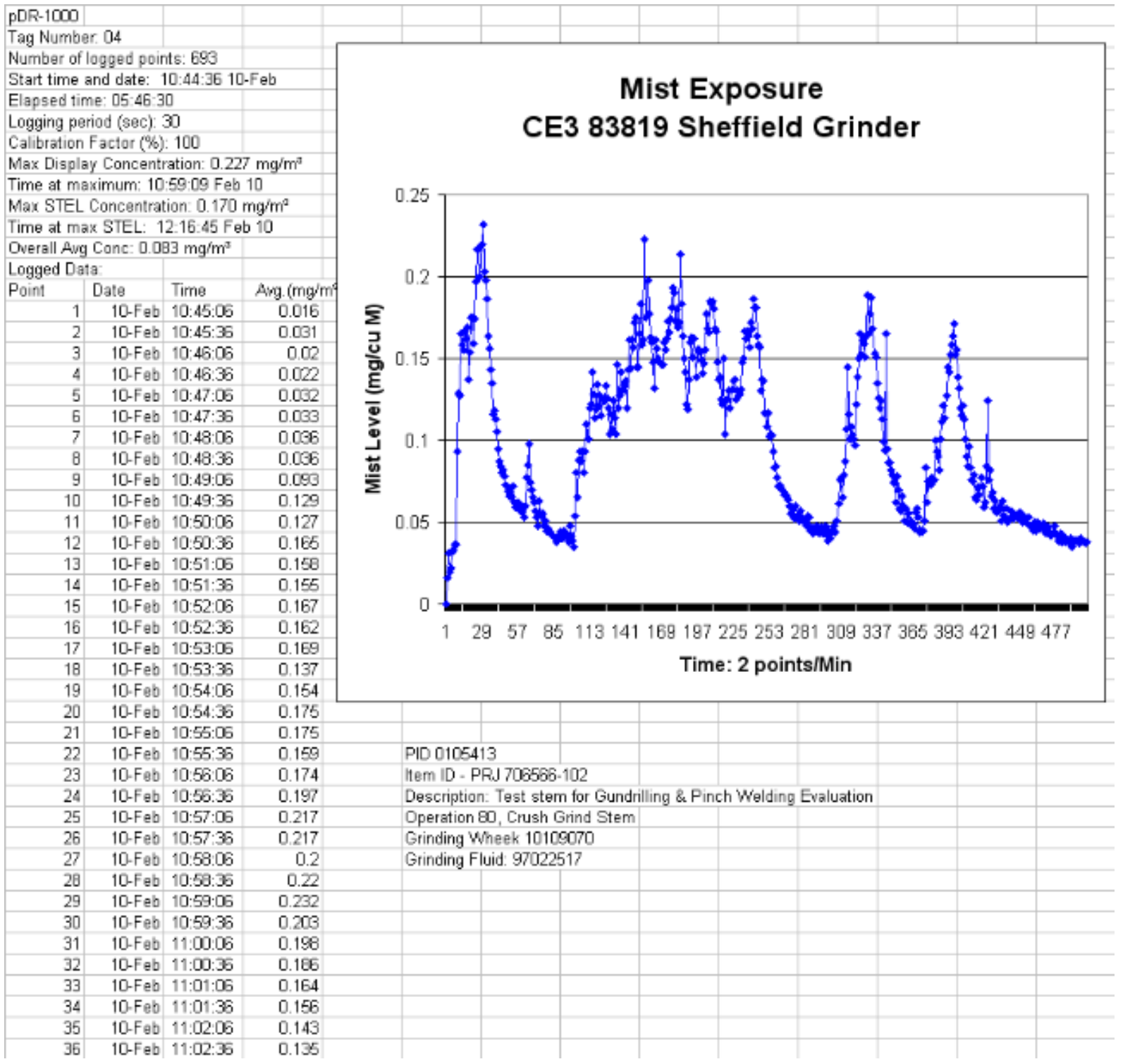




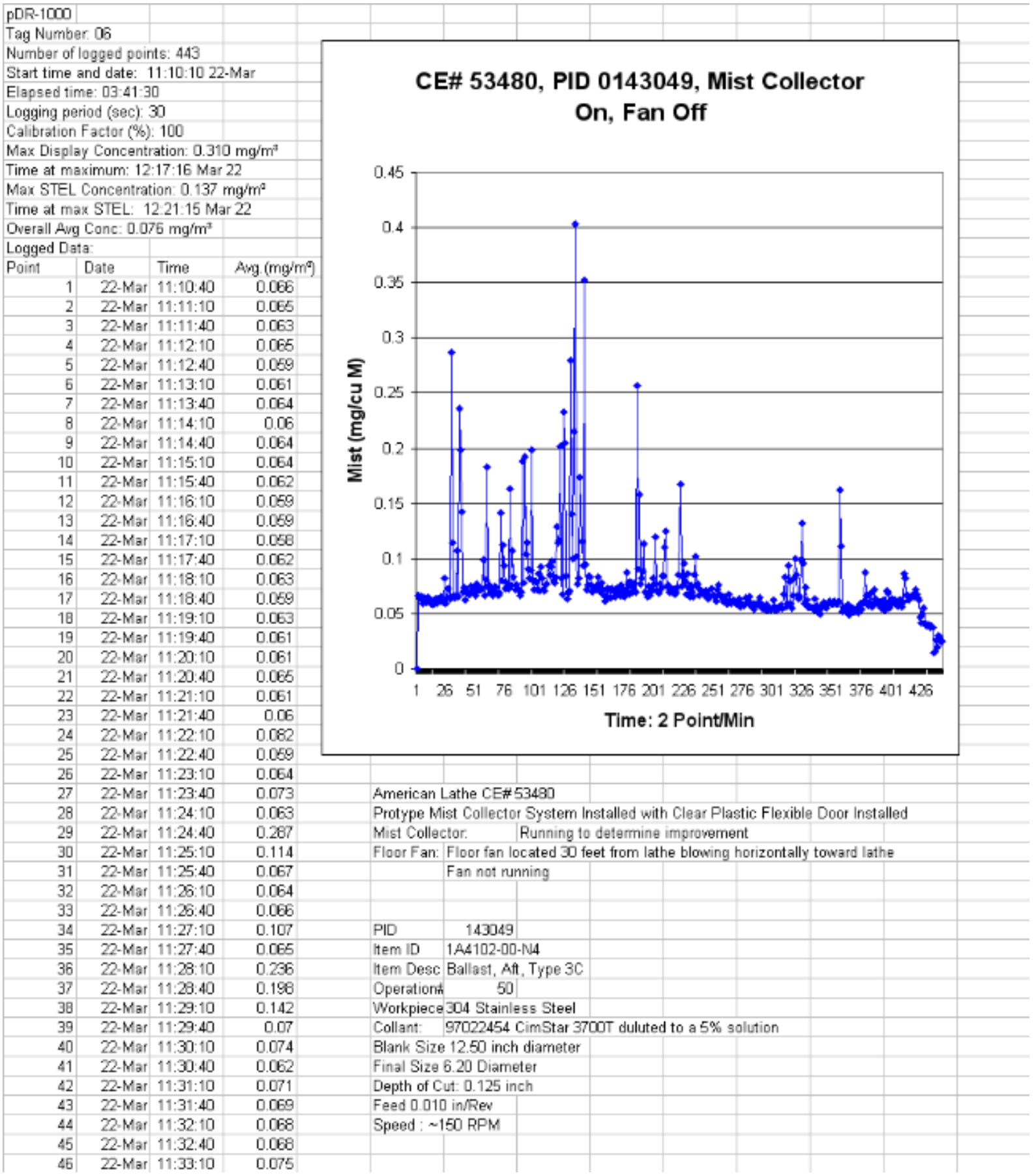




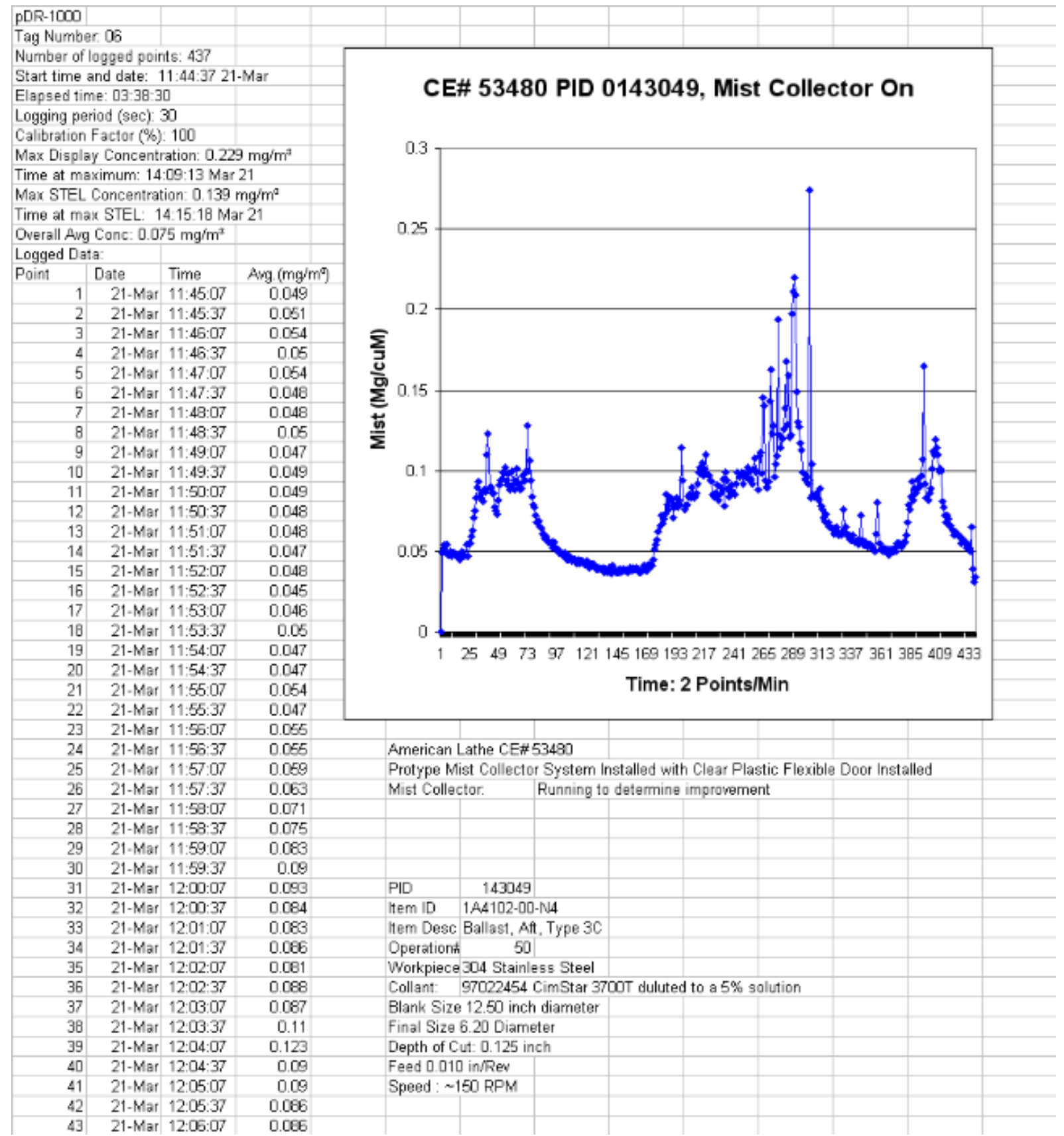




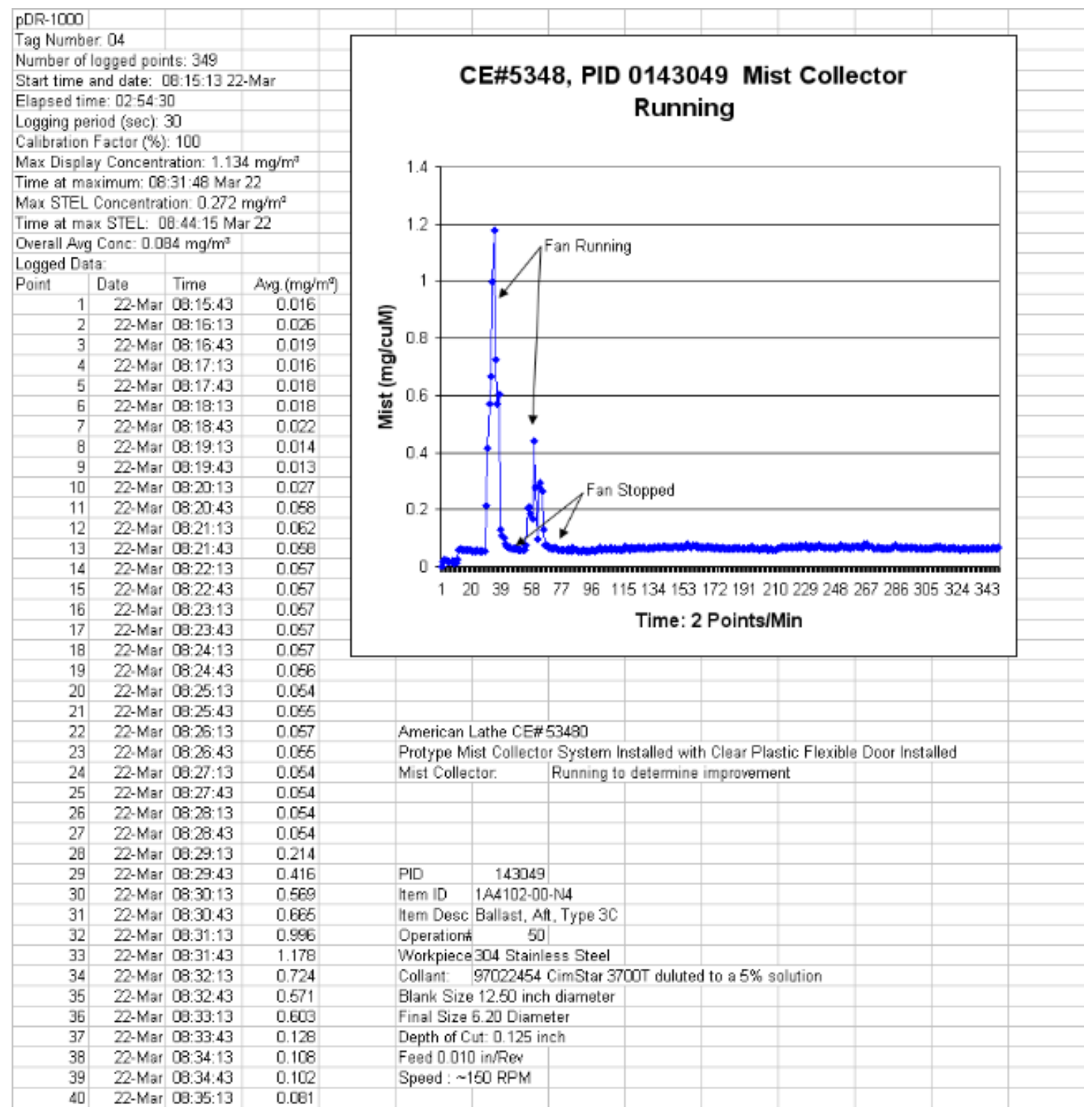




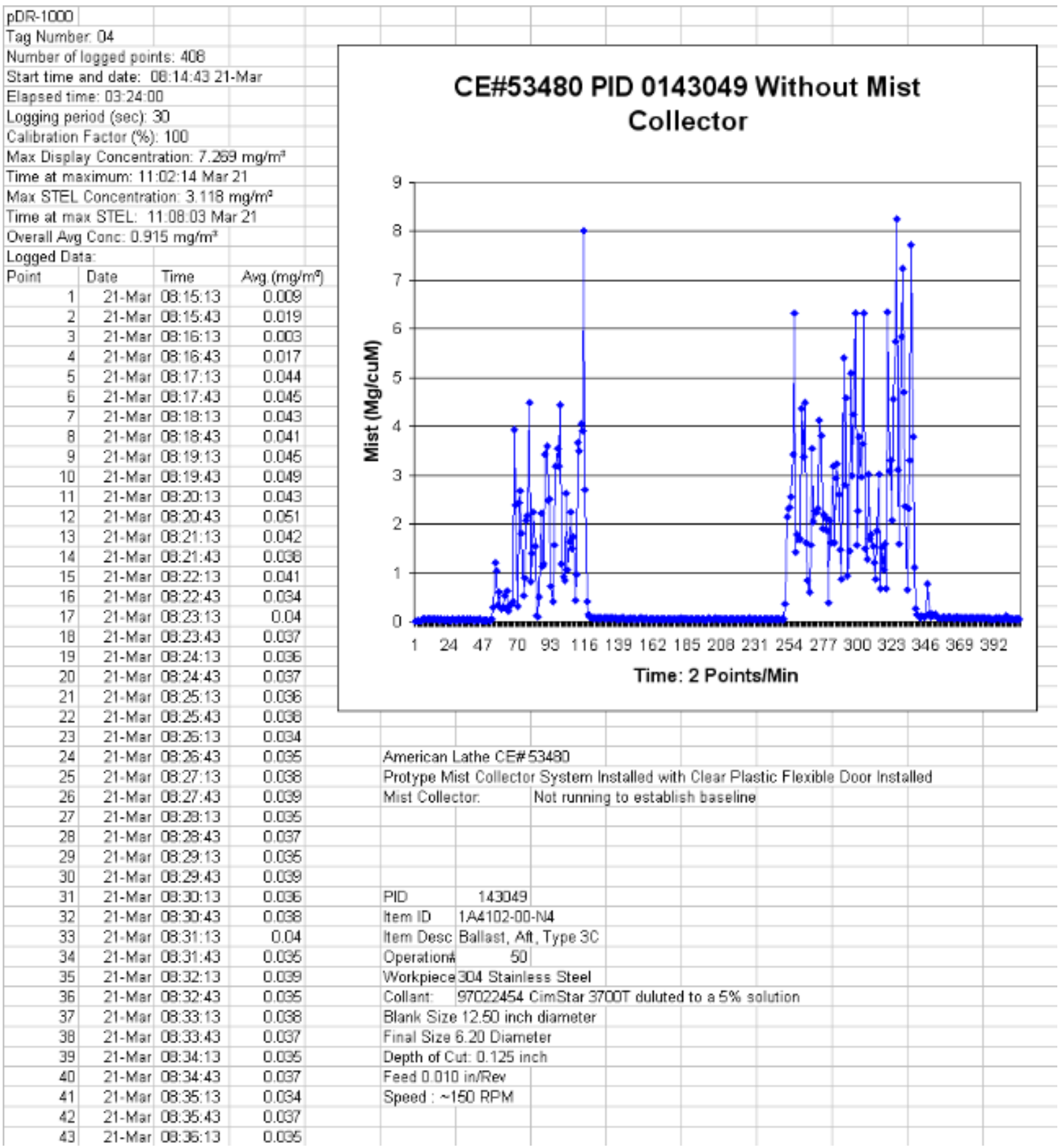




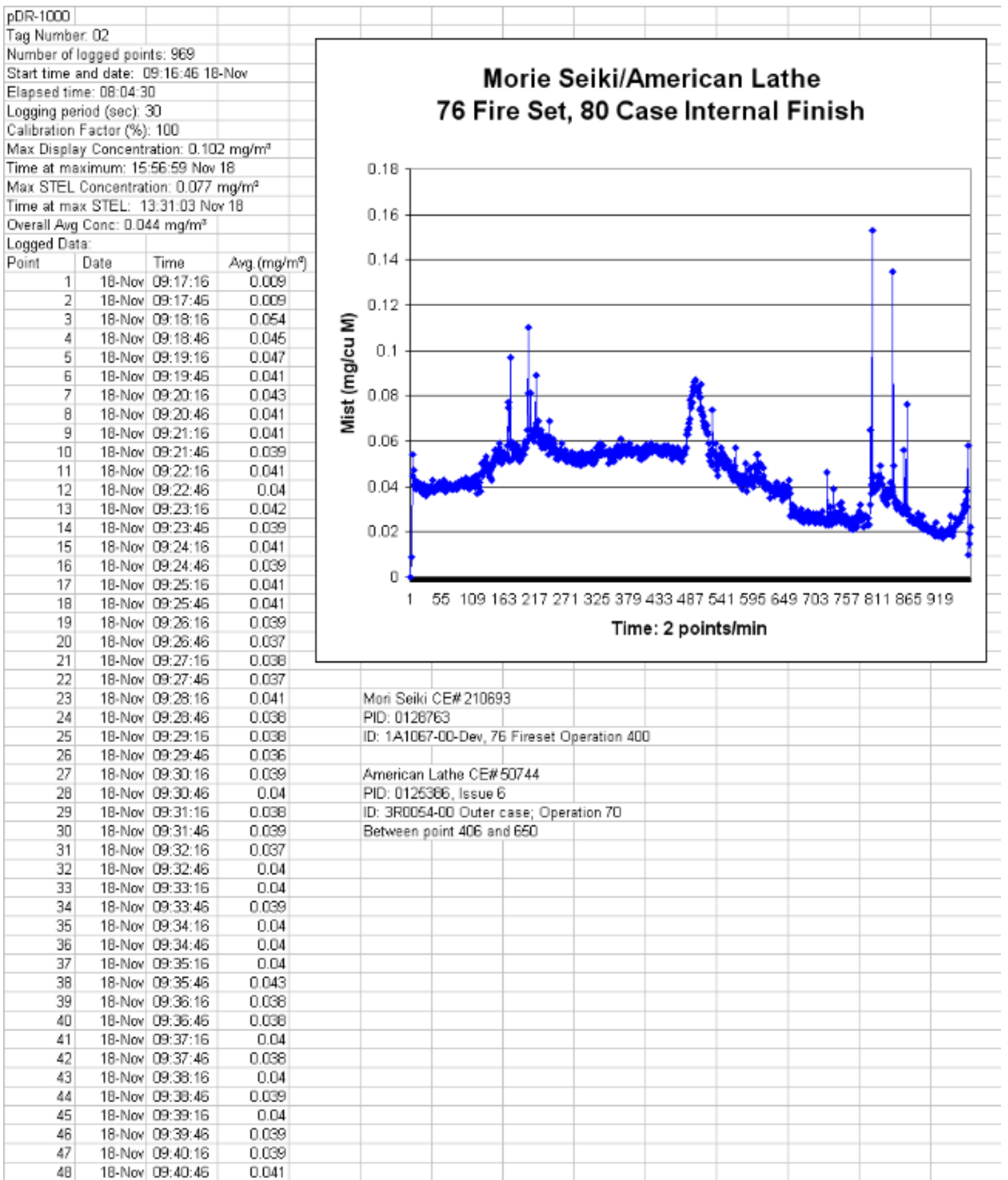




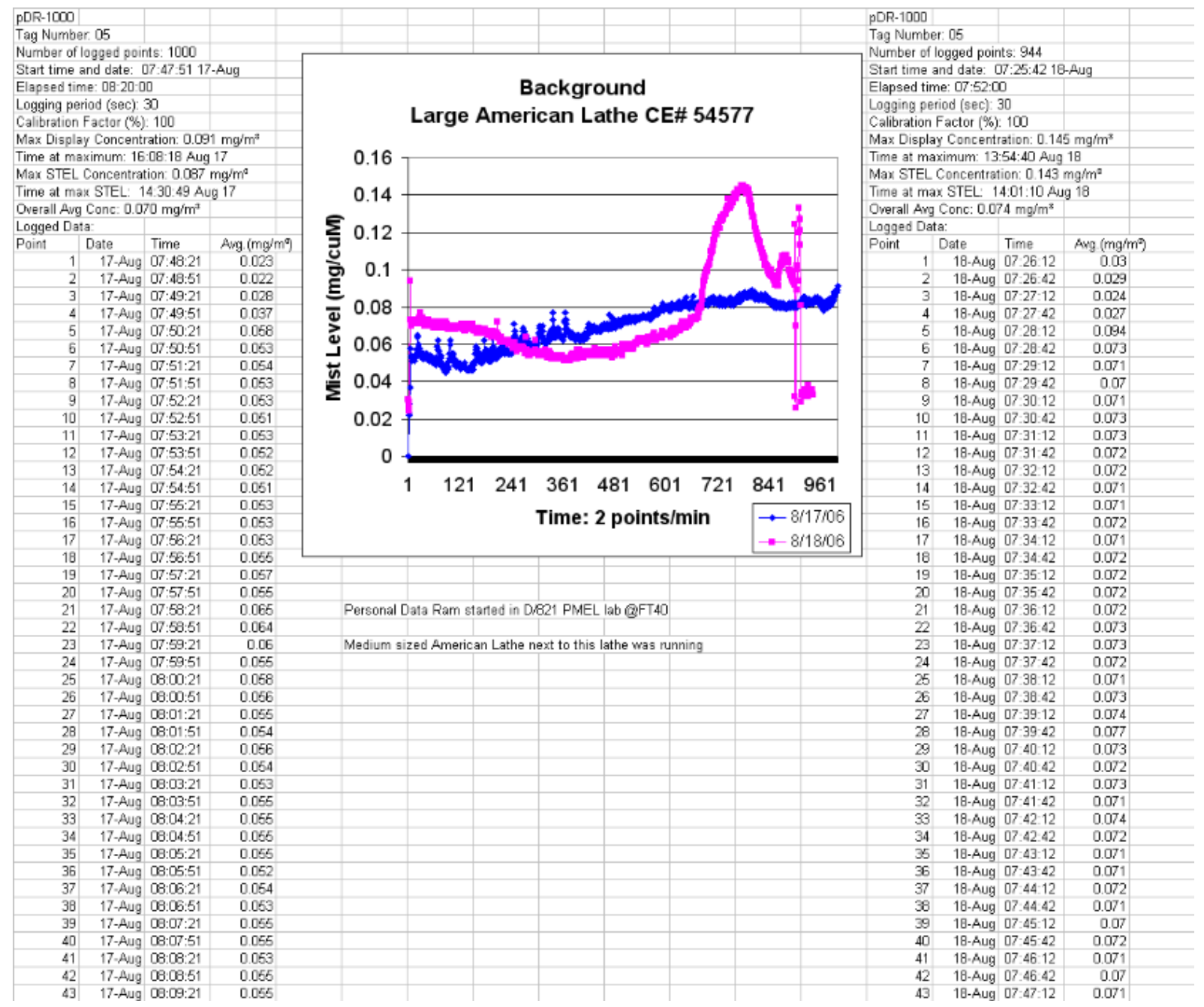




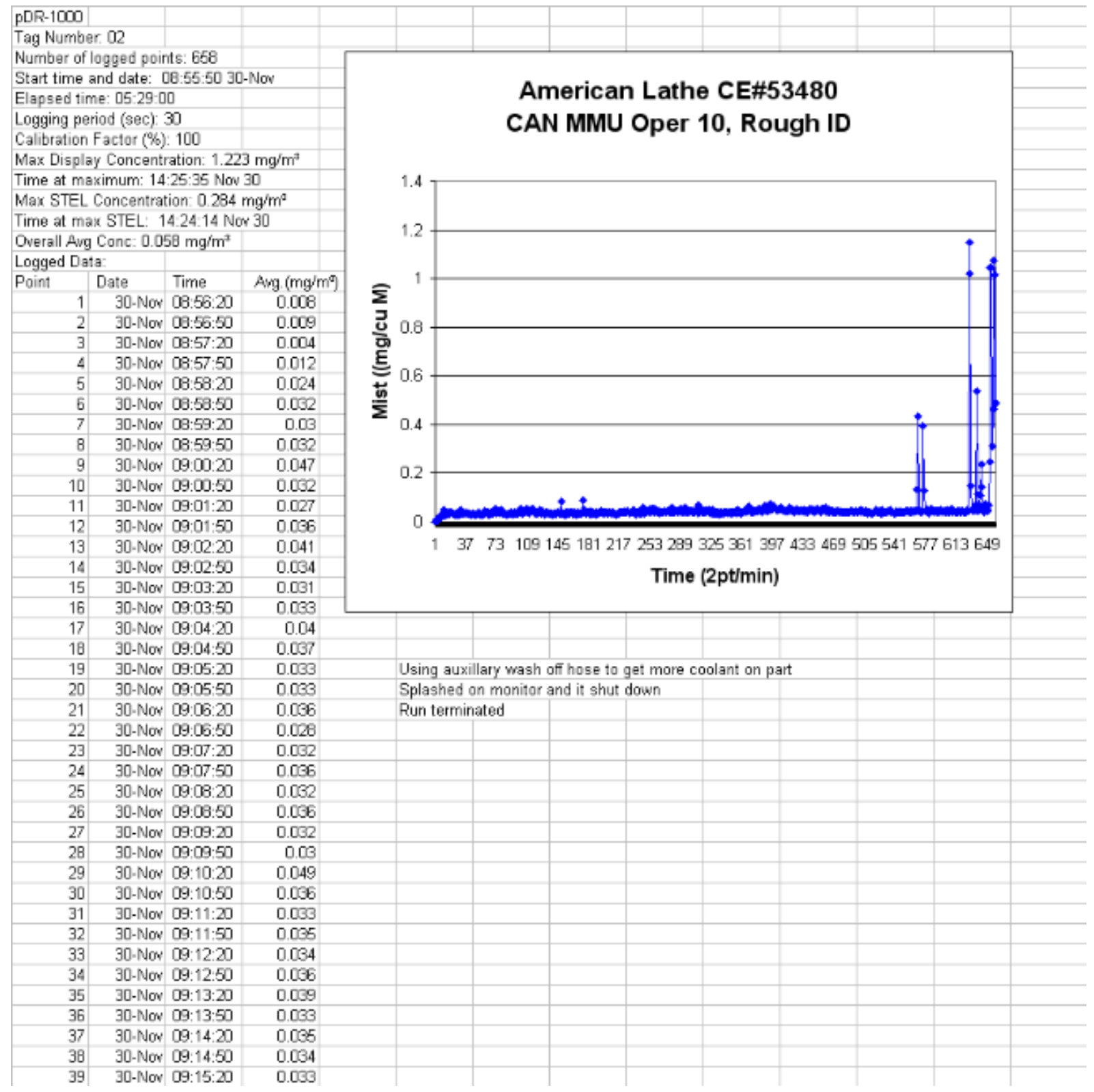




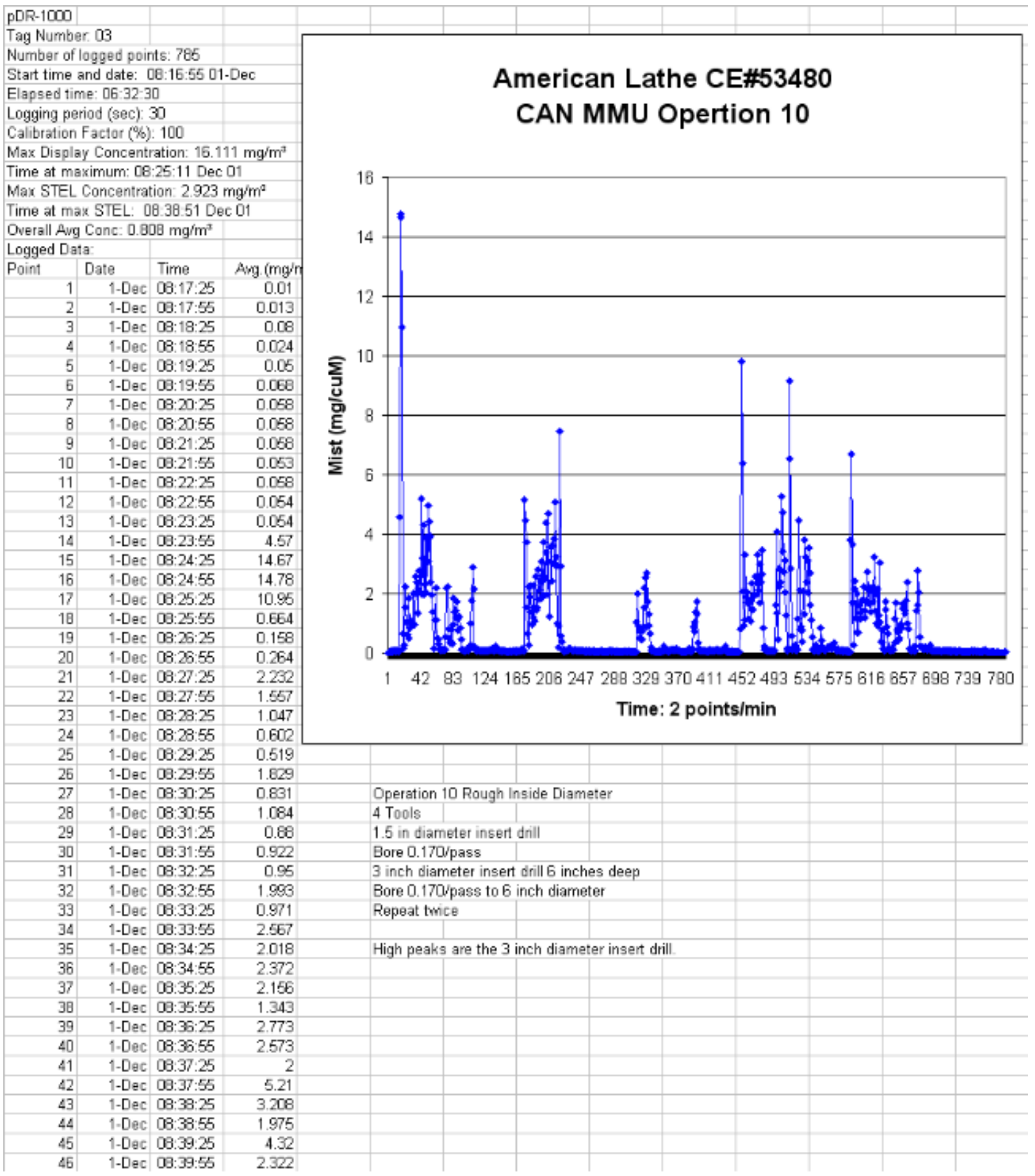




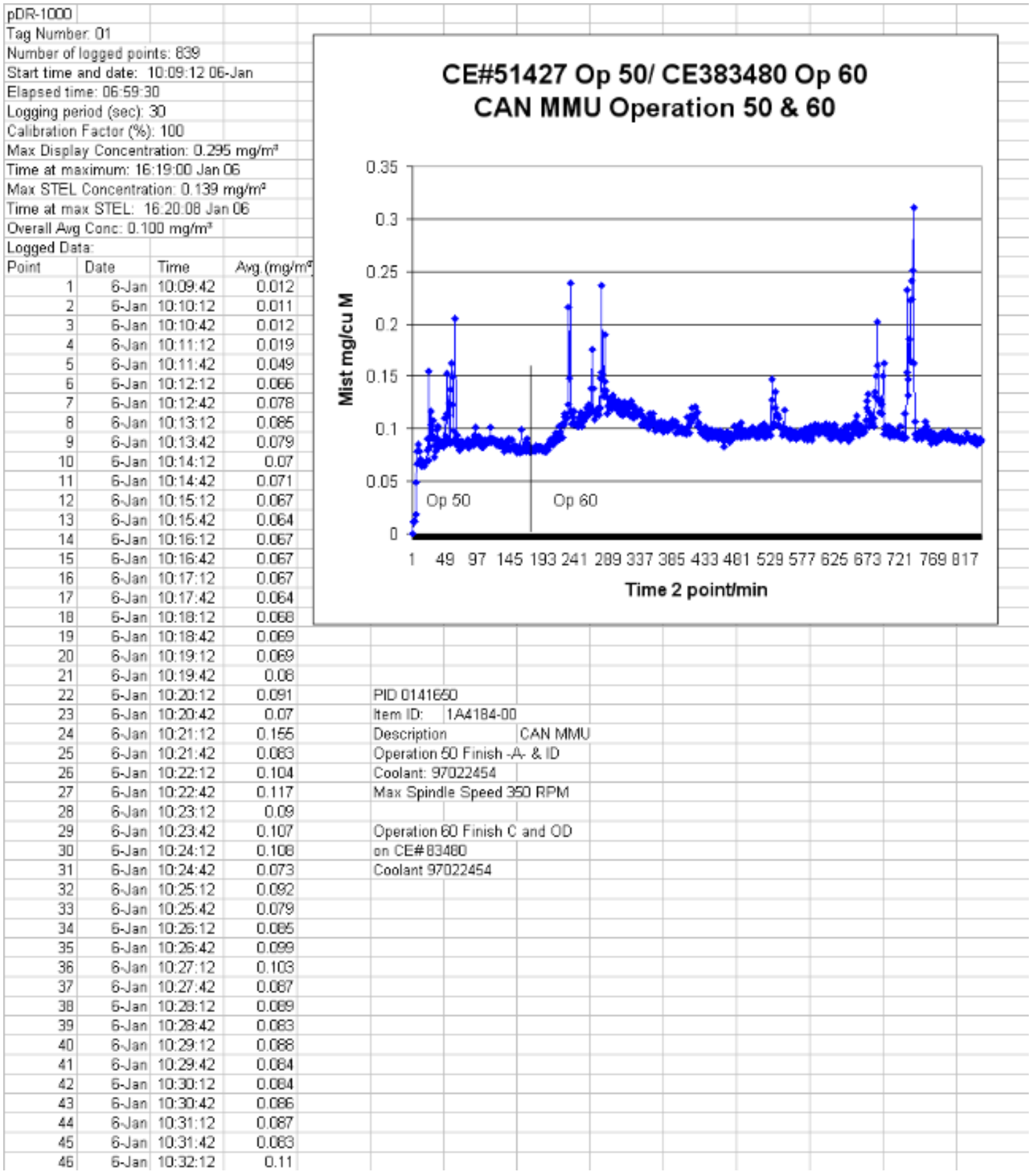




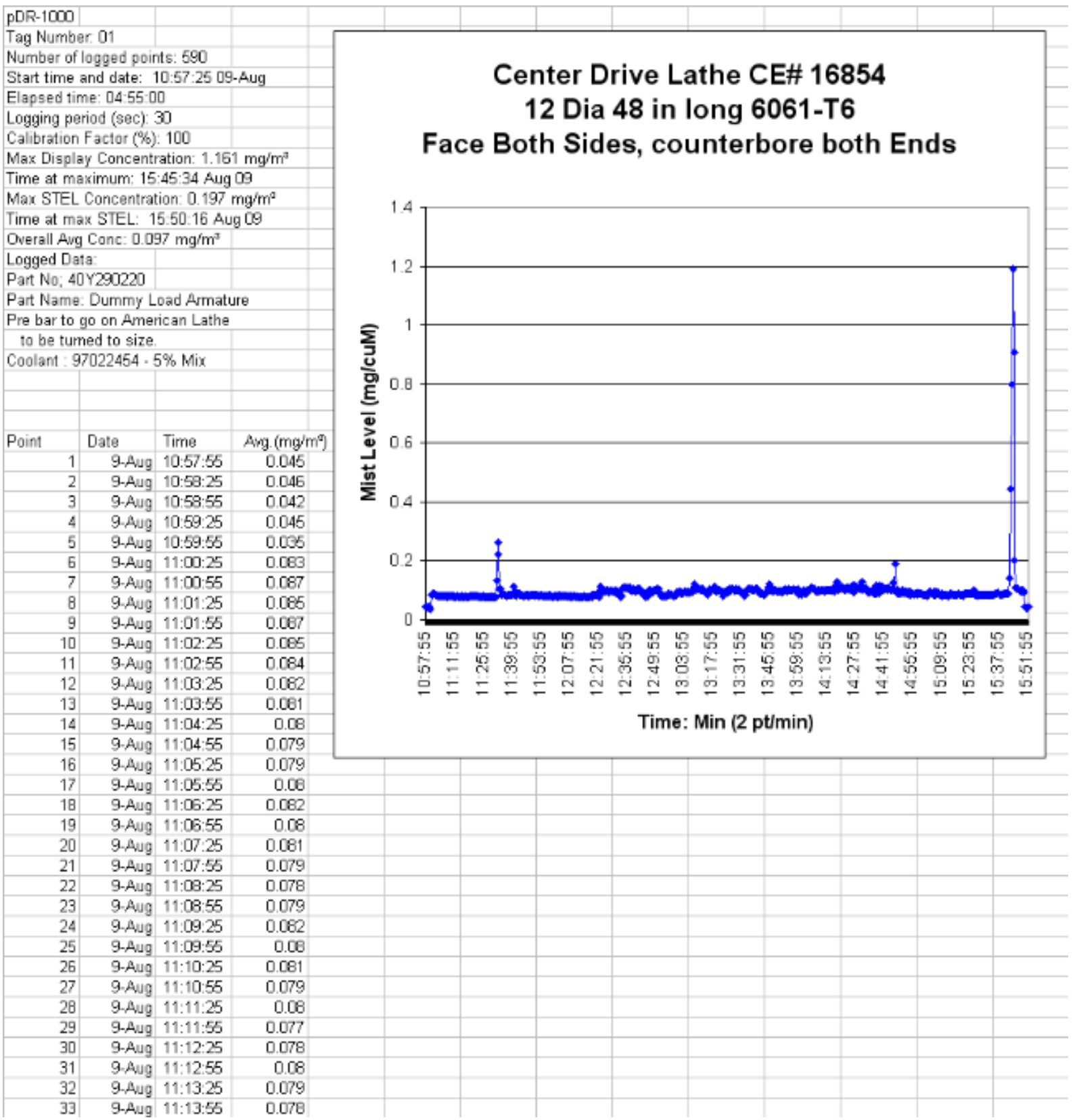




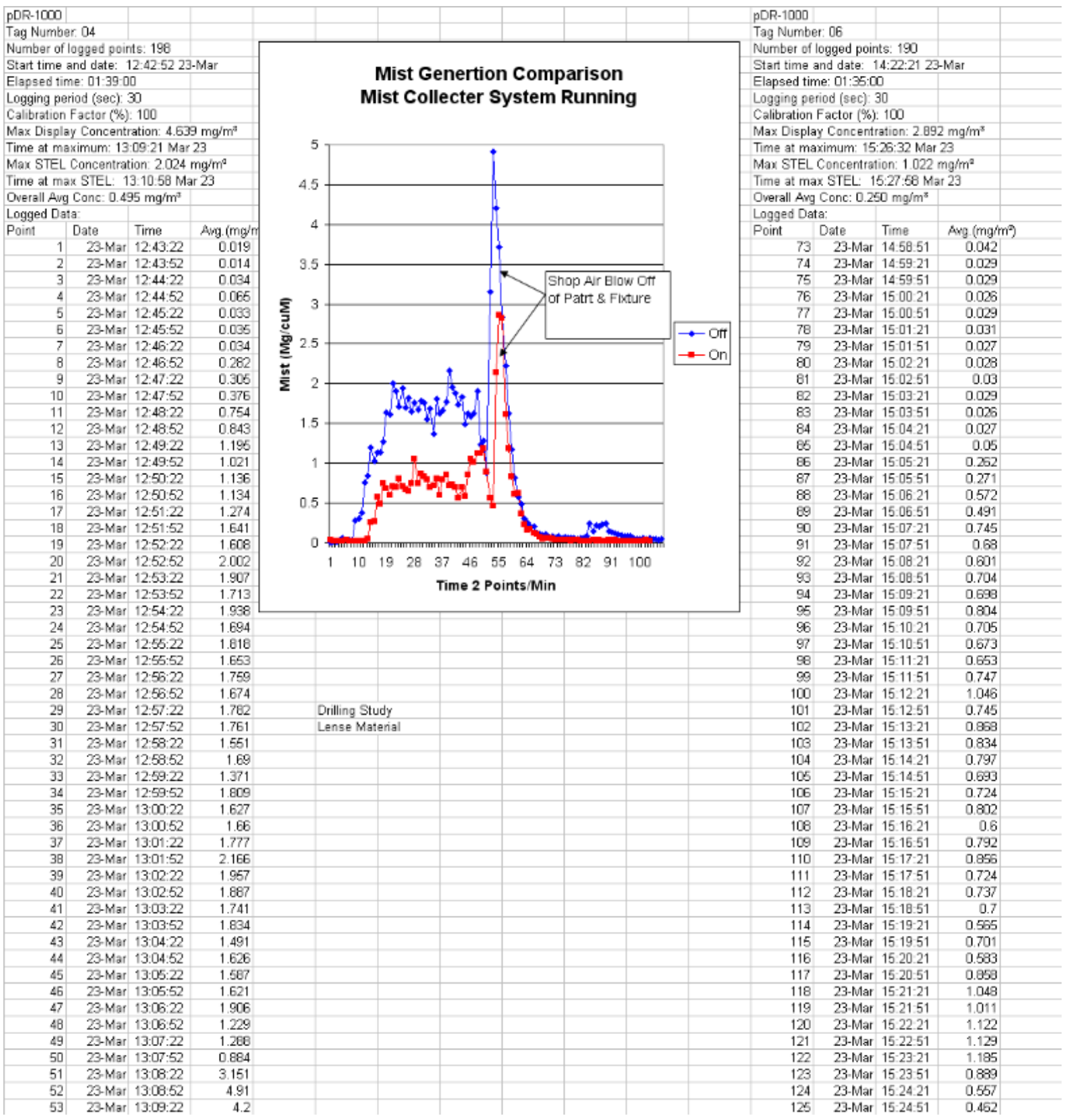

\section{Monarch VMC-75B Machining Center}




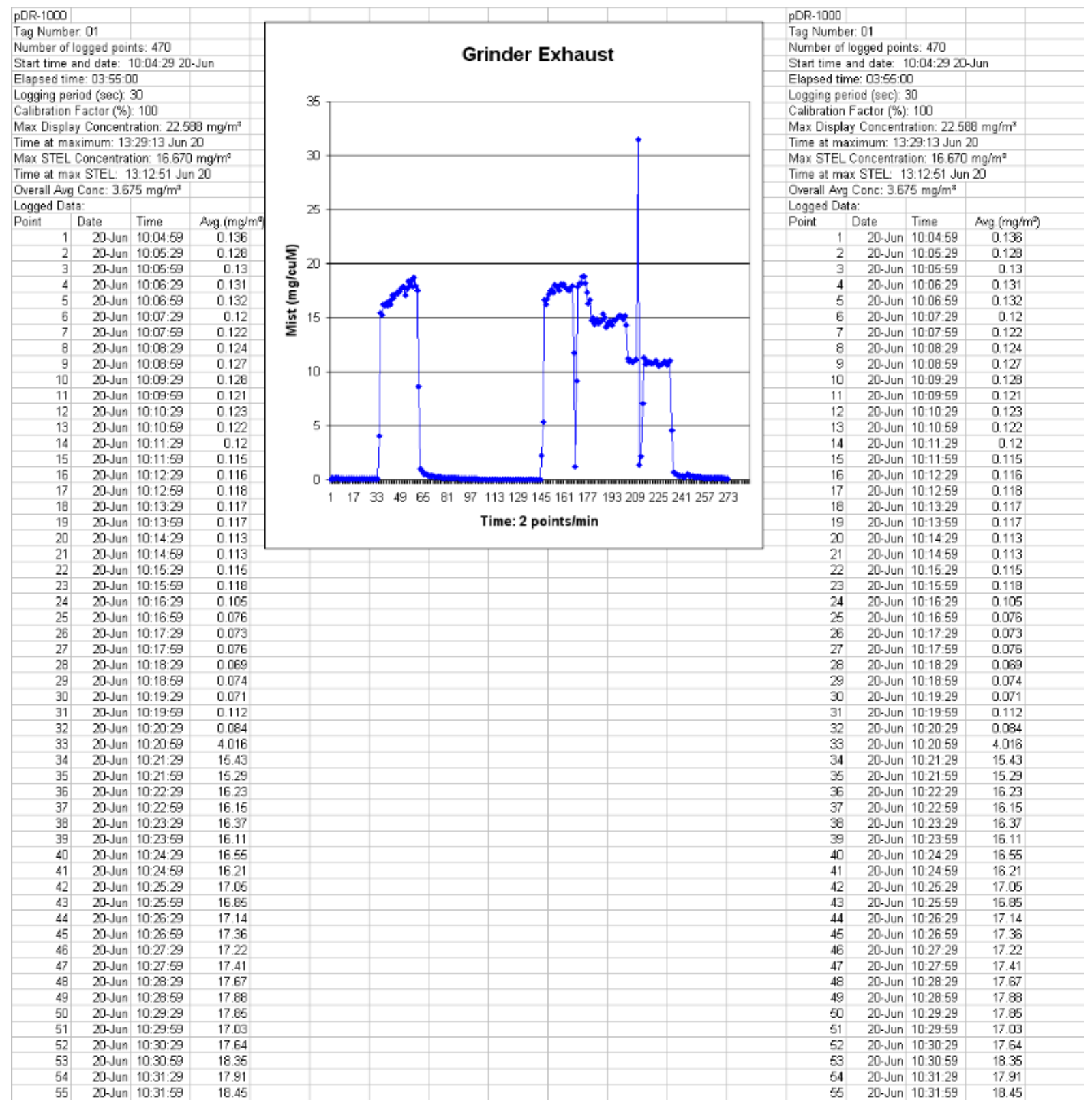




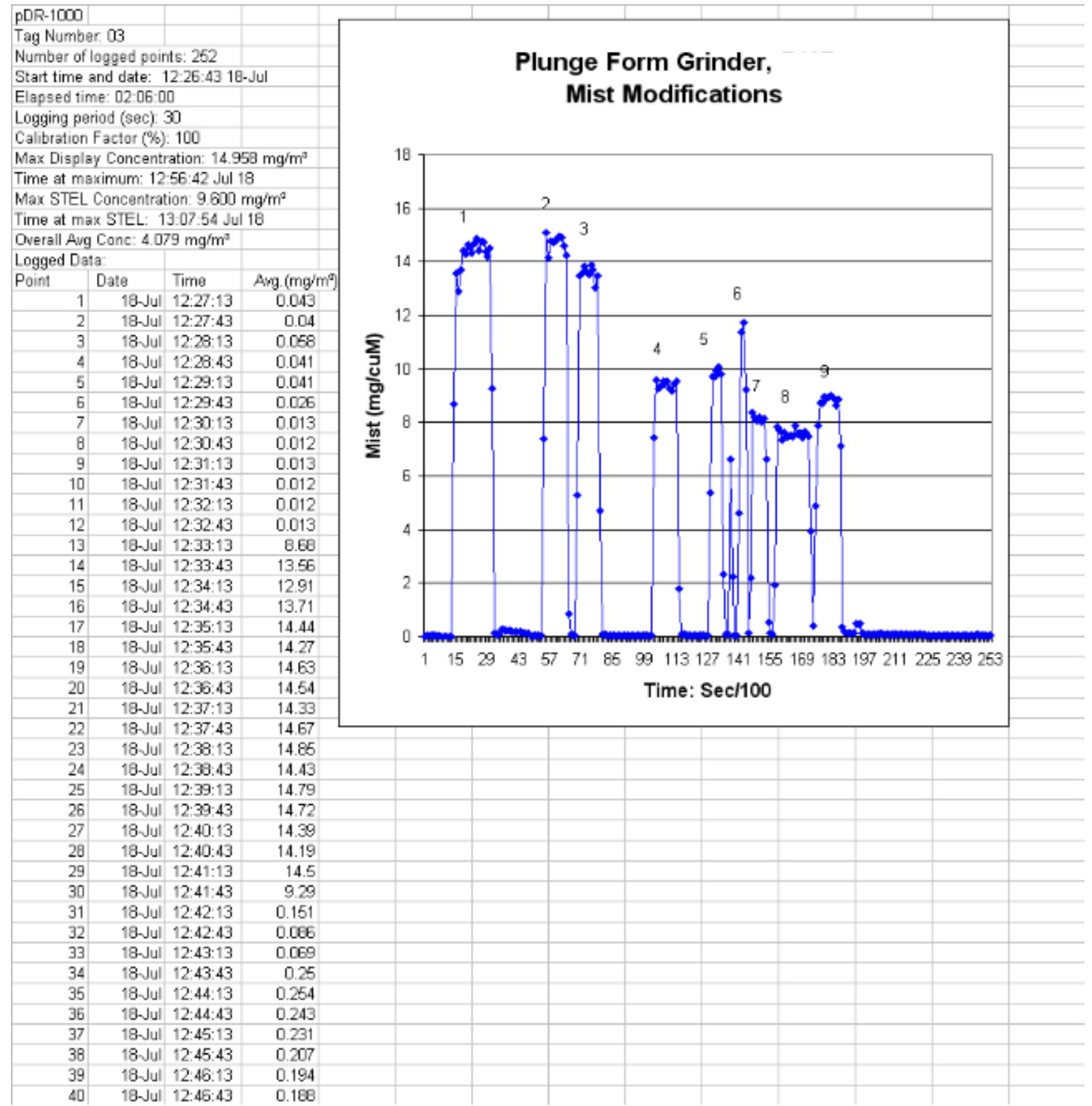




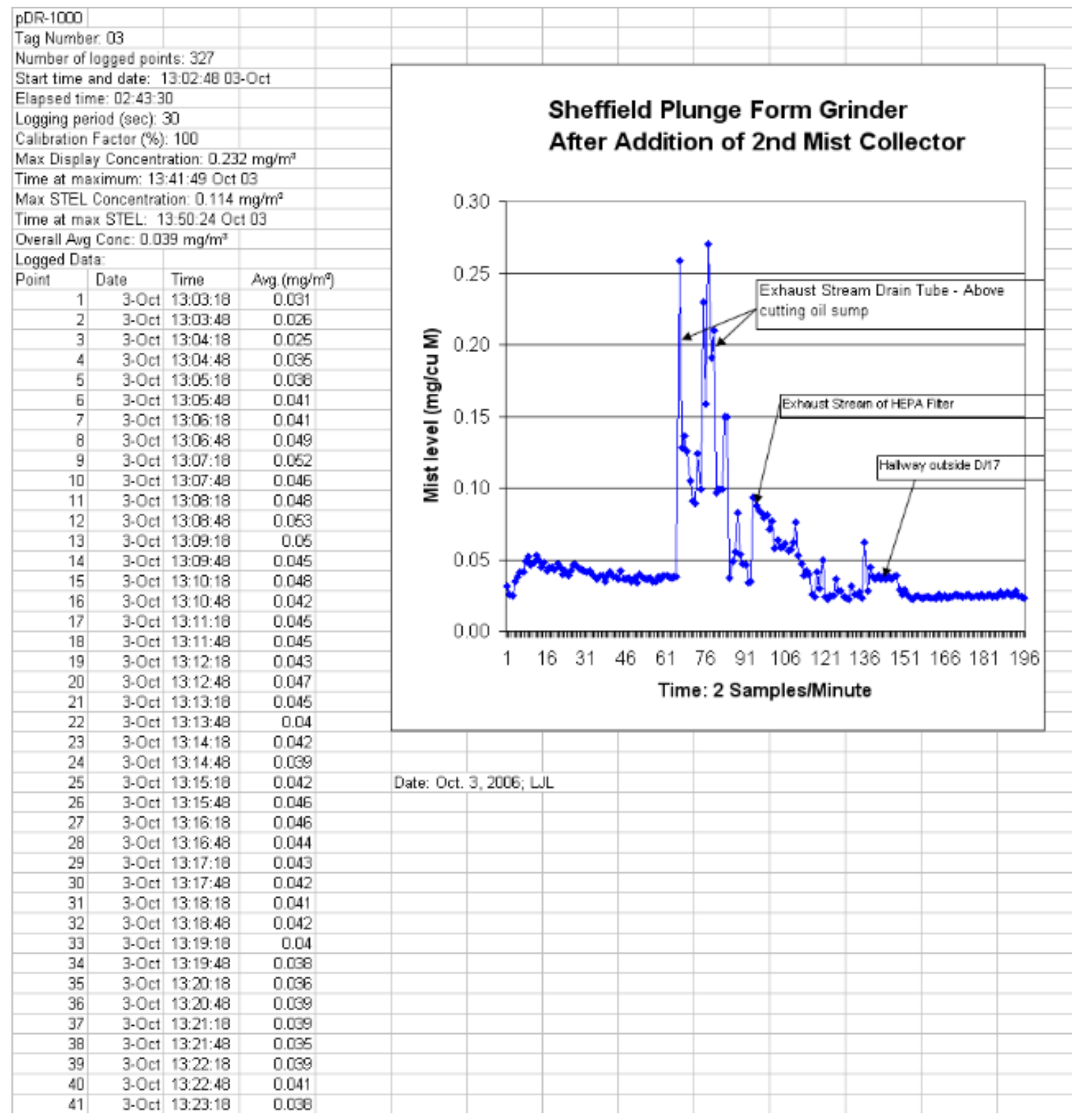




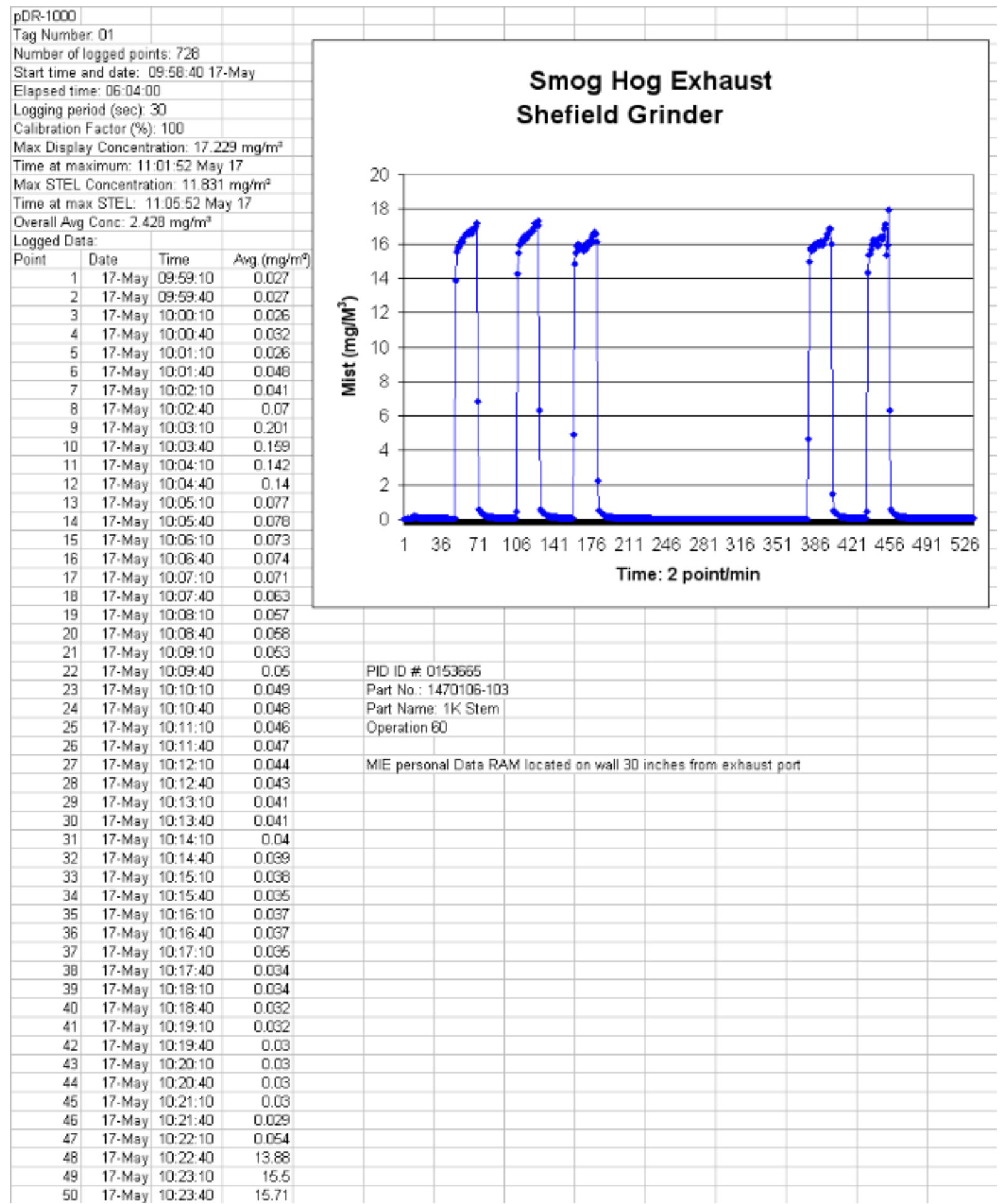




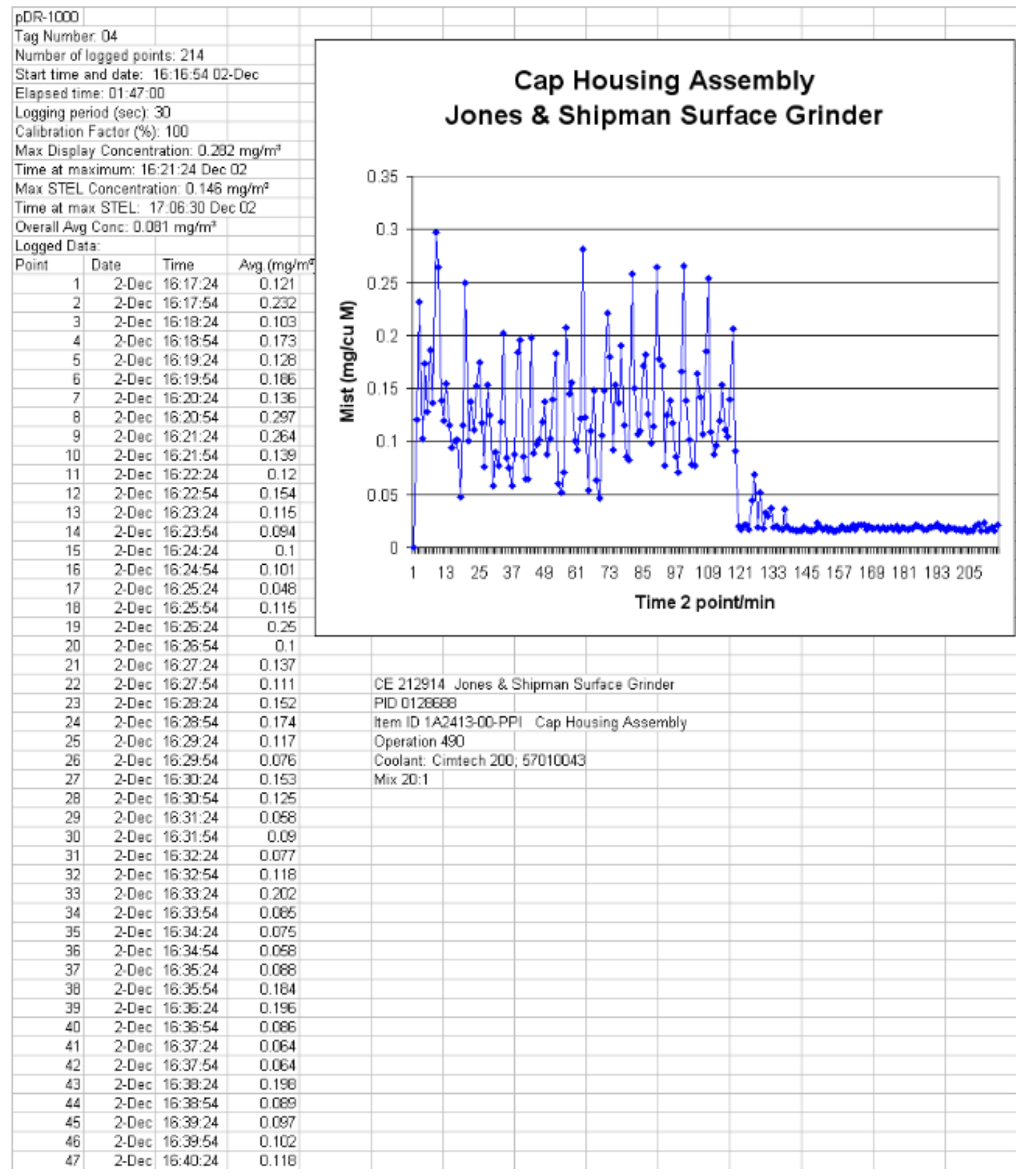




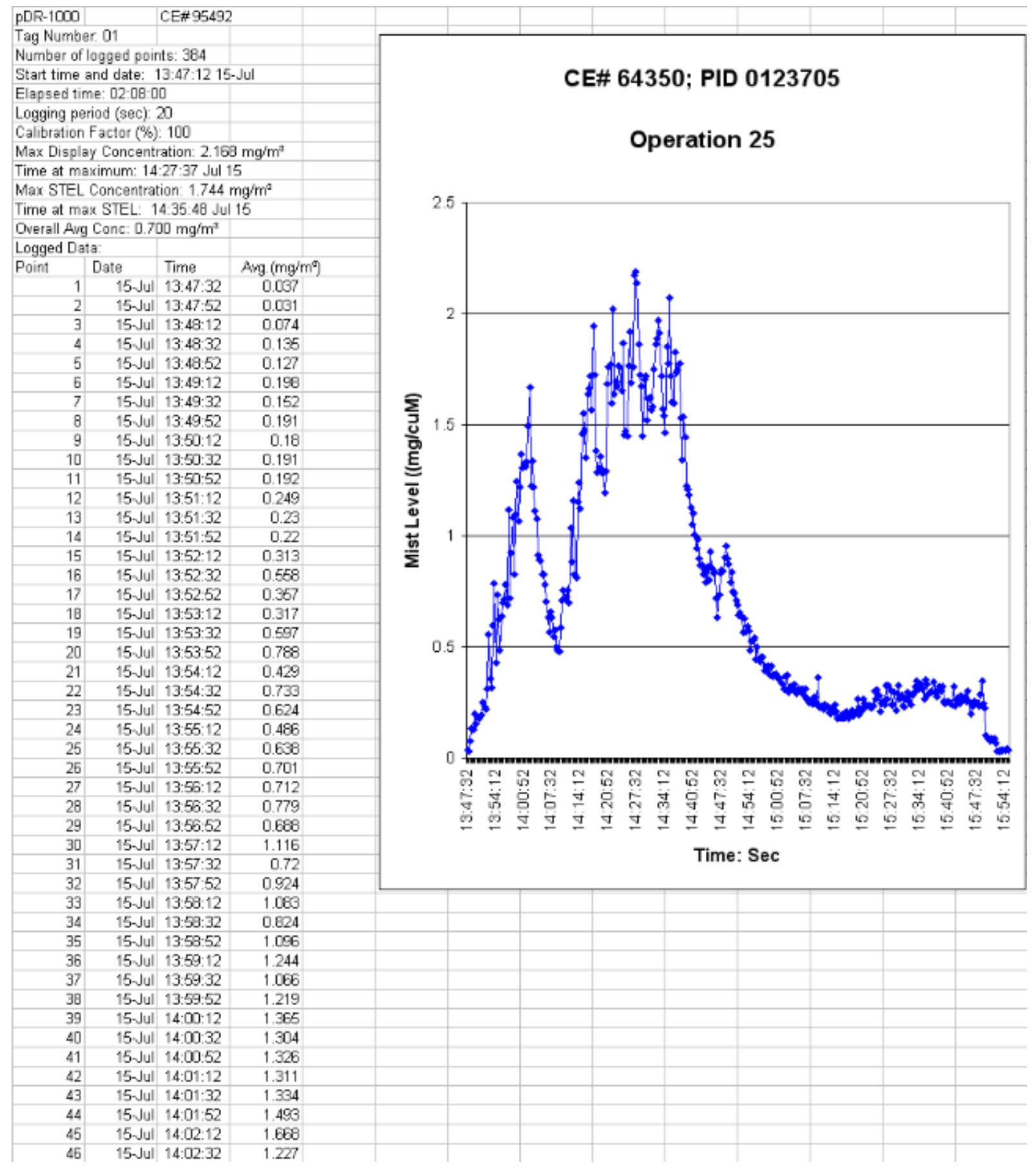




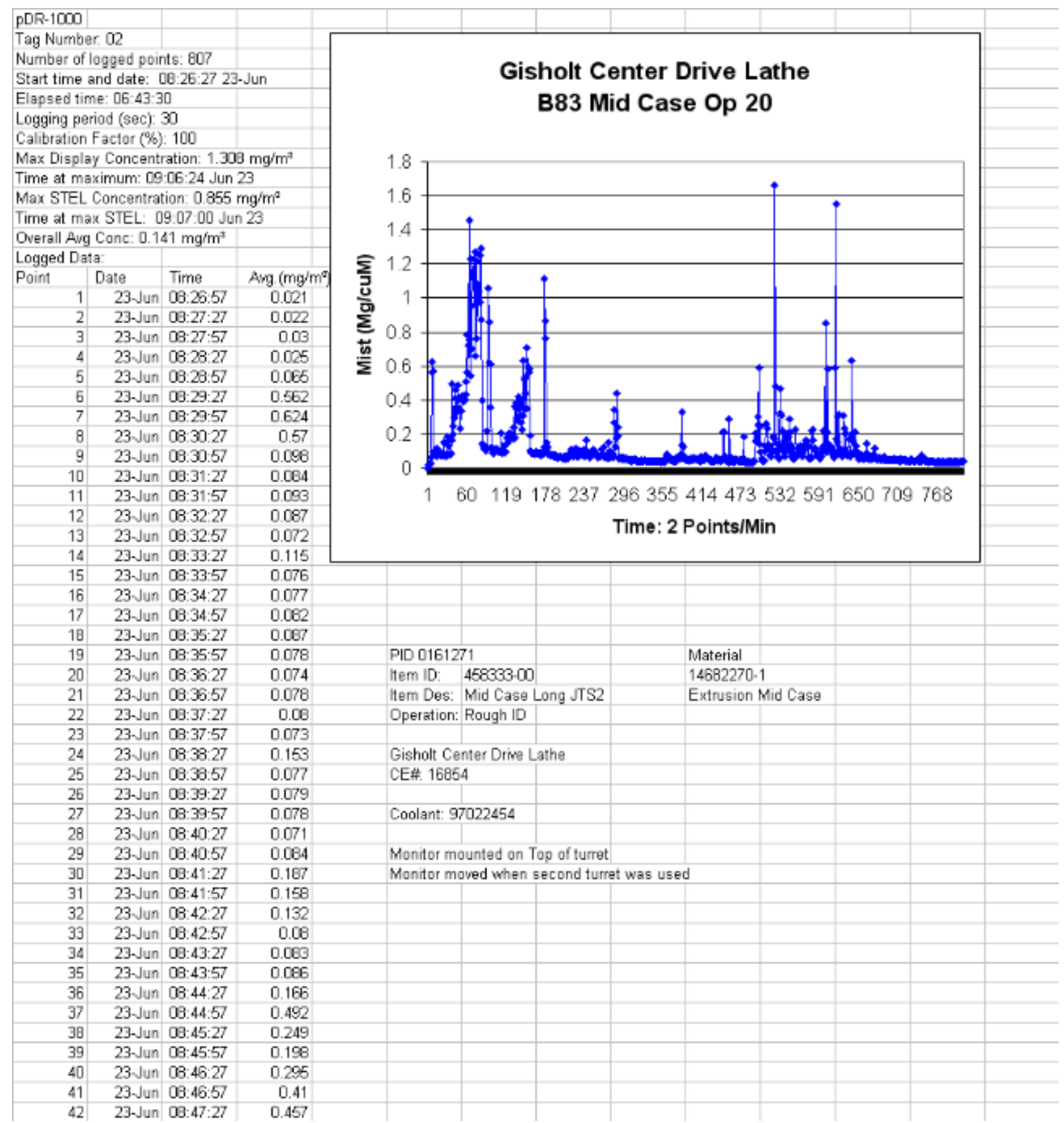




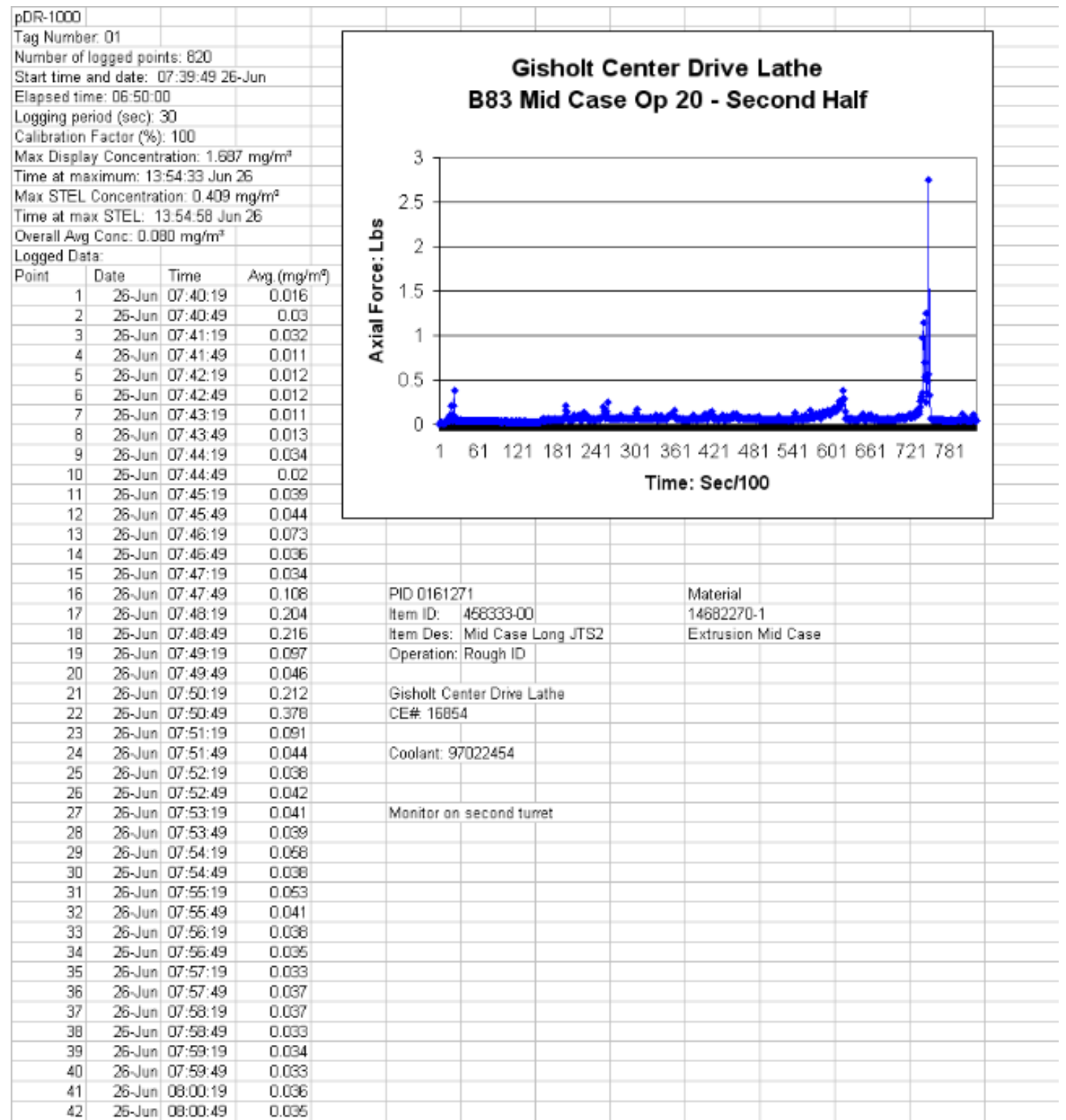




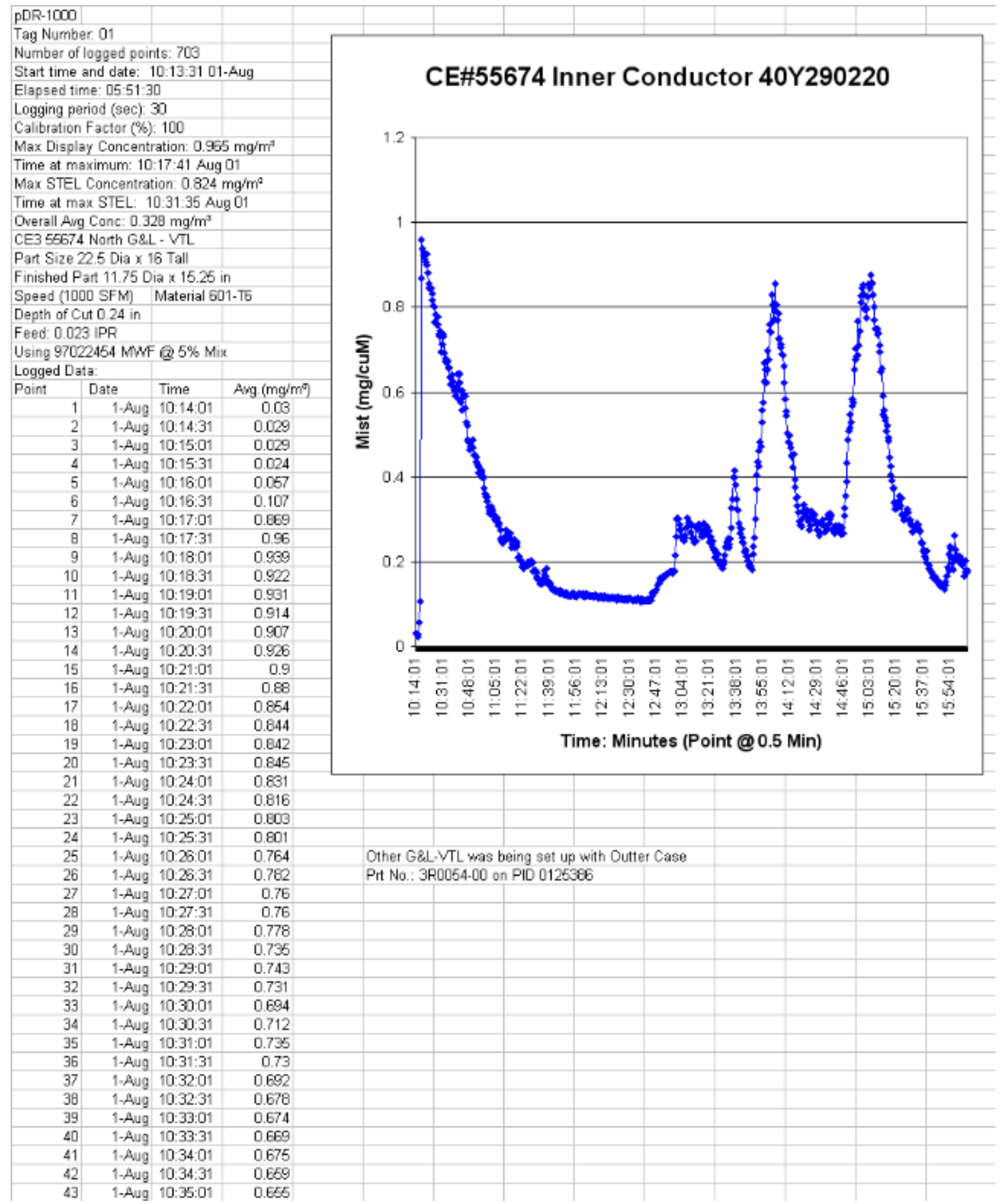




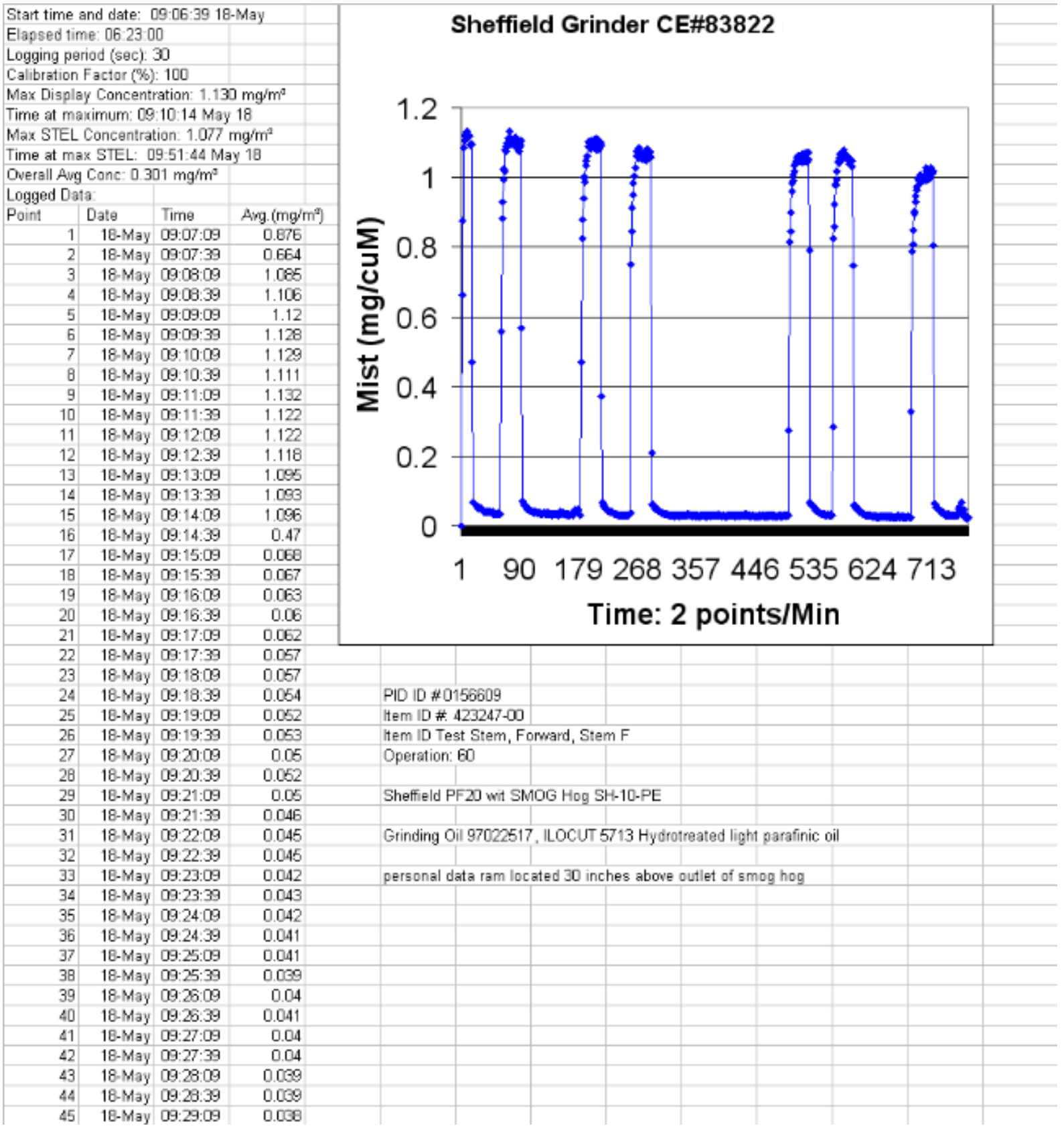




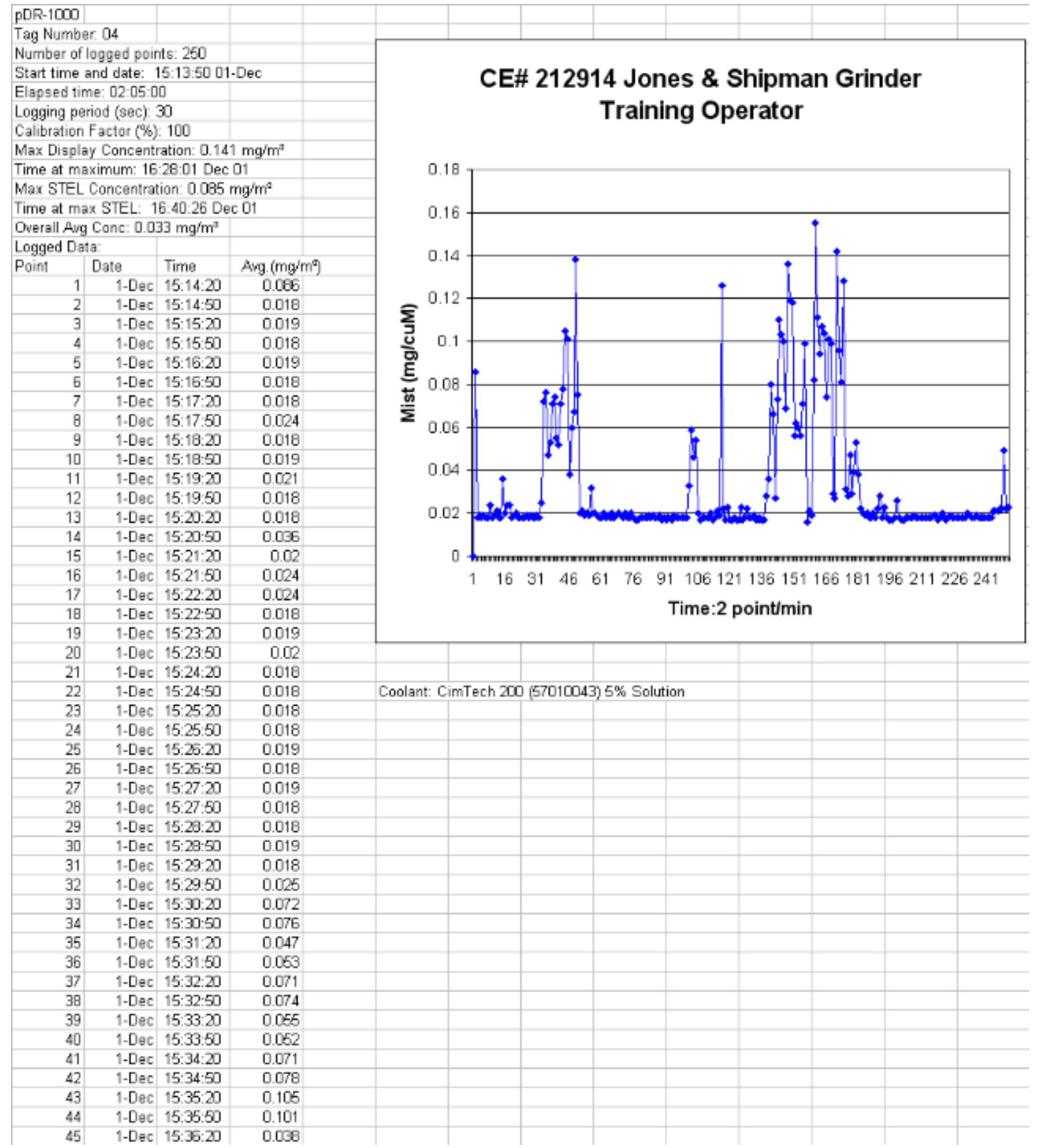




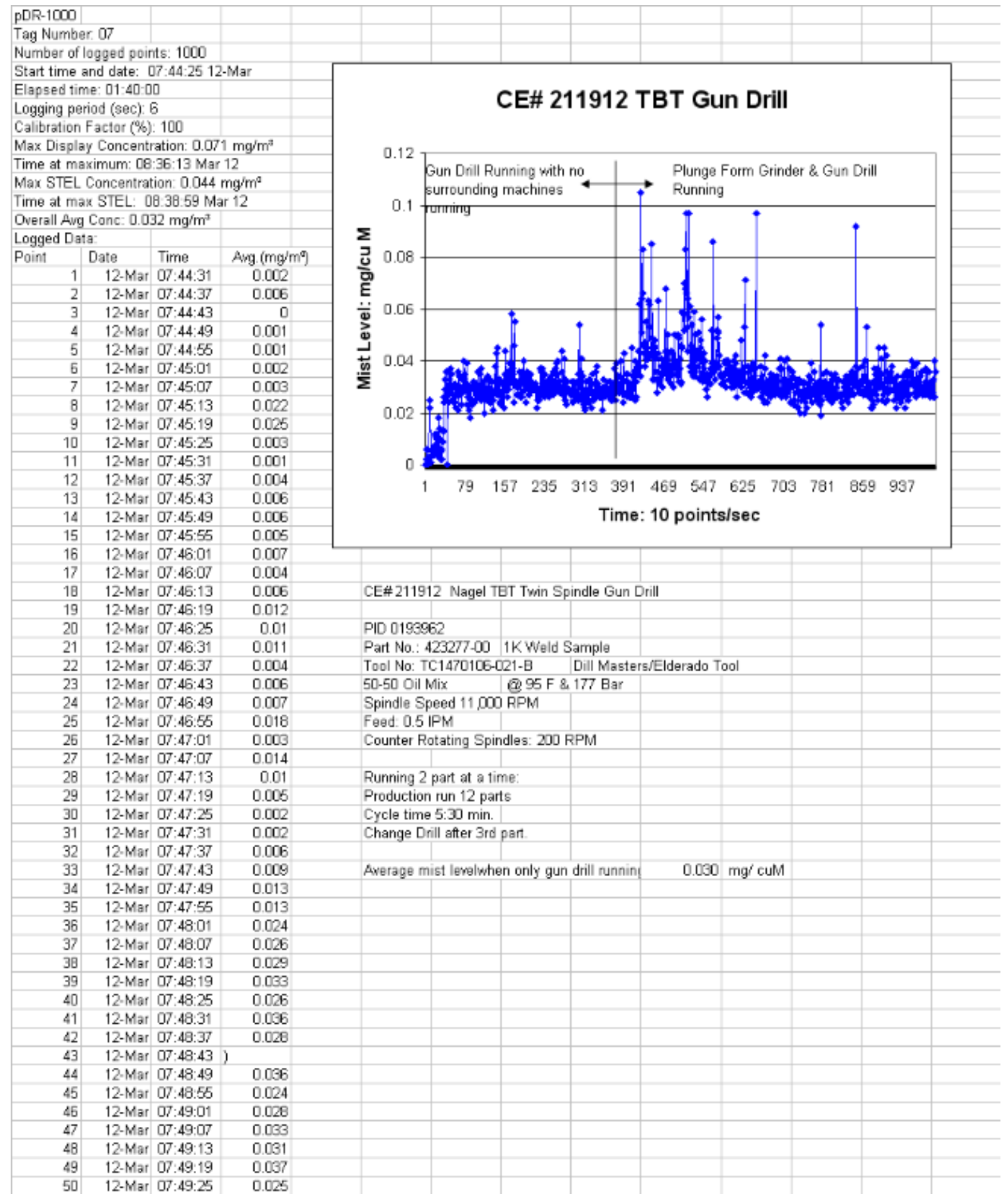




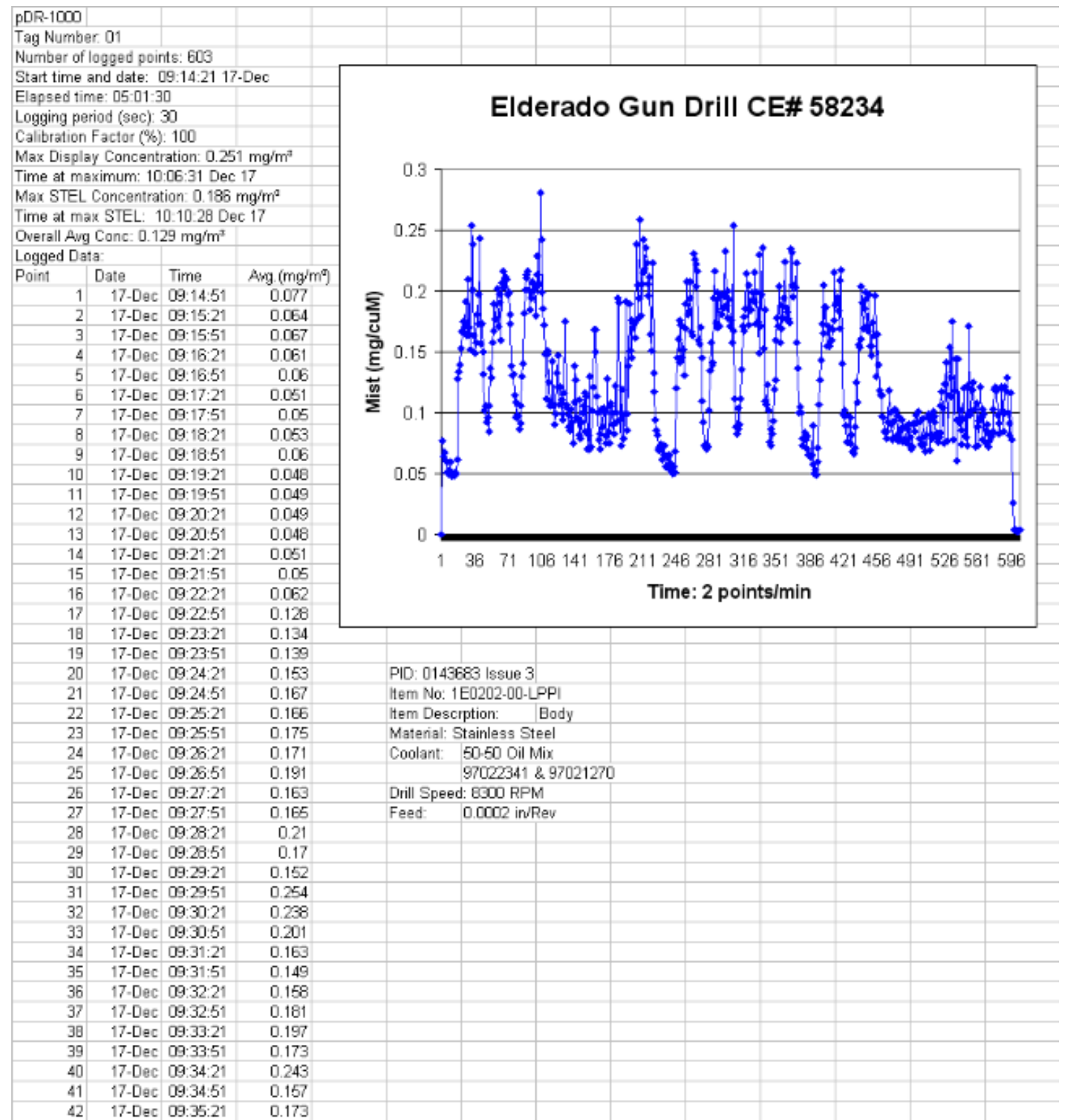




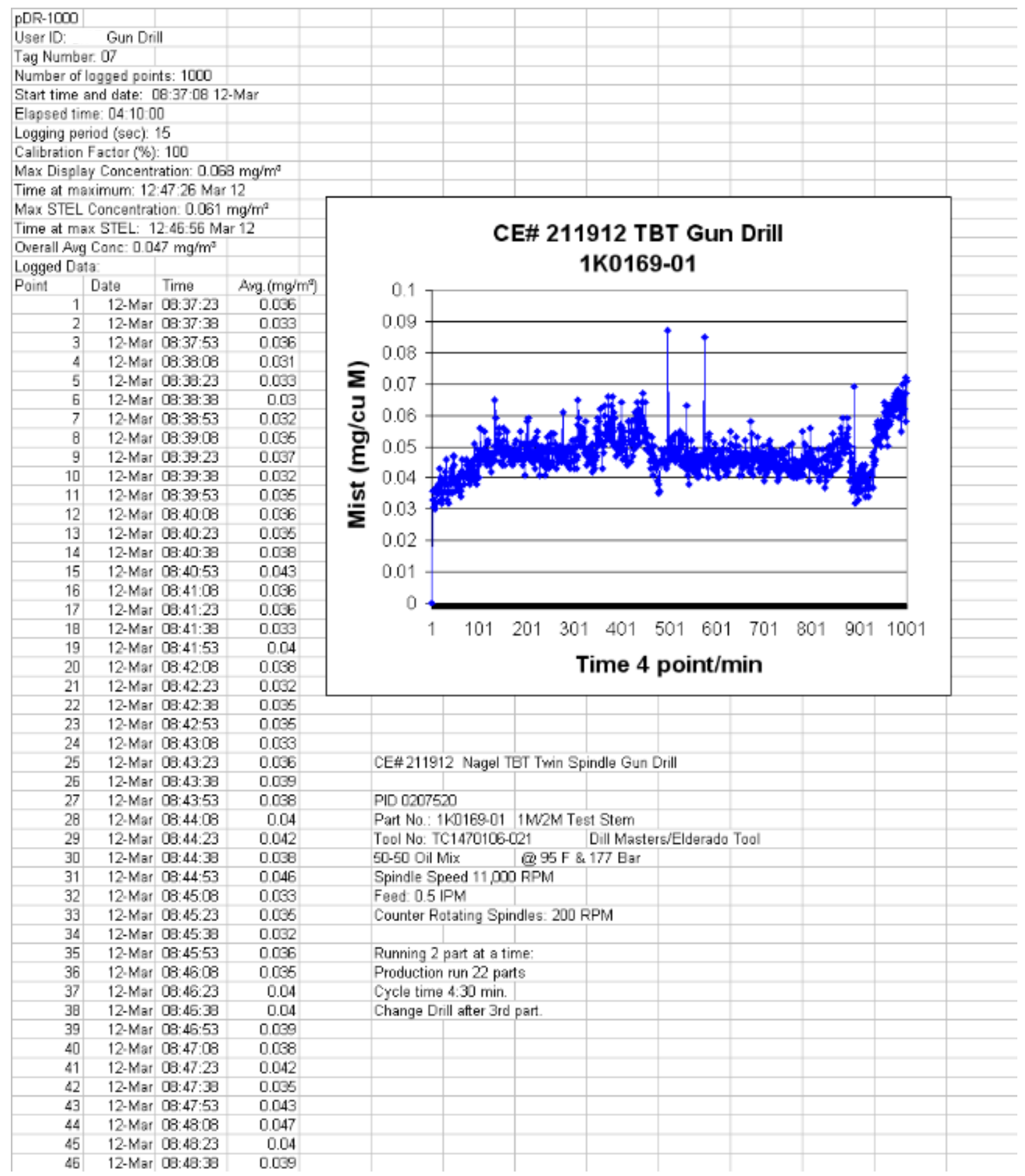




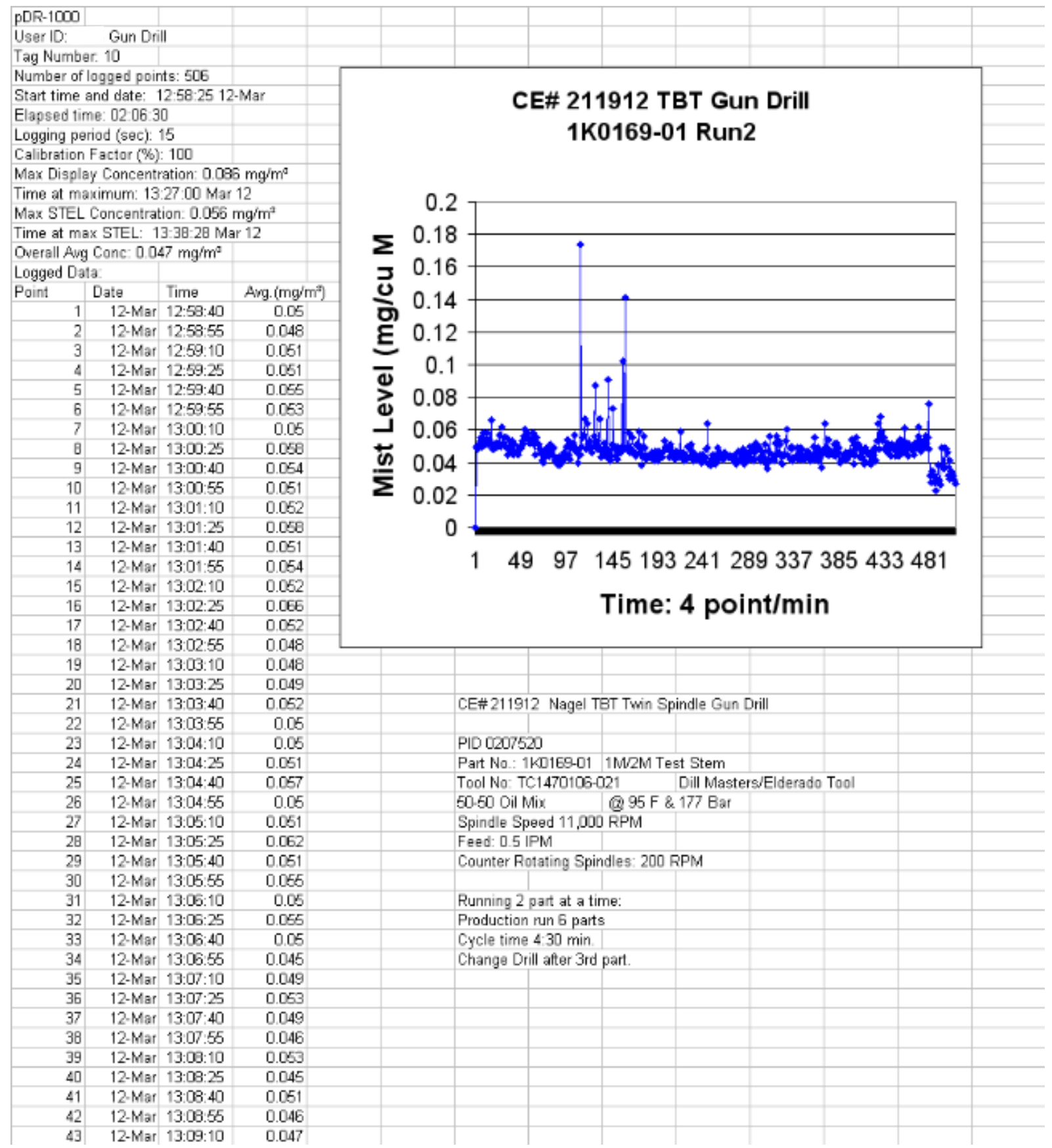




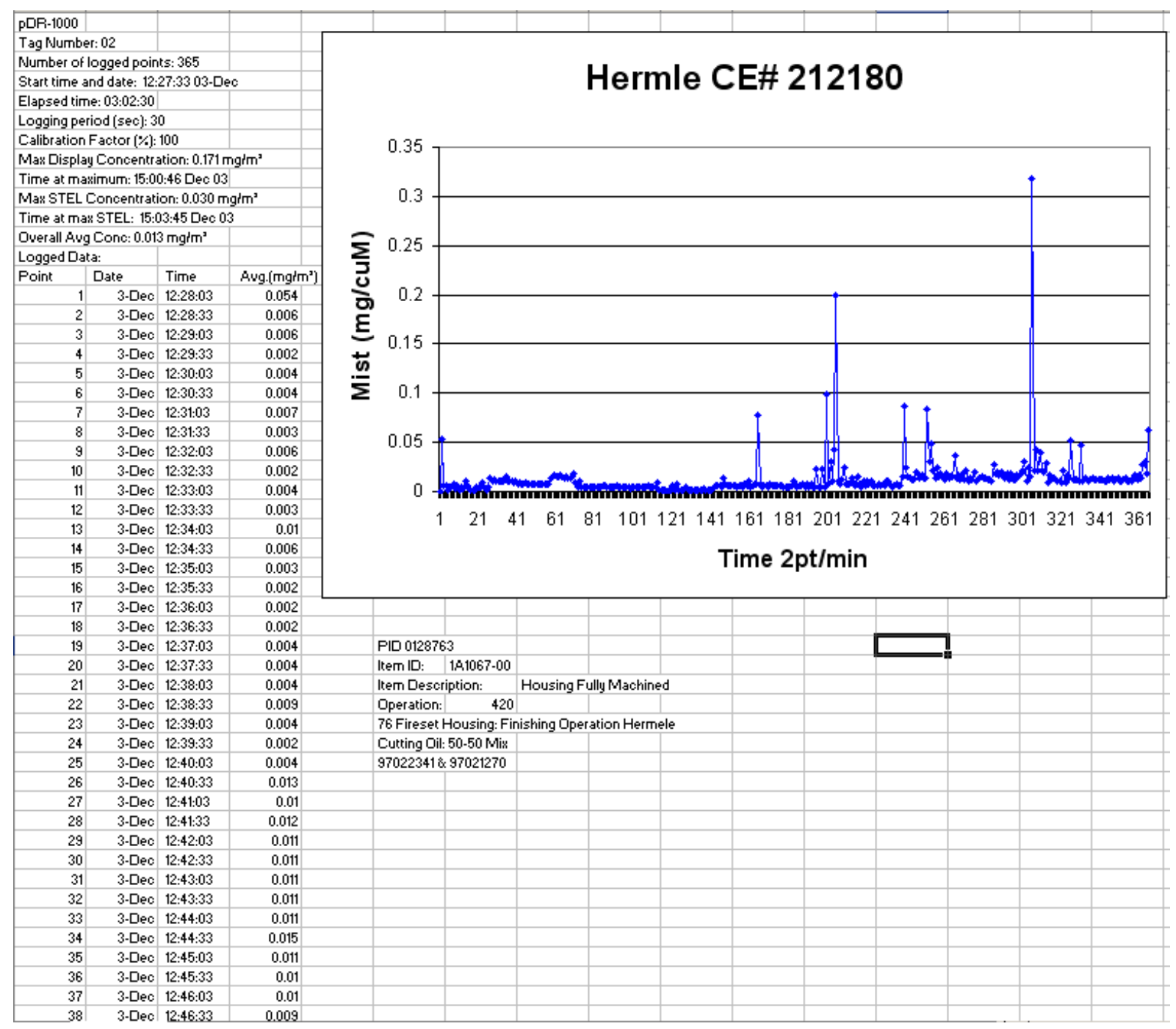




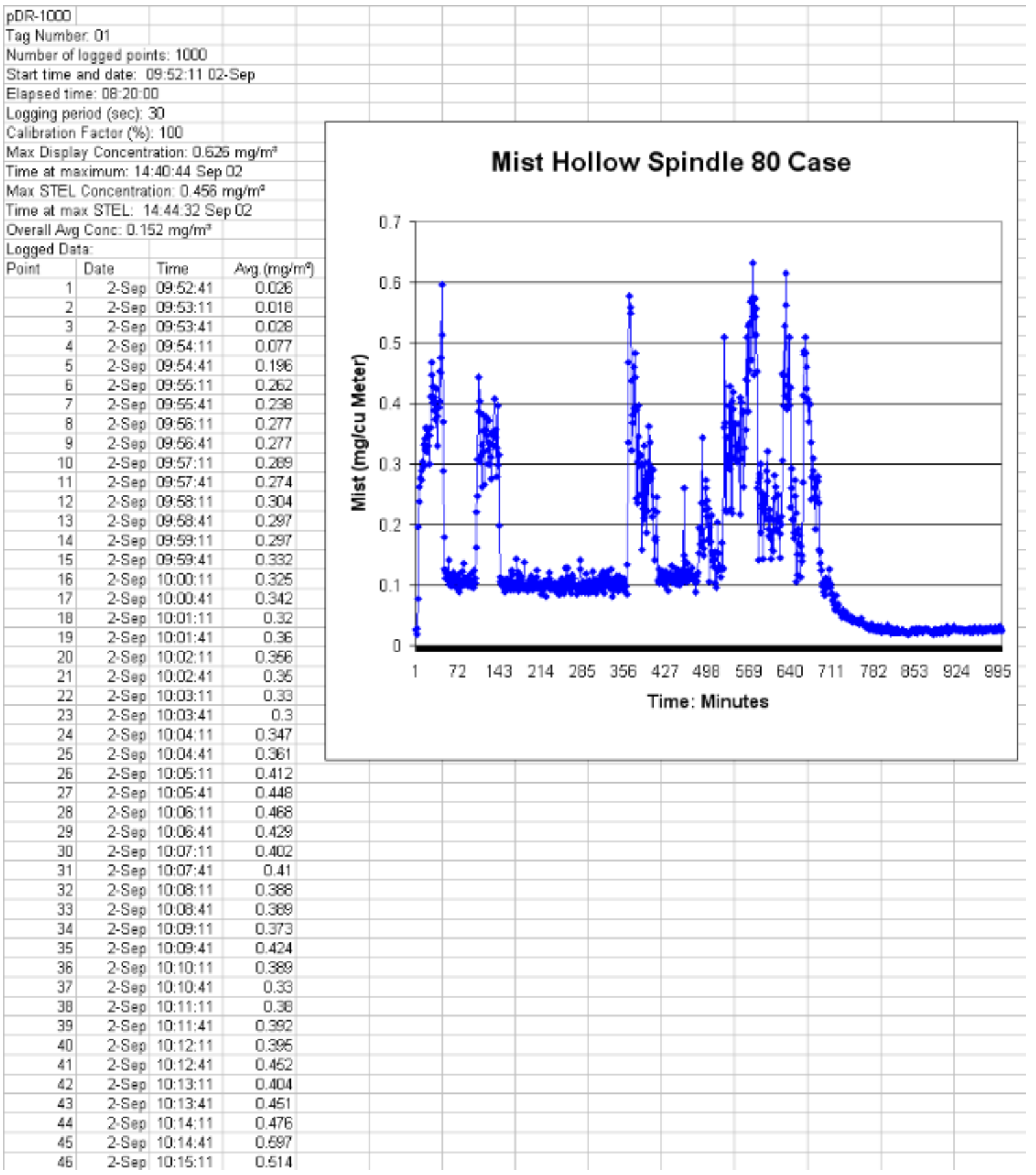




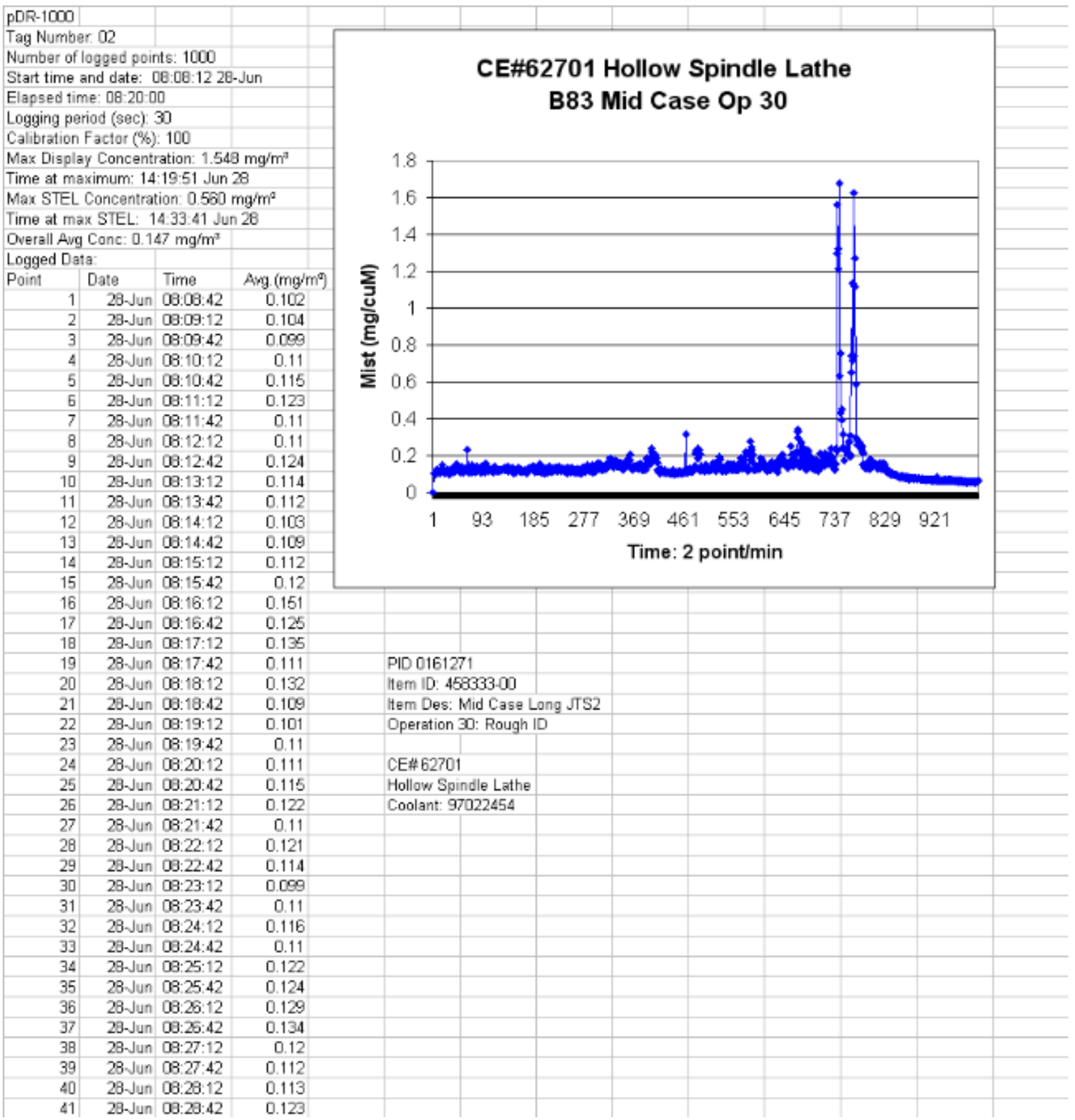




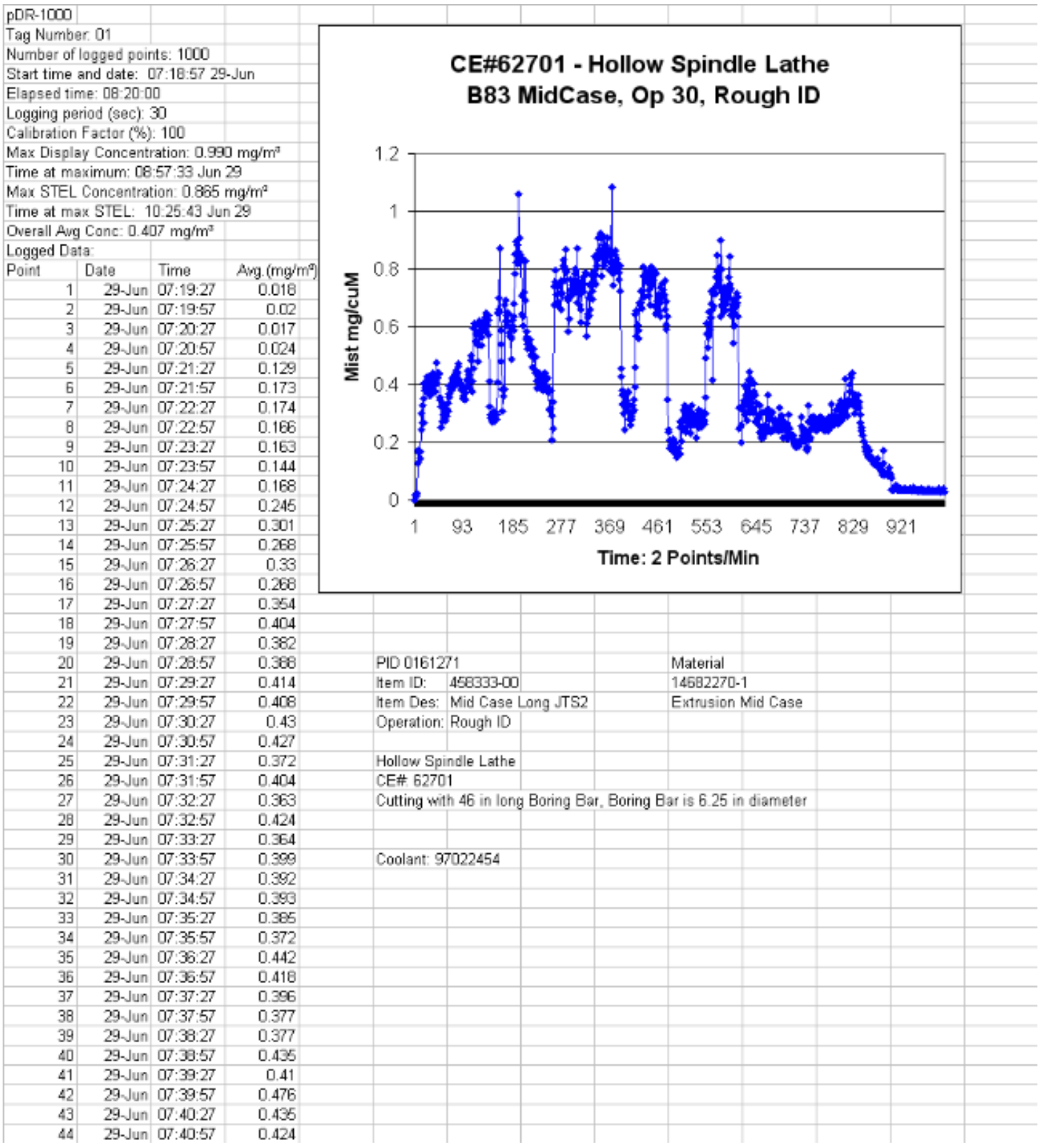


pDR-1000

Tag Number. 03

Number of logged points: 1000

Start time and date: 08:29:57 27-Sep

Elapsed time: 08:20-00

Logging period (sec): 30

Calibration Factor (\%): 100

Max Display Concentration: $0.124 \mathrm{mg} / \mathrm{m}^{3}$

Time at maximum: 14:01:25 Sep 27

Mar STEL Concentration $0.041 \mathrm{mg}^{2} \mathrm{~m}^{2}$

Time at max STEL: 14.01.21 Sep 27

Overall Avg Conc: 0.033 mg/m

Logged Data

\begin{tabular}{r|r|r|}
\hline & $27-S e p$ & $08.30: 27$ \\
\hline
\end{tabular}

Ang. $\left(m g / m^{\sigma}\right)$

27-Sep 00:30:57

27-Sep 08:31:27

27-Sep 08:31:57

27-Sep 08.32:27

27-Sep 00:32:57

27-Sep 03:33:27

27-Sep 08:33:57

27-Sep 03:34:27

27-Sep 00:34:57

27-Sep 03:35:27

27-Sep 03:35:57

27-Sep 08:36:27

27-Sep 00:35:57

27-Sep 08:37:27

0.019

0.023

0.014

0.019

0.027

0.005

0.032

0.069

0.034

0.037

0.042

0.038

0.006

0.034
0.028

27-Sep 03.33:27 0.034

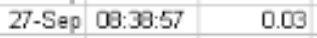

27-Sep 08:39:27 0.032

27-Sep 0839.57 0.04

\begin{tabular}{ll|l}
$27-S e p$ & $08.40: 27$ & 0.03
\end{tabular}

27-Sep 00:40:57

27-Sep 08:41:27

27-Sep 08:41:57

27-Sep 08:42:27

27-Sep 00:42:57

27-Sep 08:43:27

27-Sep 08:43.57

27-Sep 08:44:27

27-Sep 03:44:57

27-Sep 03:45:27

27-Sep 08:45:57

27-Sep 03.46:27

27-Sep 00:45:57

27-Sep 08:47:27

27-Sep 08:47:57

27-Sep 08.48:27

27-Sep 03:48:57

27-Sep 08:49:27

27-Sep 08:49:57

27-Sep 03.50:27

27-Sep 00:50:57

27-Sep 08:51:27

27-Sep 08:51:57

27-Sep 08.52.27

27-Sep 00:52:57

\section{CE\#50744 Large American Lathe Machining Lead}

Time: 2 points/ min

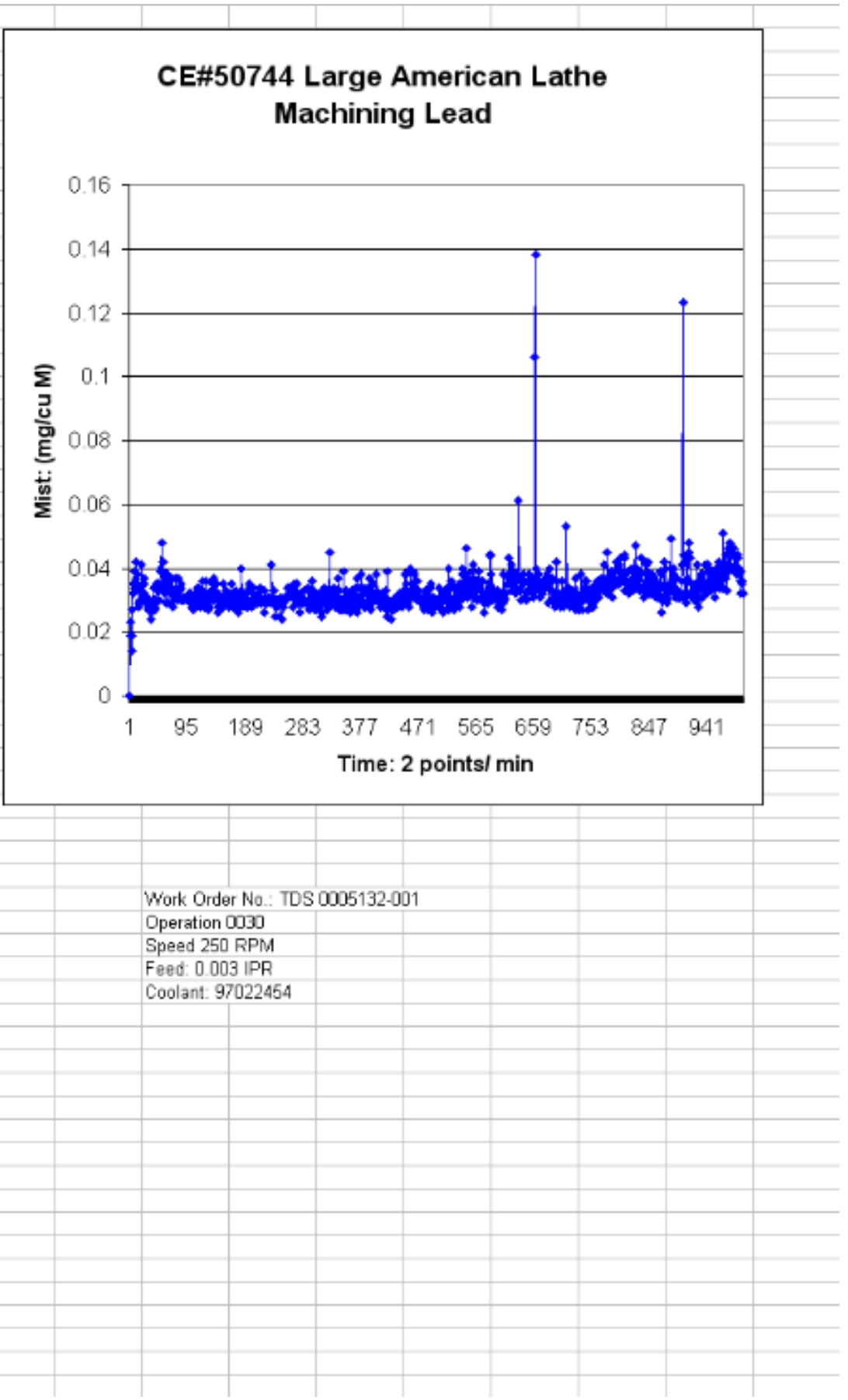

0.037
0.062

0.006

0.029

0.03
0.031

0.029

0.027

0.03

0.029

0.028

0.024

0.026

0.028

0.029

0.034

0.029

0.02

0.028

0.029

0.005 


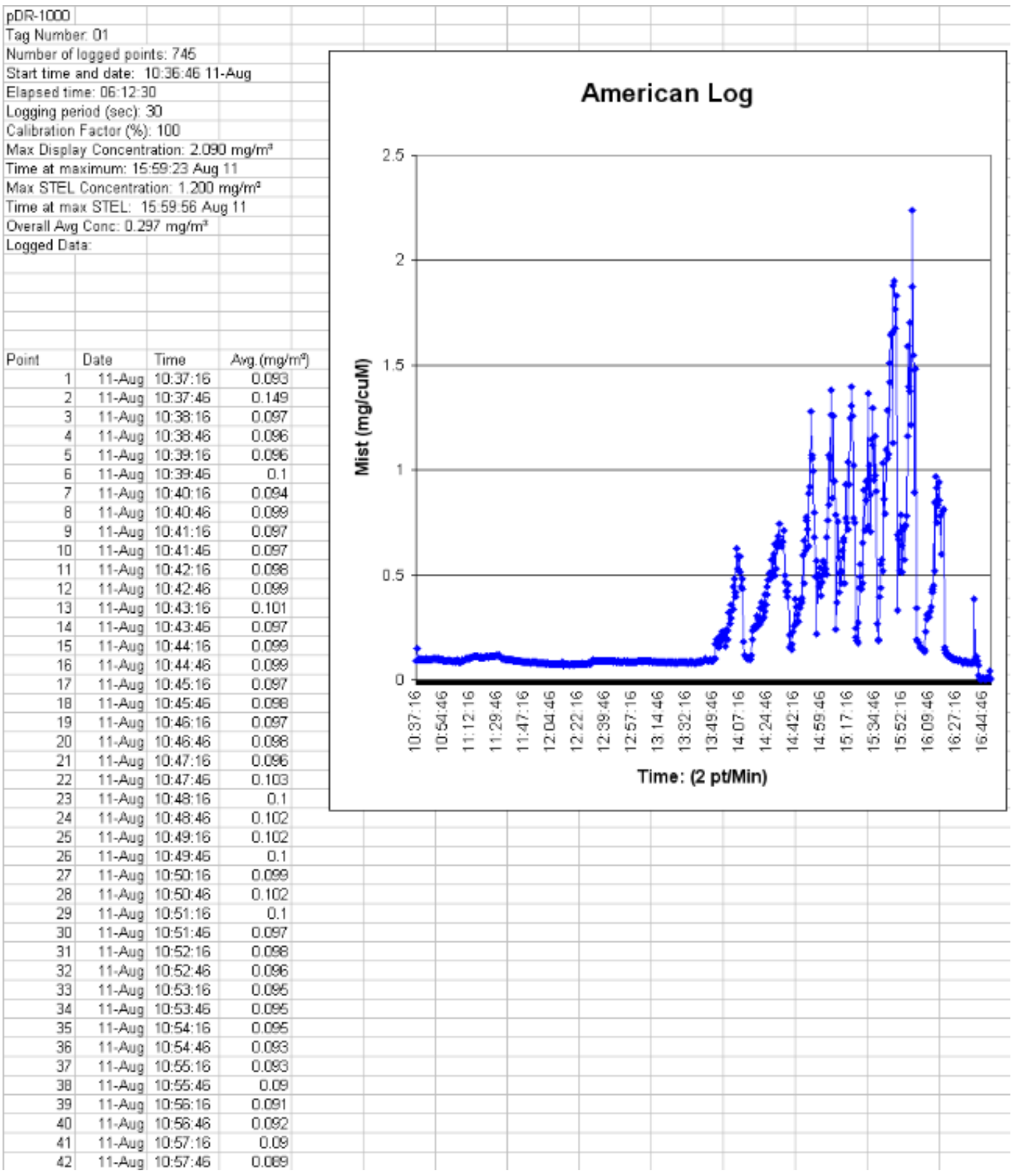




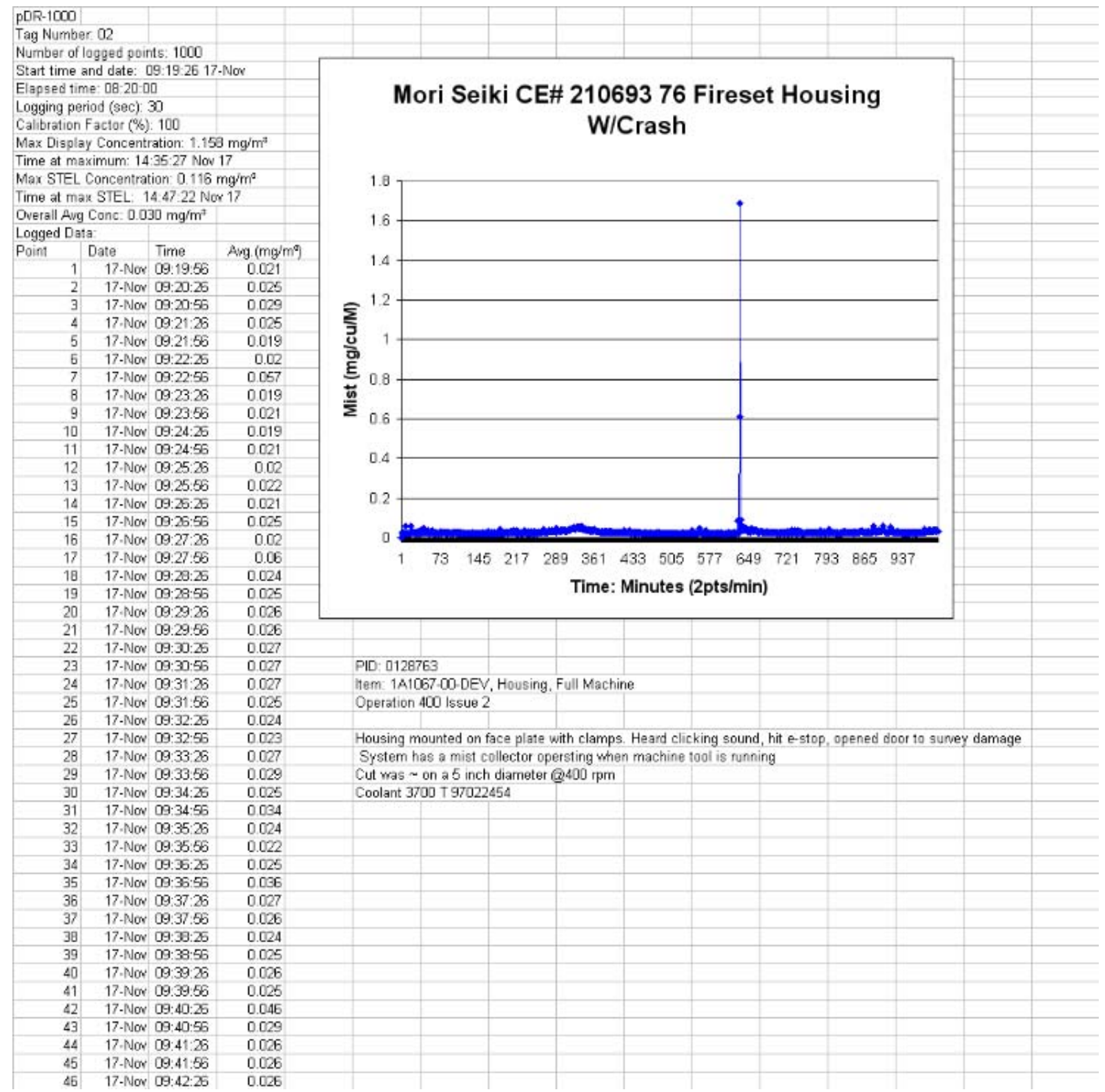




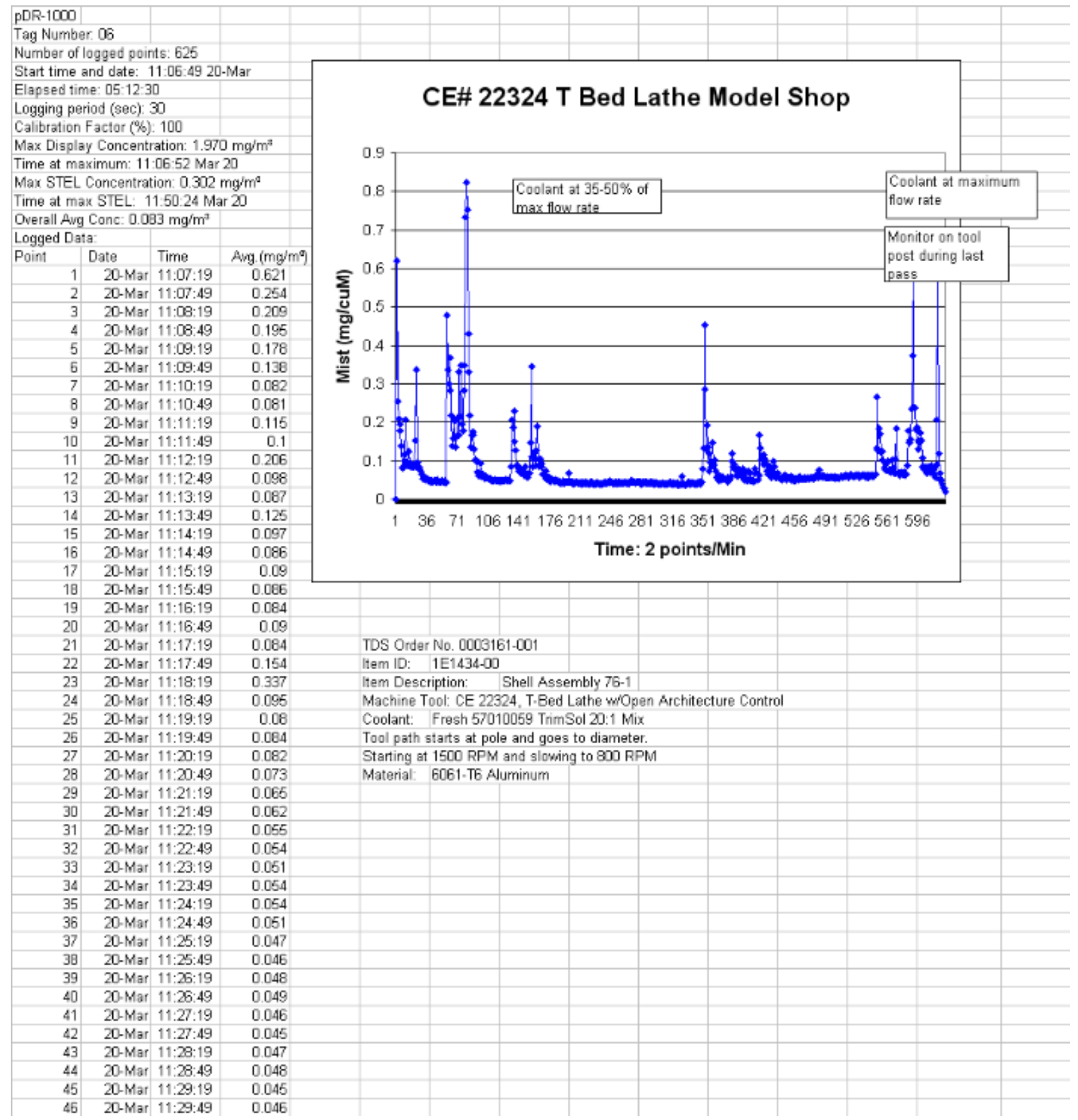




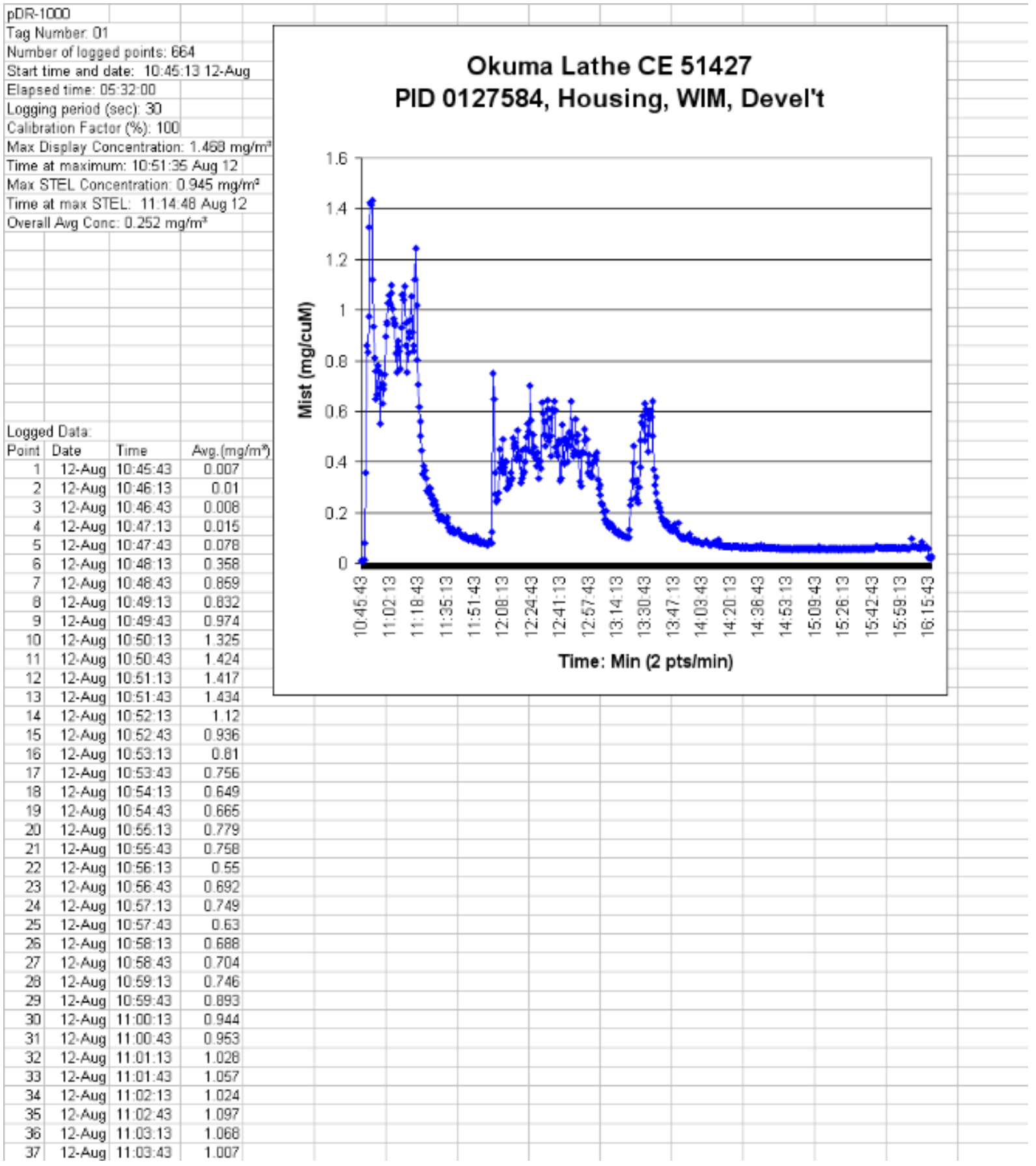




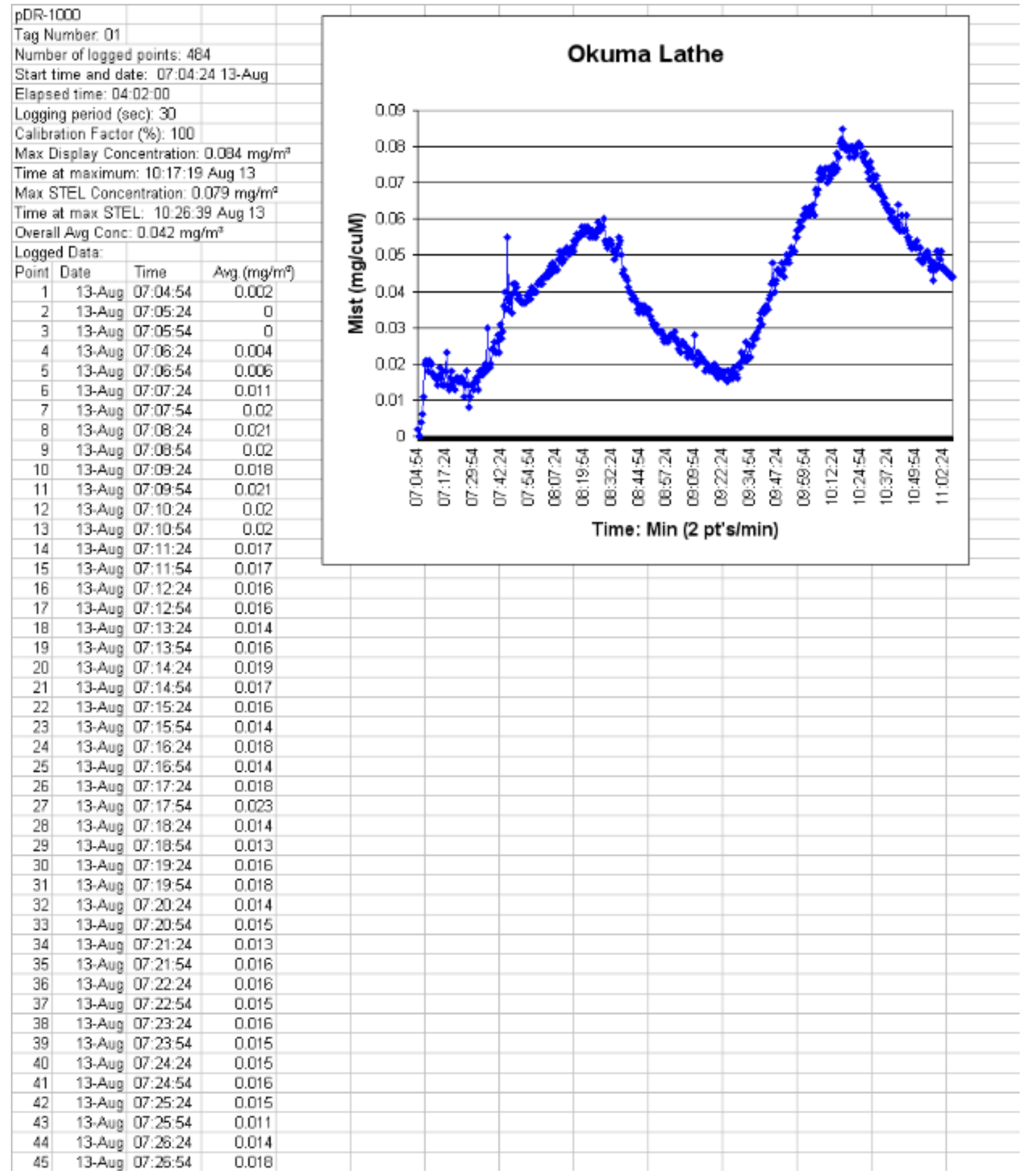


pDR-1000

Tag Number. 02

Number of logged points: 579

Start time and date: 11:07:53 13-Aug

Elapsed time: 04-49-30

Logging period (sec): 30

Calibration Factor (\%): 100

Max Display Concentration: $0.097 \mathrm{mg} / \mathrm{m}^{3}$

Time at maximum: 14:18:26 Aug 13

Mar STEL Concentration $0.091 \mathrm{mg} / \mathrm{m}^{2}$

Time at max STEL: 14:24.38 Aug 13

Overall Avg Conc: $0.060 \mathrm{mg} / \mathrm{m}^{\mathrm{x}}$

Logged Data

Point

Date Time

13-Aug 11:08:23

13-Aug 11:00:53

13-Aug 11:09:23

13-Aug 11:09:53

13-Aug 11:10:23

13-Aug 11:10:53

13-Aug 11:11:23

13-Aug 11:11:53

13-Aug 11:12:23

13-Aug 11:12:53

13-Aug 11:13:23

13-Aug 11:13:53

13-Aug 11:14:23

13-Aug 11:14:53

13-Aug 11:15:23

13-Aug 11:15:53

13-Aug 11:16:23

13-Aug 11:16:53

13-Aug 11:17:23

13-Aug 11:17:53

13-Aug 11:18:23

13-Aug 11:18:53

13-Aug 11:19:23

13-Avg 11:19:53

13-Aug 11:20:23

13-Aug 11:20:53

13-Aug 11:21:23

13-Aug 11:21:53

13-Aug 11:22:23

13-Aug 11:22:53

13-Aug 11:23:23

13.Aug 11:2353

13-Aug 11:24:23

13-Aug 11:24:53

13-Aug 11:25:23

13-Aug 11:25:53

13-Aug 11:26:23

13-Aug 11:25:53

13-Aug 11:27:23

13-Aug 11:27:53

13-Aug 11:23:23

13-Aug 11:20:53

13-Aug 11:29:23

13-Aug 11:29:53

13-Aug 11:30:23

13-Aug 11:30:53
Ang (mig/m

0.041

0.04

0.039

0.069

0.066

0.009

0.066

0.066

0.005

0.005

0.037

0.034

0.034

0.04

0.032

0.03

0.033

0.030

0.032

0,032

0.031

.0.4

0.031
0.03

0.03

0.03

0.03

0.03
0.03

0.03

0.029

0.03

0.00

0.027

0.028

0.027

0.027

0.03
0.031

. 152

0.032

0.032

0.032

0.063

0.005

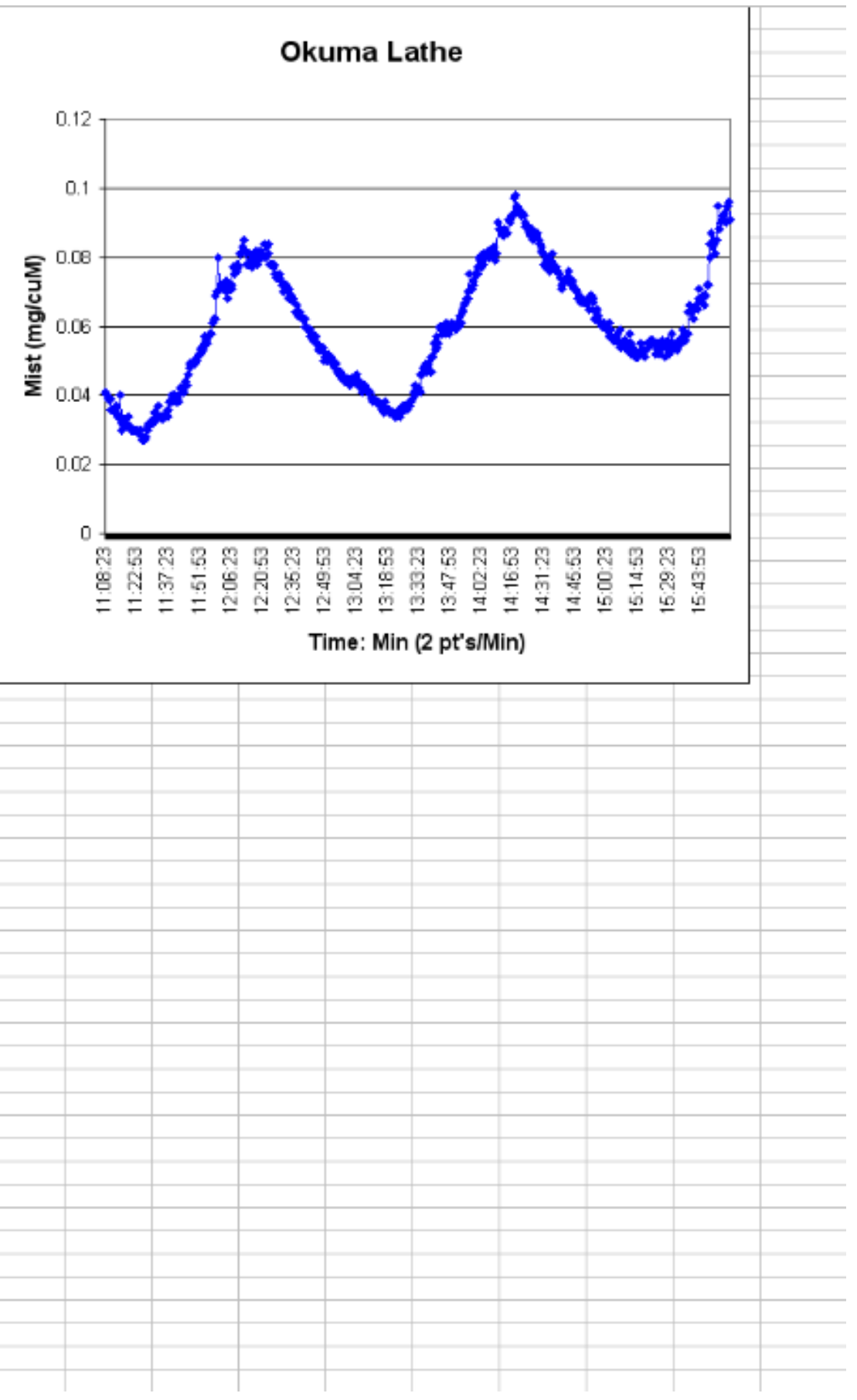




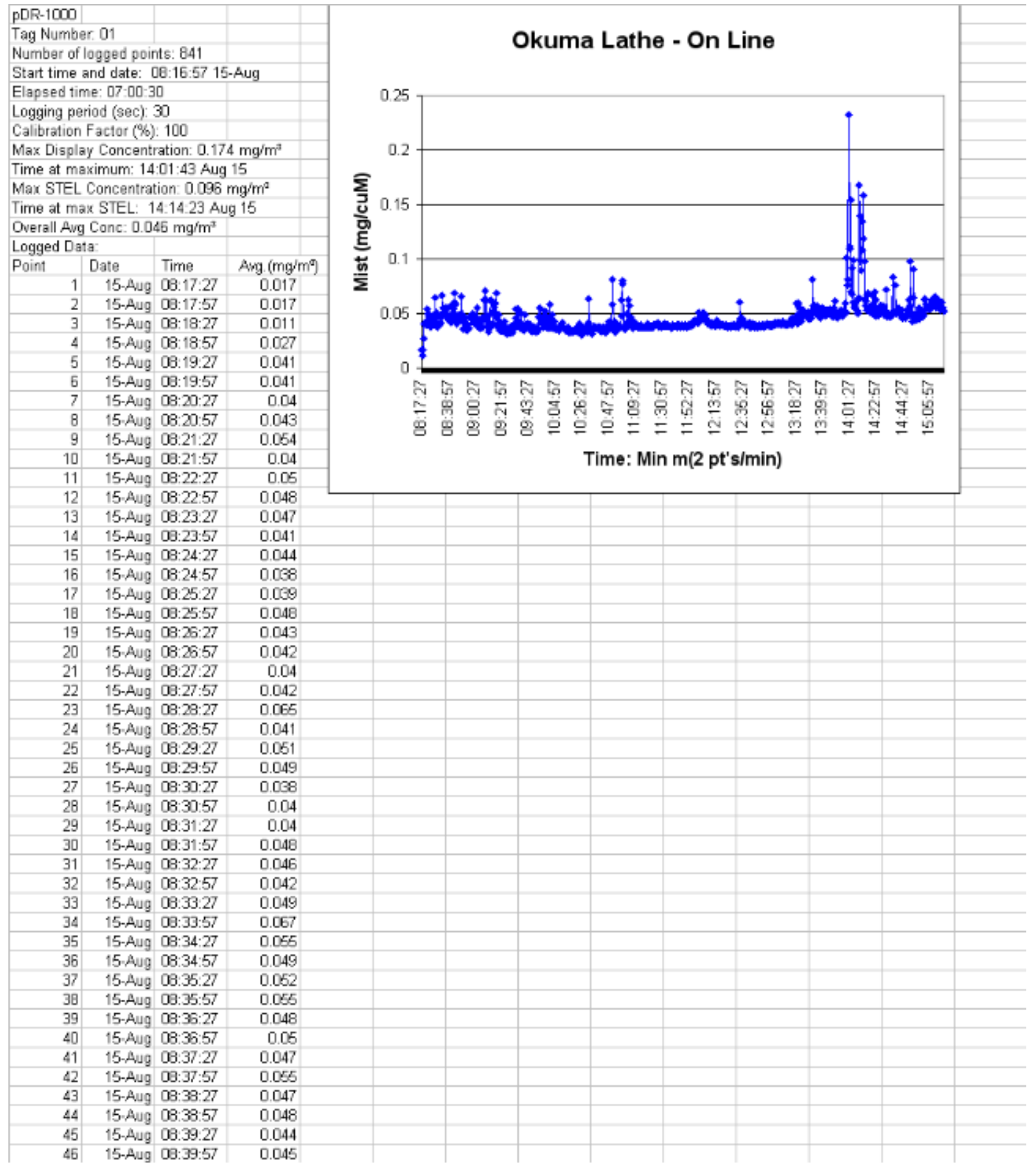

73 


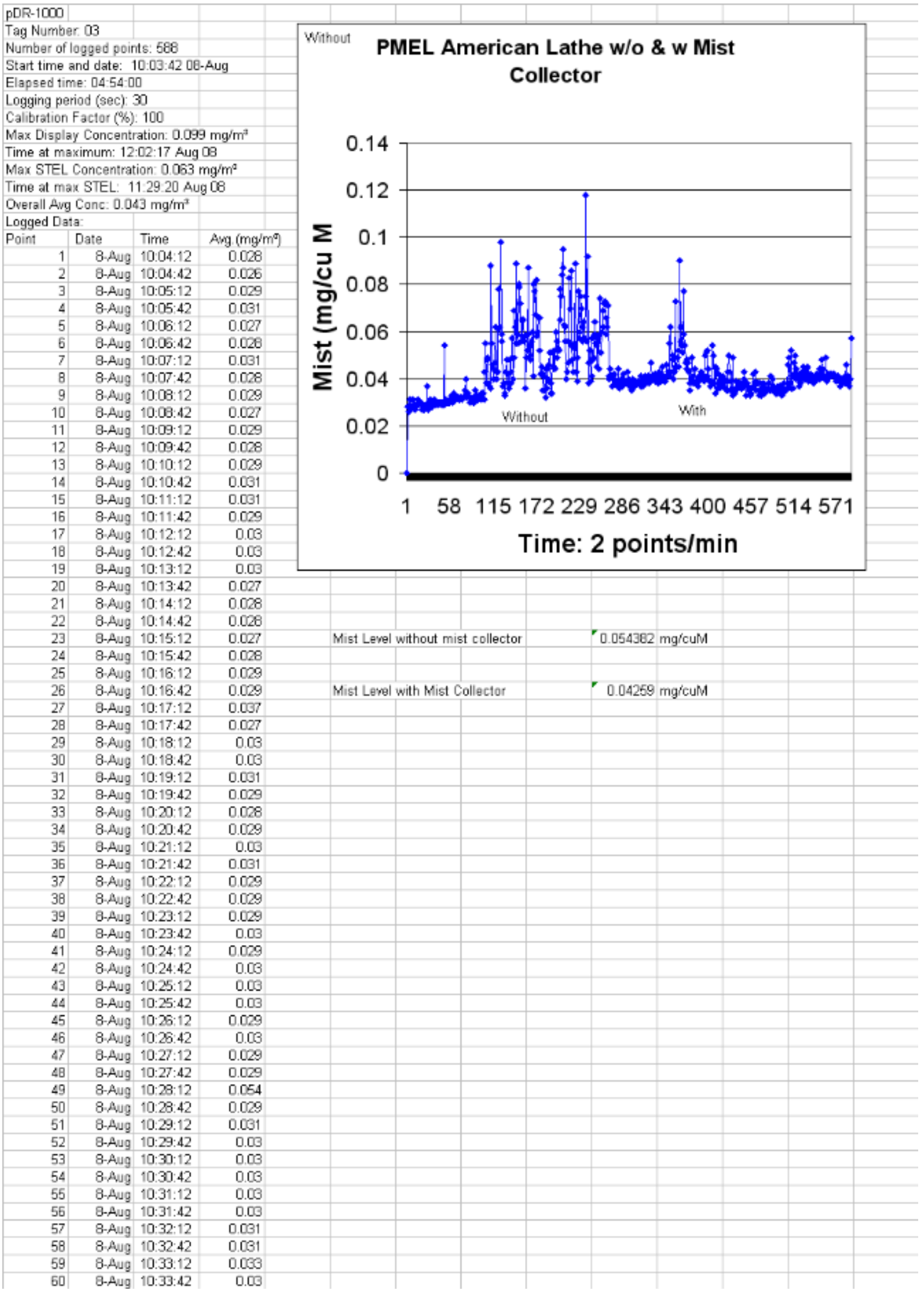




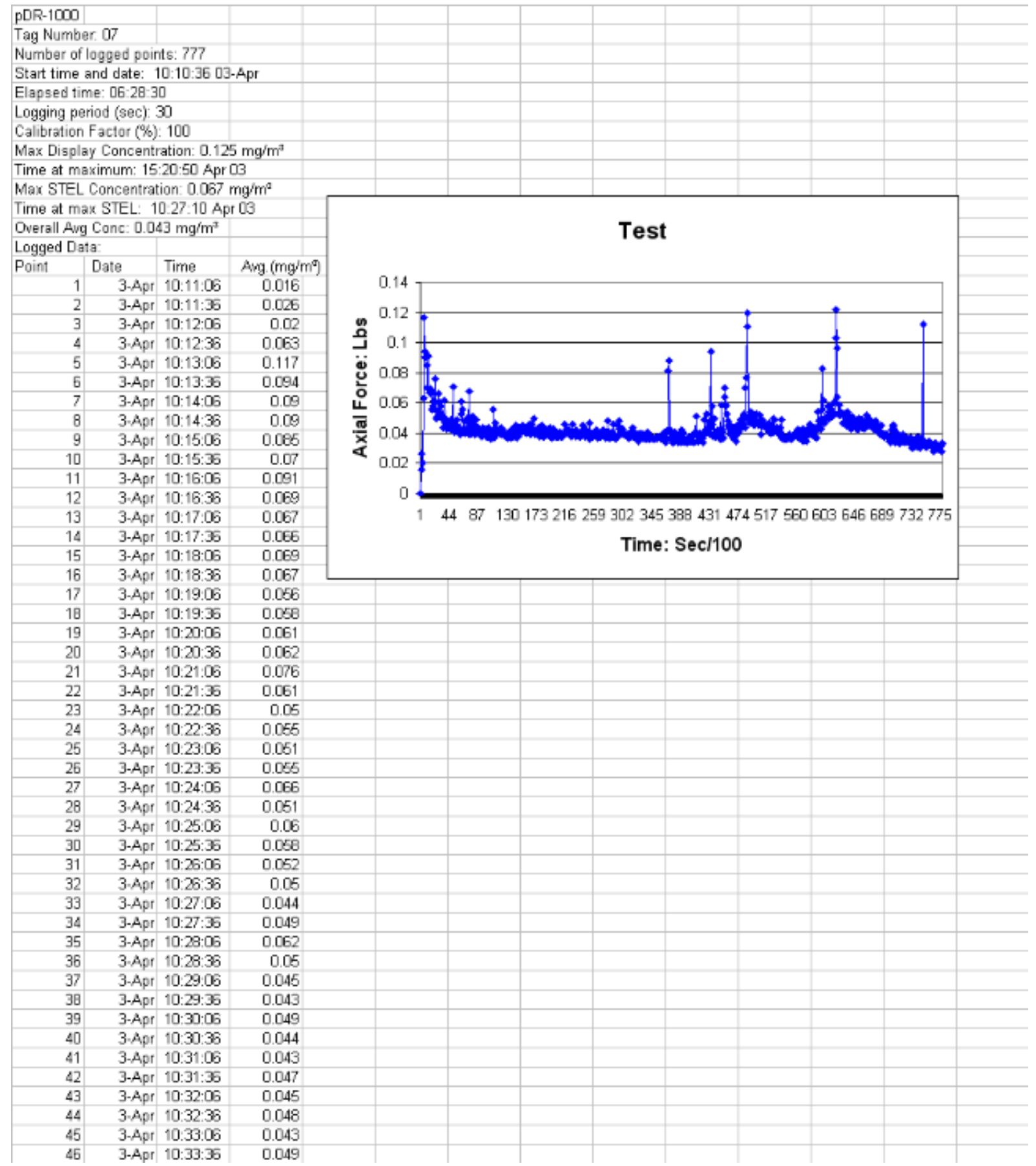




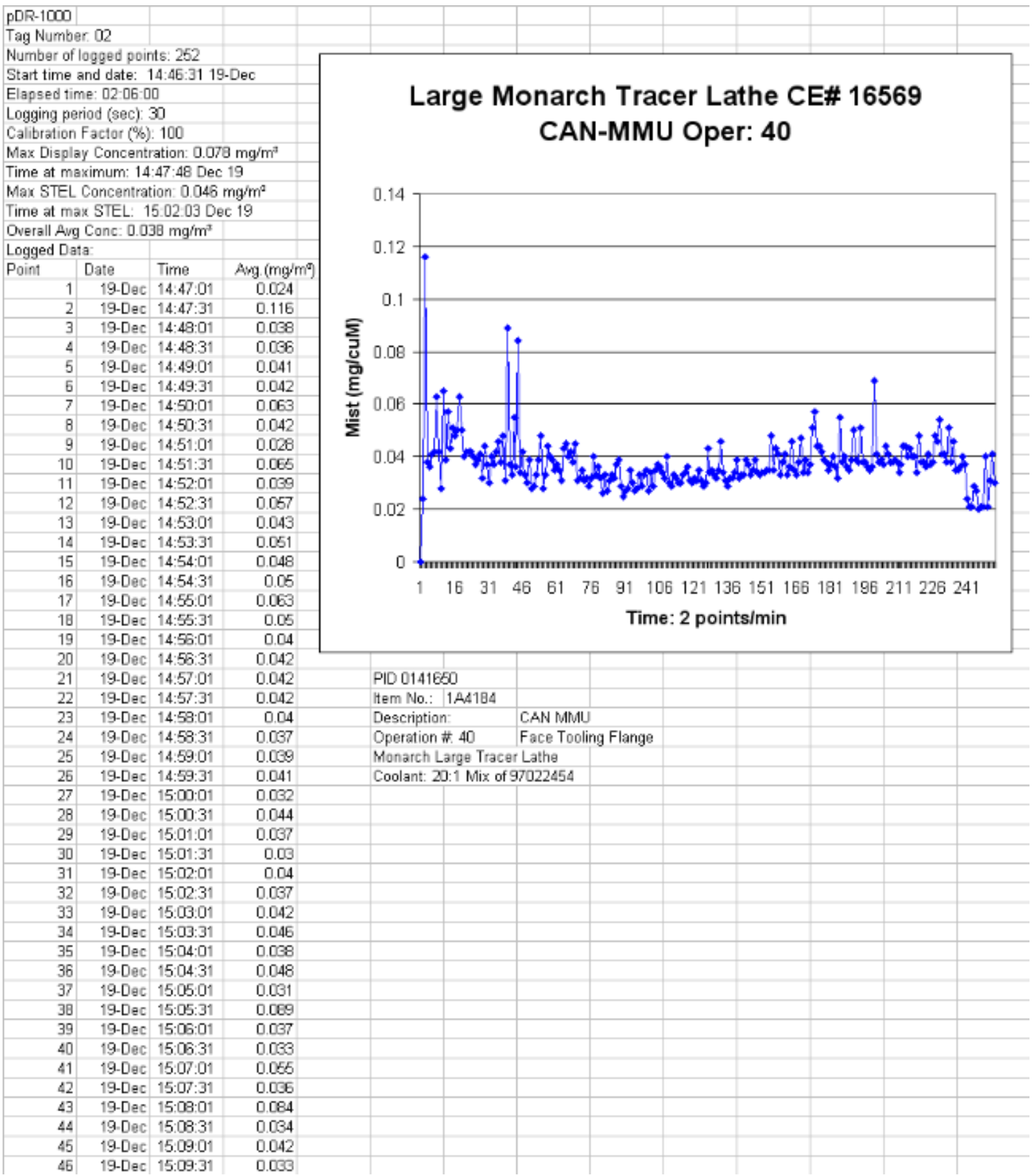




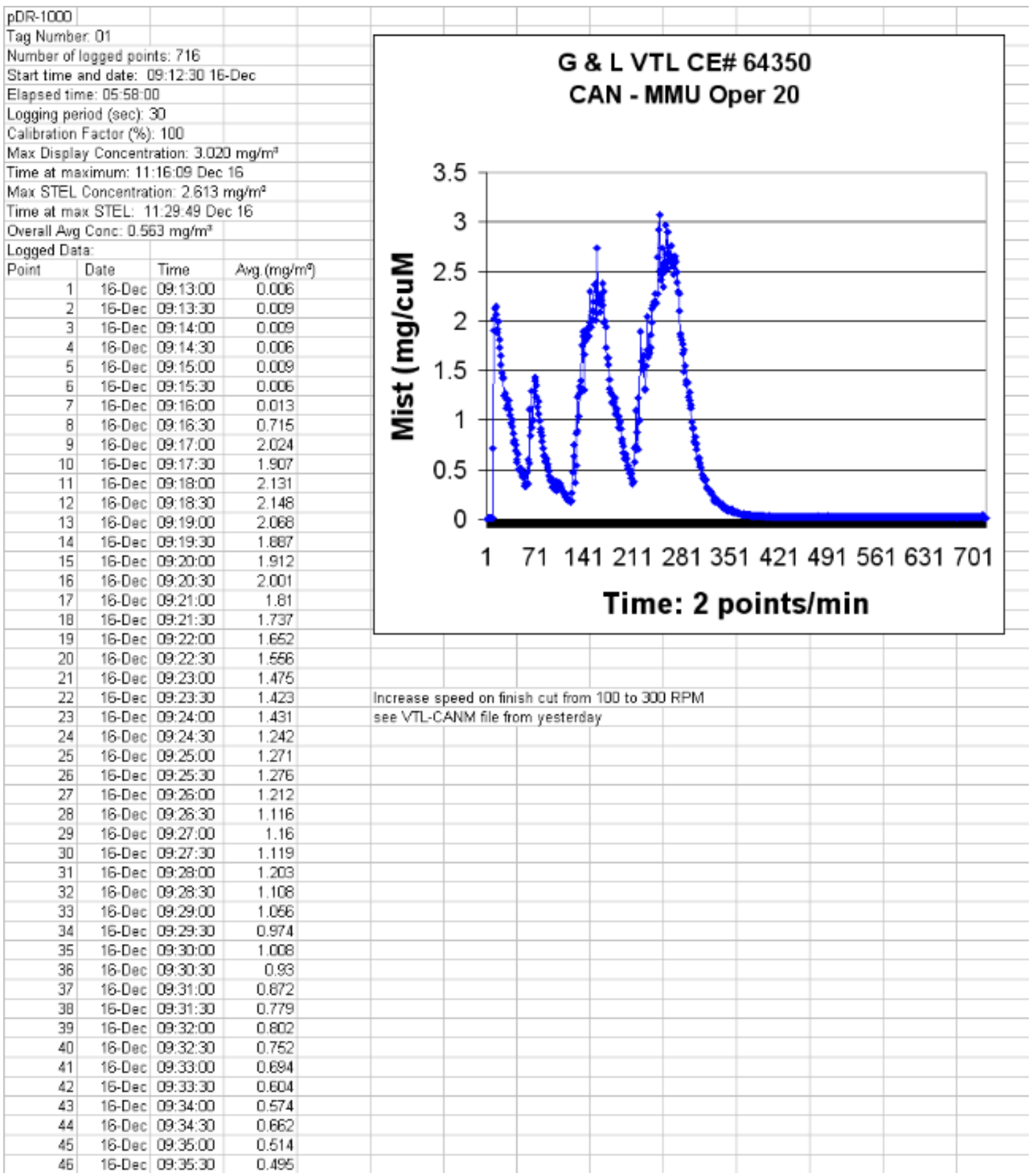




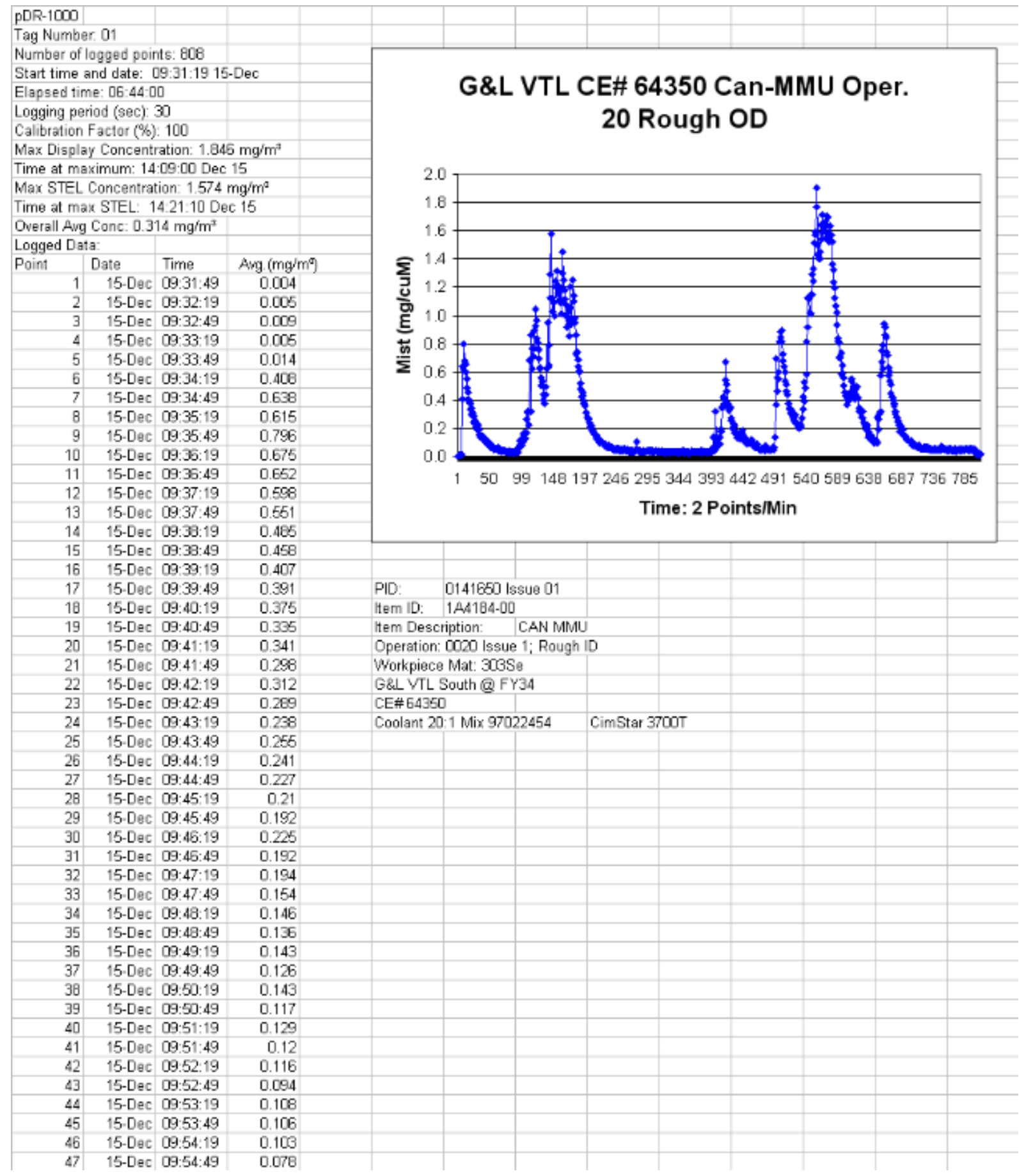




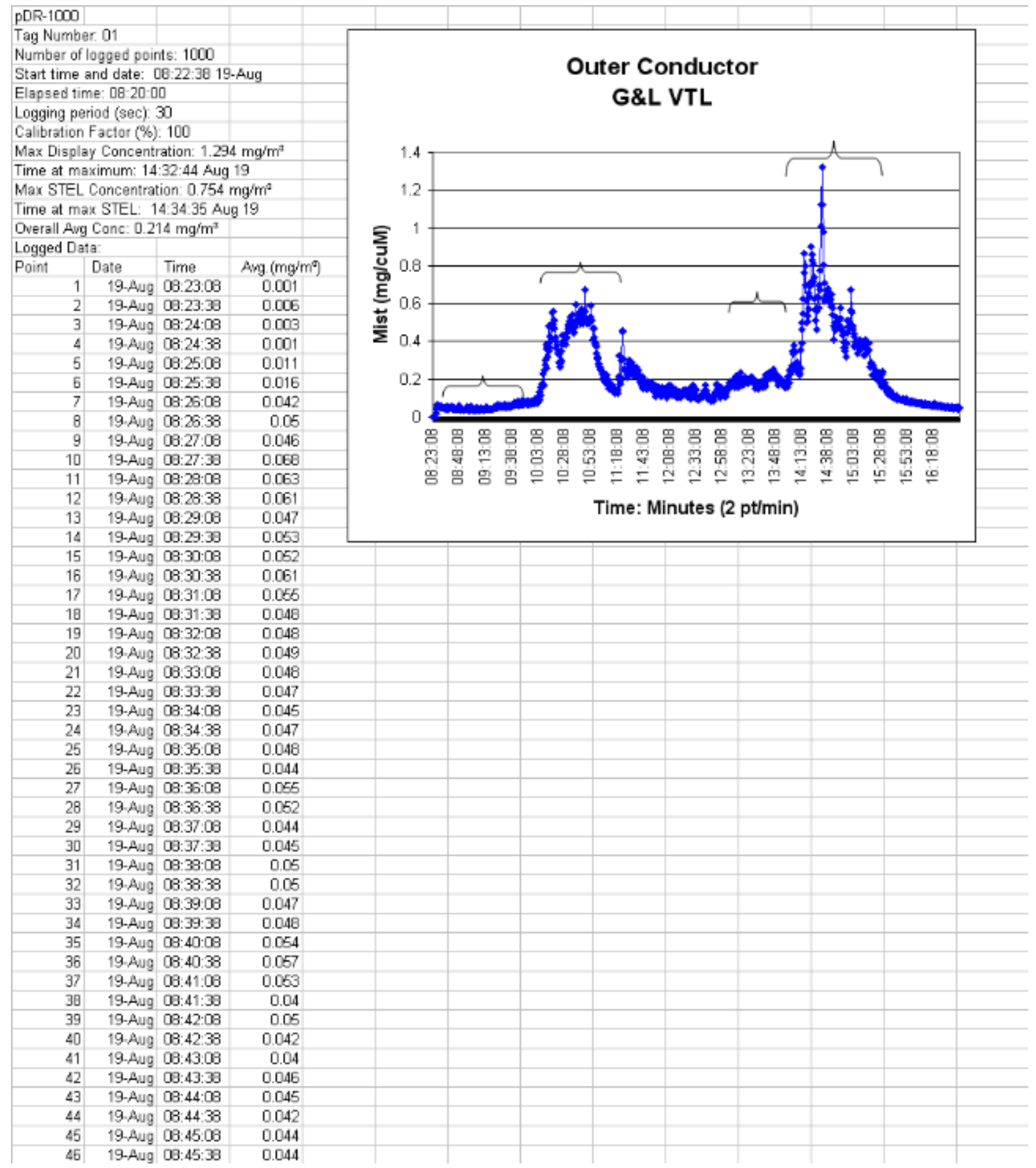




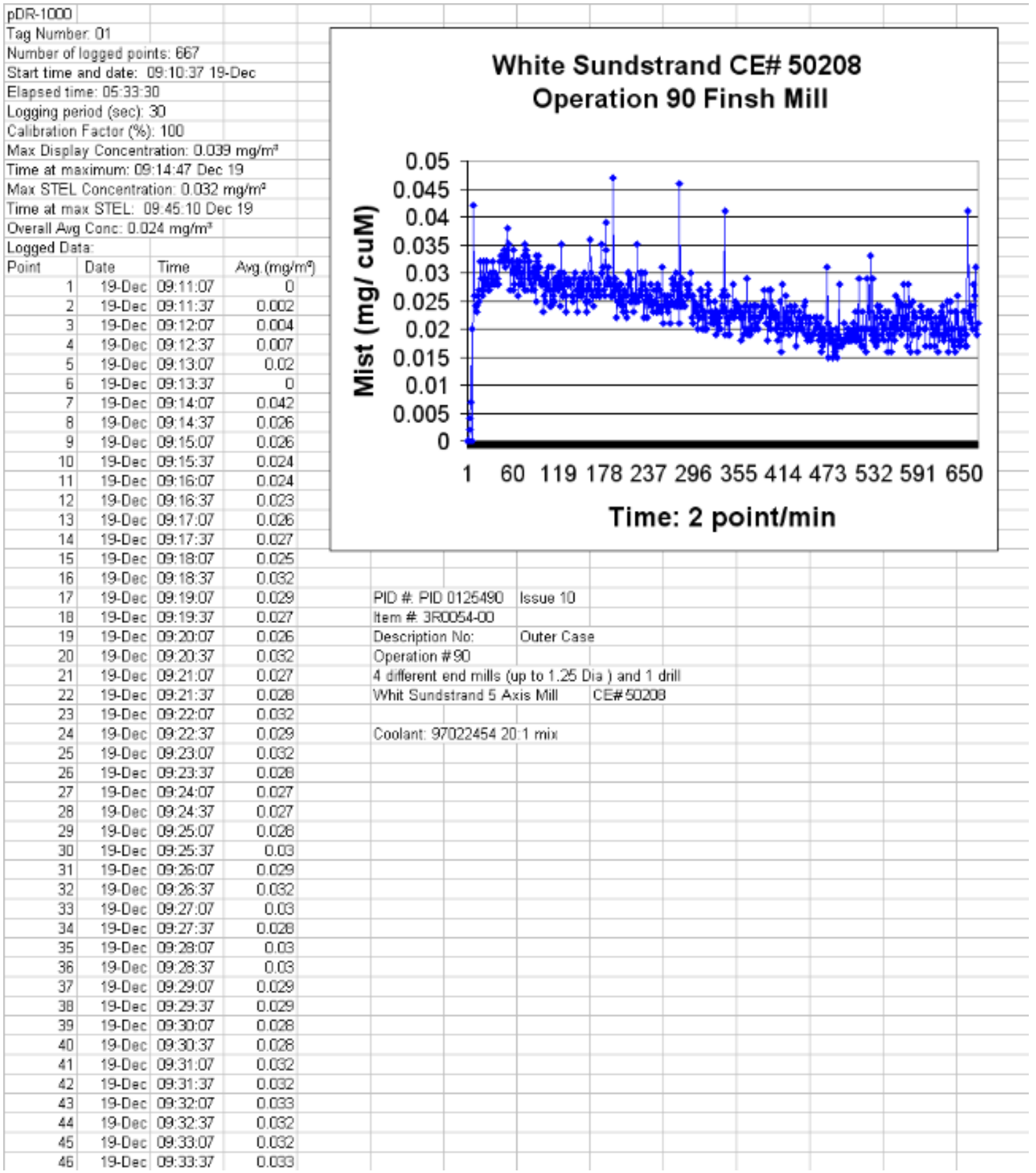


Appendix 2

Bibliography 
SAE, NCMS, Reliability and Maintainability for Manufacturing Machinery \& Equipment, 1993, SAE

ILMA, Waste Treatment and Wastewater Treatment of Metalworking Fluids, 1990, ILMA

D. A. Felinsky, Metalworking Fluids Symposium II, The Individual Metalworking Environment, 1997, AAMAJ.

B D’Arcy Editor Symposium Proceedings, The Industrial Metalworking Environment Assessment and Control, 1995, AAMA

Ford Motor Company, Coolant Filtration Systems - Process Principles, Ford Motor Comp. 1993

Ford Motor Company, Machine Decks, Foundations, Pits, Flumes/Trenches Sumps and Floors, Selection and Design Process Principles, ford Motor Company 19993

ORC, Management if the Metal Removal Fluid Environment, 1999, Organization Resources Counselors, Inc.

ORC, Management of Metal Removal Fluids Environment - How to Use the ORC Guide, 2000, Waubonsee Community College, 2000, ORC \& Caterpillar Corp.

NIOSH, Criteria fir the Recommended Standards - Occupational Exposure to Metalworking Fluids, US Department of Health \& Human Services, 1998

SME, Advances in Metalworking Fluids, Proceedings, 1995, SME

R. K. Springborn, Cutting and Grinding Fluids: Selection and Application, ASTME, 1967

J. D. Stillaman, Cutting and Grinding Fluids Selection and Application $2^{\text {nd }}$ Edition, 1992, SME

J. P. Byers, Metalworking Fluids, 1994, Marcel Dekker

J. P. Byers, Metalworking Fluids, Second Edition, 2006, STLE \& CRC Press

Lubrizol, Metalworking Fluids Resource Manual, Lubrizol

SME, Metalworking Fluids Management Certificate Program, 2004, STLE \& SME

K. C. Doenges, Filtration \& Conservation of Coolants/Cutting Fluids, Training Manual, 2003 Ken Doenges

AAMA, AAMA Hydraulic Fluid Standard, 1995, AAMA 
D. Bandfield, Coolant Forum Consensus, Ford Powertrain Operation, 3/17/1994, Ford

Henry Filters, Coolant Control Handbook, 10/1991, Henry Filters, Inc.

Chem-Trend, Metalworking Fluids Monitoring Program, Chem-Trend, 1984

J. Joseph,J. Coolant Filtration, 1985, Joseph Marketing

V. Levin, Using Benchmarking to Minimize Common DOE Waste Streams, 8/1995, DOE

J. Beyers, Operating Manual for Cincinnati Milacron Cimcool Metalworking Fluids Service Kit, Milaron Marketing, 2002, part \# 3442291

A. Bracker, Metalworking Fluids hazards \& Disease Prevention: State of the Art Control Strategies, Univ of Connecticut, 11/15/1999 
Appendix 3

Supplier Technical Data

on

MIE Personal Data Ram

\&

Mist Collectors 


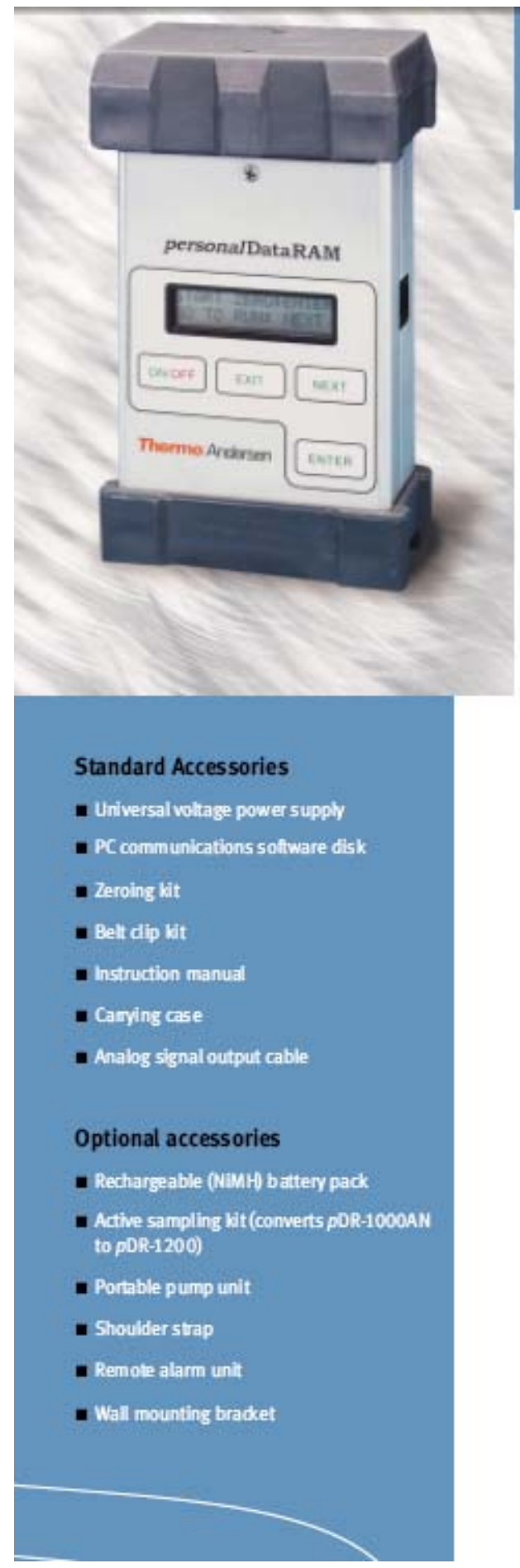

\section{pDR-1000AN}

\section{Hand-held and fixed-point, real-time aerosol monitor/data logger}

\section{Measure airborne particulate concentration in real-time}

The personaDataRAM (pDR-1000AN) measures mass concentrations of dust, smoke, mists, and fumes in real time, and sounds an audible alam whenever the userdefined level is exceeded. With conventional air quality monitoring methods, the indication that you have reached dangenus levels or are out of compliance is not available in real-time. In contrast, the pDR-1 000AN alerts you to a problem within seconds, allowing you to take immediate action. With the logging enabled, this instrumert automatically tags and time 5 tamps the data collected, then stores it for subsequent retrieval/printout/graphing through a computer.

\section{Highest performance of any real-time personal particulate monitor}

With a measurement range from 0.001 to $400 \mathrm{mg} / \mathrm{m}^{3}$ (auto-ranging), an optically feedback-stabilized sensing system, ultra-low power consumption, the pDR-1000AN sets the standard for sensifvity, long-term stability, and reliability. Air surround ing the monitor circulates freely through the open sensing chamber by natural convection, diffusion, and background air motion.

\section{Rugged and extremely compact}

The palm-sized pDR-1000AN weights only 18 oz (0.5 kilogram) and can be attached to a belt or a shoulder strap, hand held, operated on a table top, or mounted on a tripod. The absence of any moving parts (pumps, motors, valves, etc.) and the use of low-power semiconductors and a nggedized case ensures long life and dependable operation.

\section{High correlation with gravimetric measurement}

The pDR-1000AN is a light-scattering photameter (i.e, nephelometer), which incorporates a pulsed, high output, nearinfared light emitting diade source, a silicon detector/hybrid preamplifier, collimating optics, and a source reference feedback PIN silicon detector. The intensity of the light scattered over the forward angle of $45^{\circ}$ to $95^{\circ}$ by airborne particles passing through the sensing chamber is linearly proportional to their concentration. This optical configuration produces optimal response to particles in the size range of 0.1-10 $\mu \mathrm{m}$, achieving high correlation with standard gravimetric measurements of the respirable and thoracic fractions.

\section{Simple zeroing and calibration}

The pDR-1000AN comes gravimetrically calibrated (NIST traceable) in $\mathrm{mg} / \mathrm{m}^{3}$ using standart SAE Fine (ISO Fine) test dust. Zeroing with particle-free air is accomplished quickly and effectively under field conditions using the zeroing kit included with the instrument. Internal firmware controls an automatic calibration check referenced to the optical background which is factory set. Gravimetric field calibration can be performed by comparison with a filter sampler and by programming of the calib ration constant.

\section{Safety Approvals and Certifications}

The pDR-1000AN complies with US FCC rules (Part 15) and has received CEcertification, It also has intrinsic safety ap proval from the US Mine Safety and Health Administration (MSHA) for use in coal mining environments containing methane gas. The MSHA Type 26 ap proval closely resembles the standard intrinsic safety rating as defined by Class 1 , Division 1 , Groups D, In addition, it meets US FCC and European CE rules. 


\section{personalDataRAM ${ }^{\mathrm{m}}$ - Series}

pDR-1000AN pDR-1200 pDR-PU pDR-BP

\section{Applications}

- Indoor air quality monitoring

- Walkethrough surveys

- Personal exposure monitoring

- Time 8 motion Studies

- Workplace \& plant monitoring

- Flxed-point continuous monitoring

- Remedilation personal surveillance

- Remote alarming

- Mobile monitoring in vehicles 8 airctaft

- Toxicology 8 epidemiology studies

- Emergency response

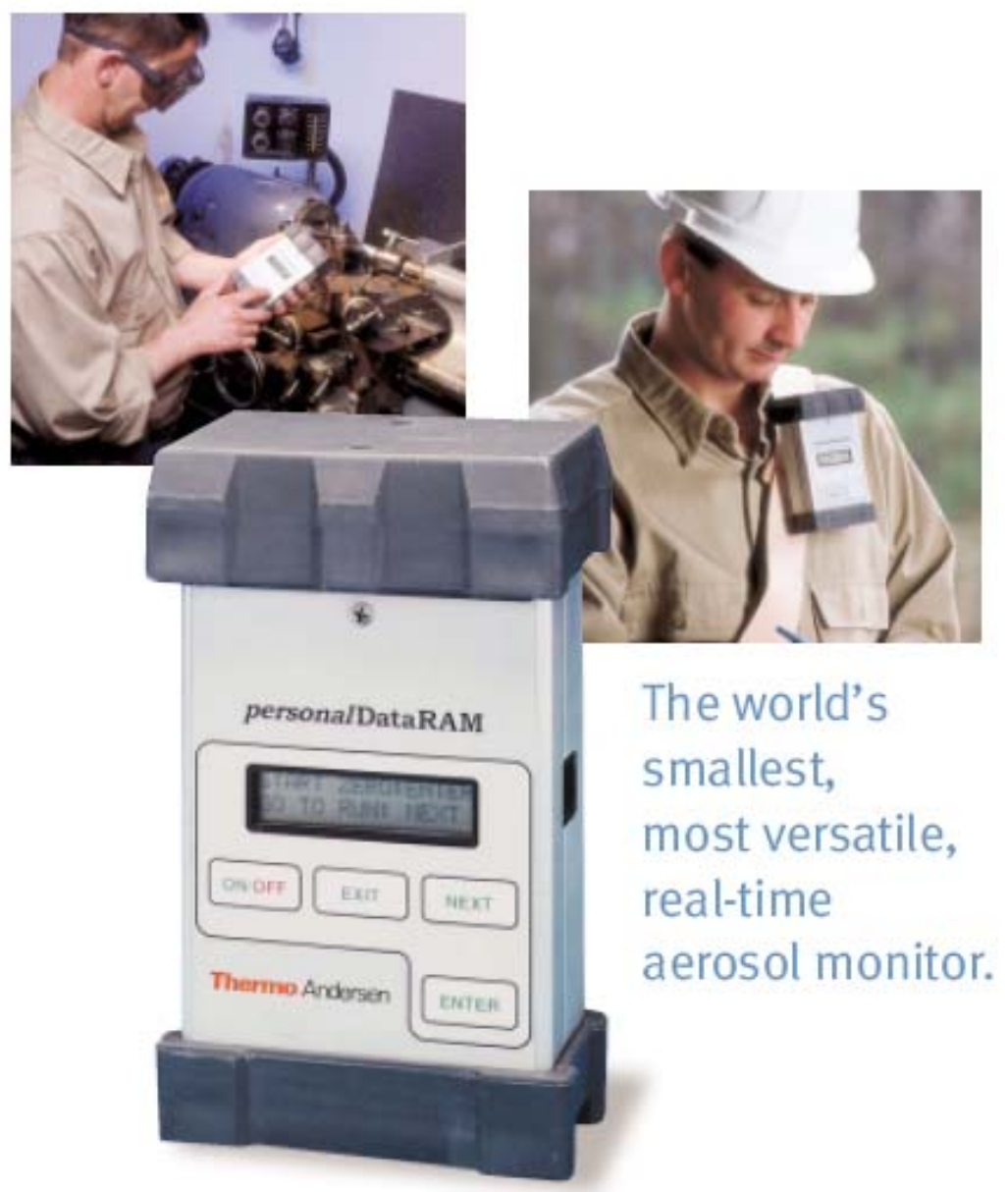




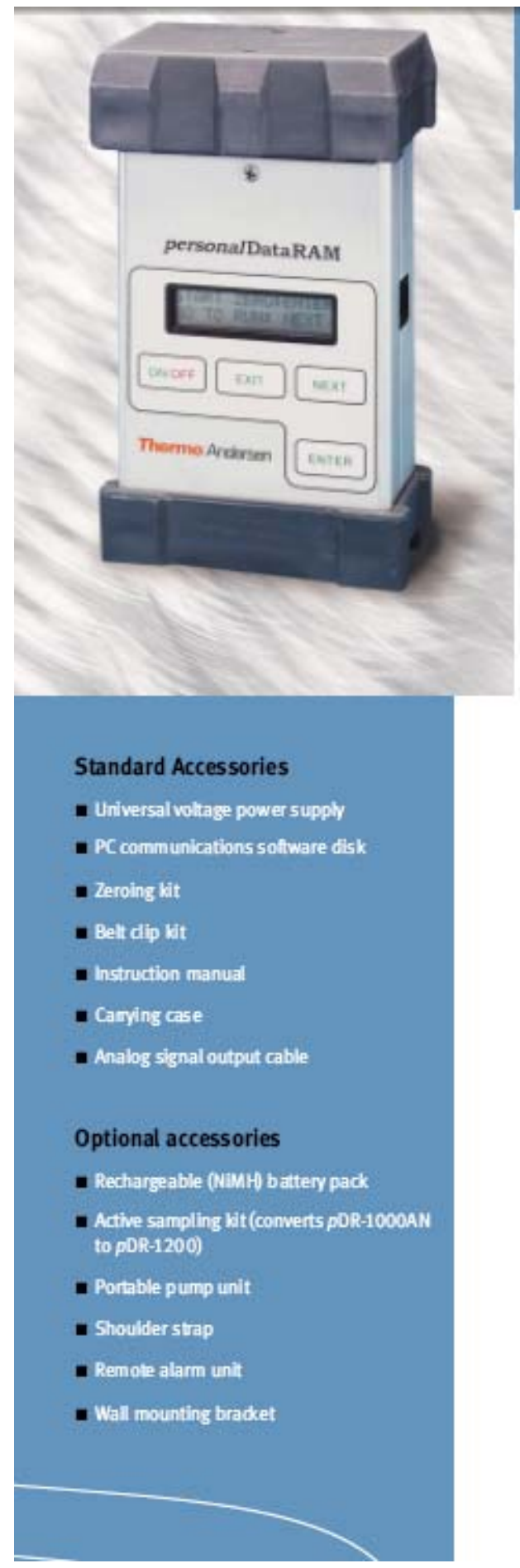

\section{pDR-1000AN}

\section{Hand-held and fixed-point, real-time aerosol monitor/data logger}

\section{Measure airborne particulate concentration in real-time}

The personaDataRAM (pDR-1000AN) measures mass concentrations of dust, smoke, mists, and fumes in real time, and sounds an audible alam whenever the userdefined level is exceeded. With conventional air quality monitoring methods, the indication that you have reached dangenus levels or are out of compliance is not available in real-time. In contrast, the pDR-1 000AN alerts you to a problem within seconds, allowing you to take immediate action. With the logging enabled, this instrumert automatically tags and time 5 tamps the data collected, then stores it for subsequent retrieval/printout/graphing through a computer.

\section{Highest performance of any real-time personal particulate monitor}

With a measurement range from 0.001 to $400 \mathrm{mg} / \mathrm{m}^{3}$ (auto-ranging), an optically feedback-stabilized sensing system, ultra-low power consumption, the pDR-1000AN sets the standard for sensifvity, long-term stability, and reliability. Air surround ing the monitor circulates freely through the open sensing chamber by natural convection, diffusion, and background air motion.

\section{Rugged and extremely compact}

The palm-sized pDR-1000AN weights only 18 oz (0.5 kilogram) and can be attached to a belt or a shoulder strap, hand held, operated on a table top, or mounted on a tripod. The absence of any moving parts (pumps, motors, valves, etc.) and the use of low-power semiconductors and a nggedized case ensures long life and dependable operation.

\section{High correlation with gravimetric measurement}

The pDR-1000AN is a light-scattering photameter (i.e, nephelometer), which incorporates a pulsed, high output, nearinfared light emitting diade source, a silicon detector/hybrid preamplifier, collimating optics, and a source reference feedback PIN silicon detector. The intensity of the light scattered over the forward angle of $45^{\circ}$ to $95^{\circ}$ by airborne particles passing through the sensing chamber is linearly proportional to their concentration. This optical configuration produces optimal response to particles in the size range of 0.1-10 $\mu \mathrm{m}$, achieving high correlation with standard gravimetric measurements of the respirable and thoracic fractions.

\section{Simple zeroing and calibration}

The pDR-1000AN comes gravimetrically calibrated (NIST traceable) in $\mathrm{mg} / \mathrm{m}^{3}$ using standart SAE Fine (ISO Fine) test dust. Zeroing with particle-free air is accomplished quickly and effectively under field conditions using the zeroing kit included with the instrument. Internal firmware controls an automatic calibration check referenced to the optical background which is factory set. Gravimetric field calibration can be performed by comparison with a filter sampler and by programming of the calib ration constant.

\section{Safety Approvals and Certifications}

The pDR-1000AN complies with US FCC rules (Part 15) and has received CEcertification, It also has intrinsic safety ap proval from the US Mine Safety and Health Administration (MSHA) for use in coal mining environments containing methane gas. The MSHA Type 26 ap proval closely resembles the standard intrinsic safety rating as defined by Class 1 , Division 1 , Groups D, In addition, it meets US FCC and European CE rules. 


\section{Designed for active particulate monitoring applications}

The personalDataRam", the world's smallest, most versatile, real-time aerosol monitor, is now available for artive sampling ap plications and aerosol siz ing. The pDR-1200 uses a pump module (pDR. PU) or other sampling pump to perform particle size selective measurements under field conditions with this filter. With optional inlet accessories, the pDR-1200 is excellent for ambient air measurements under variable wind and high humidity conditions. Compact, lightweight, and easy to use, it is ideal for respirable, thoracic, and PMA 2.5 monitoring, as well as continuous emission and test chamber monitoring. With an Isokinetic Sampling Set, the pDR-1200 can be used for stack and duct extractive sampling/monitoring. Use membrant filters to capture particles for chemical analysis.

\section{Aerodynamic particle sizing}

The pDR-1 200 incorporates an optimally designed metal cyclone (BGI Model GK 2.05) with sharp, well defined particle separation characteristics. By operating the pump at specific sampling flow rates, the pDR-1200 cyclone preseparator provides precisely defined particle size cuts. (See chart on right)

Primary calibration and particle samples by filter collection

An integral filter holder directly downstream of the photometric sensing stage accepts $37 \mathrm{~mm}$ filters. The calibration constant of the pDR-1200 is simply adjusted to coincide with the filter-determined concentration. Primary gravimetric calibration of the instrument concentration readout is easily accomplished under actual field conditions by means of this integral filter. Use membrane filters for chemical analysis or concurrent gravimetric measurements.

\section{pDR-PU}

\section{Attachable pump module}

This optional accessory is designed for use with the personaiData RAM Series. It incorporates a dual-chamber diaphragm pump, a volumetric flow sensing and control unit. The pump module operates from either an optional, rechargeable $\mathrm{NiMH}$ battery pack or from AC line current using the power supply/charger supplied with the personaiDataRAM. The pDR-PU is designed as a modular unit which can be used in various combinations.

- Flow rate (user adjustable): 1 to 5 liters/min.

- Maximum pressure drop: 10 in $\mathrm{H}_{2} \mathrm{O}(25 \mathrm{mb}$ ar $)$

- Precision of constant flow rate control: $22 \%$

- Power: 9 VDC., $200 \mathrm{~mA}$ (9) 4 liters/min. (approximate)

- Dimensions: 4 in. $(100 \mathrm{~mm}) \mathrm{H} \times 3.6 \mathrm{in}$. $(90 \mathrm{~mm}) \mathrm{W} \times 1.8 \mathrm{in} .(45 \mathrm{~mm}) \mathrm{D}$

Weight: $1 \mathrm{lb} .(0.45 \mathrm{~kg})$

\section{$p$ DR-BP}

\section{Rechargeable battery pack}

This rechargeable nickel-metal-hydride (NiMH) battery is designed to provide d.c. power to the PDR-1000AN, and/or pDR-PU, allowing it to operate for extended periods of time without requiring line power or battery replacement. It is recharged by means of the $A C$ power supply provided as standard accessory with the PDR-100QAN.

- Rated capacity (9) $68^{\circ} \mathrm{F}\left(20^{\circ} \mathrm{C}\right): 1.9$ ampere-hrs.

- Full charging time: 2 hrs.

= Operating time to power the pDR-1 OOOAN @ $68^{\circ} \mathrm{F}\left(20^{\circ} \mathrm{C}\right): 70 \mathrm{hrs}$. (typical

- Operating time to power the pDR-1200 \& pDR-PU@ $68^{\circ} \mathrm{F}\left(20^{\circ} \mathrm{C}: 36 \mathrm{hrs}\right.$. (typical)

n Weight: $1 \mathrm{lb} .(0.45 \mathrm{~kg})$
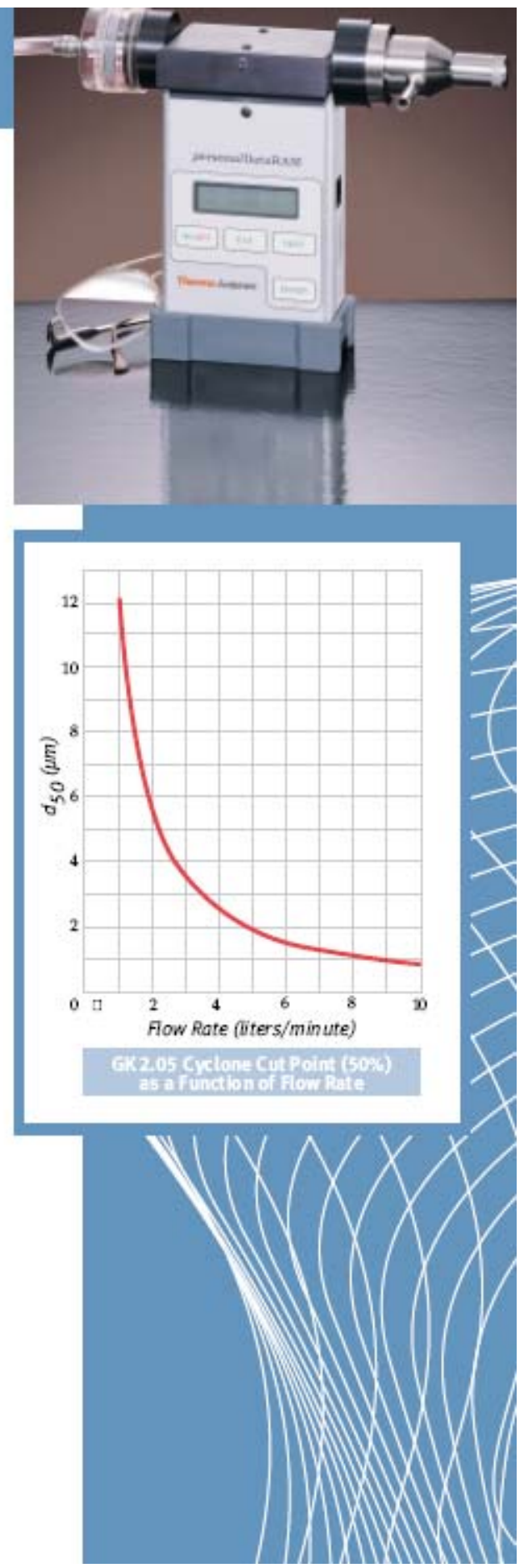


\section{pDR-1000AN/pDR-1200}

\section{Hand-held and fixed-point, real-time aerosol monitor/data logser}

\section{Specifications}

Concentration measurement range (outo-ranging): Refewed to gowinetre callowation wat SAE Five test dust

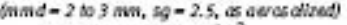
0.001 to $400 \mathrm{mg} / \mathrm{m}^{3}$

Scattering coefficient range: $1.1 \times 10^{-6}$ to $0.6 \mathrm{~m}^{-1}$ (approximately) $\odot \lambda-880 \mathrm{~nm}$

Precision/repeatability (2-sigma at constant temperature): $25 \mathrm{jg} / \mathrm{m}^{3}$ for $1.5 \mathrm{ec}$. averaging

$21.5 \mu \mathrm{g} / \mathrm{m}^{3}$ for $10-5 e c$. averaging

\section{Accuracy}

Regered to gownetic cullbwation with SAE Fine tect dust

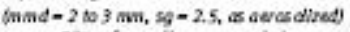
$\pm 5 \%$ af reading 2 precision

Resolution: $0.1 \%$ of reading or $0.001 \mathrm{mg} / \mathrm{m}^{3}$, whichever is larger

Particle size range of maximum response: 0.1 to $10 \mu \mathrm{m}$

Concentration display updating intervat: $1 \mathrm{sec}$.

Alarm level adjustment range (us er selectable): selectable over entire measurem ent range

Alarm averaging time (user selectable): real-time (1 to 60 sec.) ar STEL (15 min.)

Data logging averaging periods (user s electable): 1 sec. to 4 hrs.

Total number of data points in memory: 13,000

Number of data tags:

Readout display:

LCD 16 characters ( $4 \mathrm{~mm}$ height) $\times 2$ lines

Serial interface:

RS232, 4800 baud
Ana log signal output:

0 is $5 \mathrm{~V}$ and 4 to $20 \mathrm{~mA}$, with selectable full scale ranges

between 0.1 and $400 \mathrm{mg} / \mathrm{m}^{3}$

Computer requirem ents:

IBM-cam patible PC, 286 or higher; Windows" 3.1

3.11, of $95 ; 2 \mathrm{NB}$ memary of $\mathrm{m}$ are; hasd dive;

$3.5^{\circ}$ ar $5.25^{\circ}$ flappy dive; VGA or higher resolution monitar

Power:

- internal battery: $9 \mathrm{~V}$ alkaline, 20-hr fun time (typicall $9 \mathrm{~V}$ lithium, 40 -hr run time (typical)

- AC source: universal woltage adapter (included)

100-250 wolts, $50-60 \mathrm{~Hz}$ (CE marked)

- Optianal battery pack: rechargeable NiMH, 70-hr nin time ttyica 0

Operating ervironm ent:

$14^{\circ} \mathrm{F}$ to $122^{\circ} \mathrm{F}\left(-10^{\circ} \mathrm{C}\right.$ to $\left.50^{\circ} \mathrm{C}\right), 10$ to $95 \%$ RH, nan-condensing

Storage environment:

$-4^{*} \mathrm{~F}$ to $158^{*} \mathrm{~F}\left(-20^{2} \mathrm{C}\right.$ to $\left.70^{*} \mathrm{C}\right)$

Dimensions:

$6.0 \mathrm{in} .(153 \mathrm{~mm}) \mathrm{H} \times 3.6$ in. $(92 \mathrm{~mm}) \mathrm{W} \times 2.5 \mathrm{in} .(63 \mathrm{~mm}) \mathrm{D}$

Weight:

$18 \propto 2 .(0.5 \mathrm{~kg})$

500 Technology Court Smyrna, GA 30082

800-241-6898 (toll free in USA) $=770-319-9999$ (outside USA) $=770-319-0336$ (fax)

www.thermoandersen.com $=$ sales@thermoandersen.com

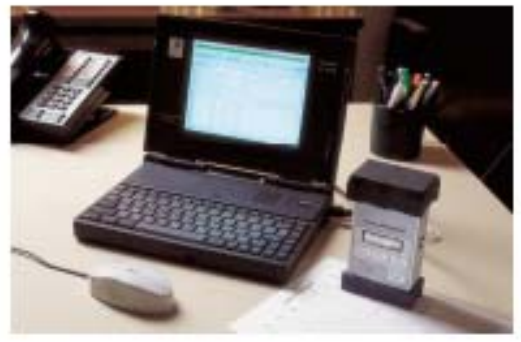




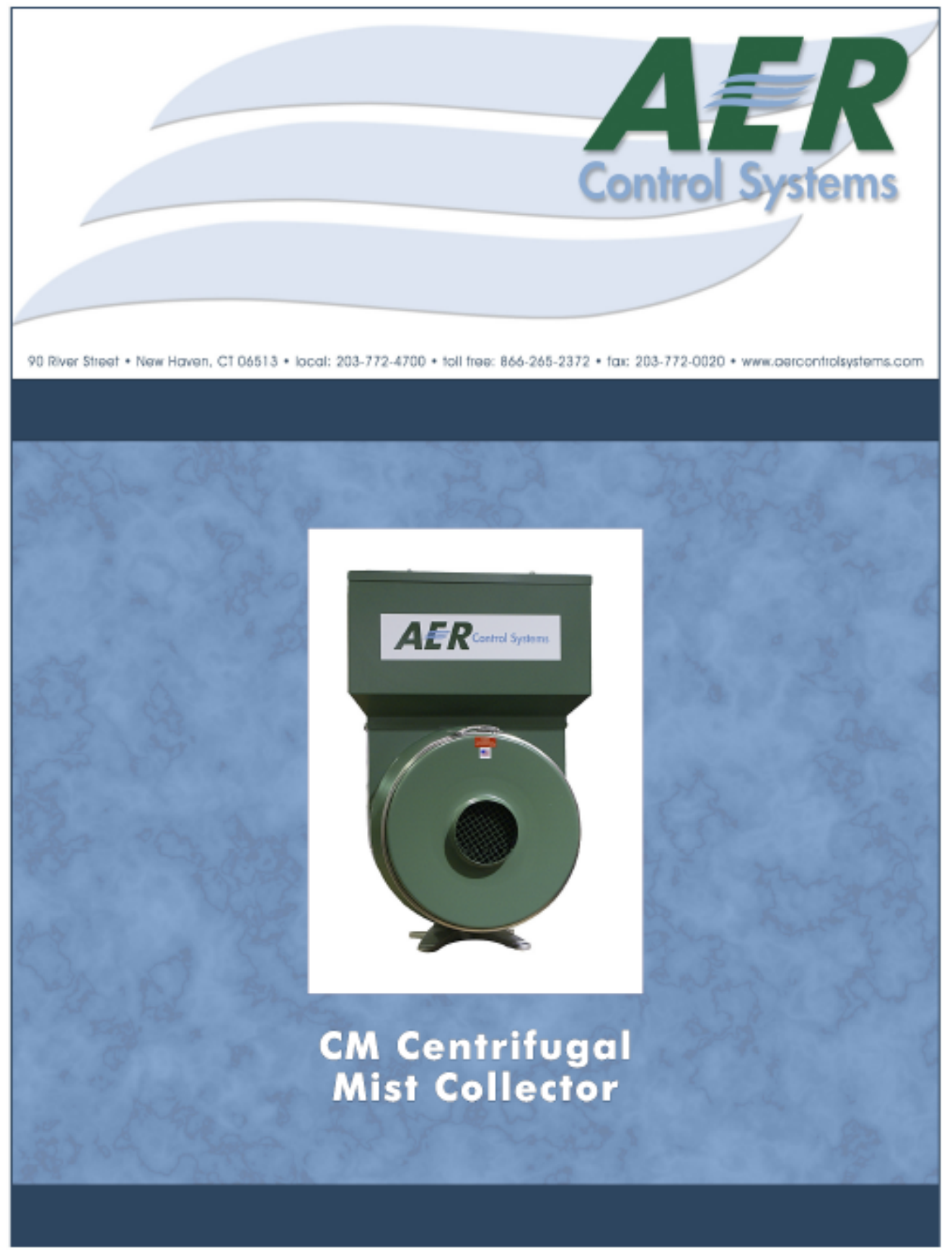




\section{Fundamentals.}

\section{Our traits transcend to value.}

Mist and smoke genenod from sacw machines, CNC lathes bar mactines, grinders and nachining cerrers contaminue in-plart air, A.ER Control Systens Centrifugal Mist Co lectors eliminate, trap. and rooover those conamirans dightwhre they stat-at the source. Designed to work on a vaiety of equipment usingeither petro-based or synthetic coclunt the AEF. Control Systems Serites Centrifugal Mix Cdloters are wo mpast, fficient, esoosmisal, and ready for direct mashine mount Our mist colletor's direct matine mount capablity makes rsal ation simple, elninates unatieacive ductwook, reduces firc hazands, prevenis cross conirnination of coolants, and redeces plat: cosis. AFR Control Systens Mist Collectors work to provide dean, concaminant-fiet, ar, so plants an opcraic and promote cleancr, safic, and bathixr vork envirconment

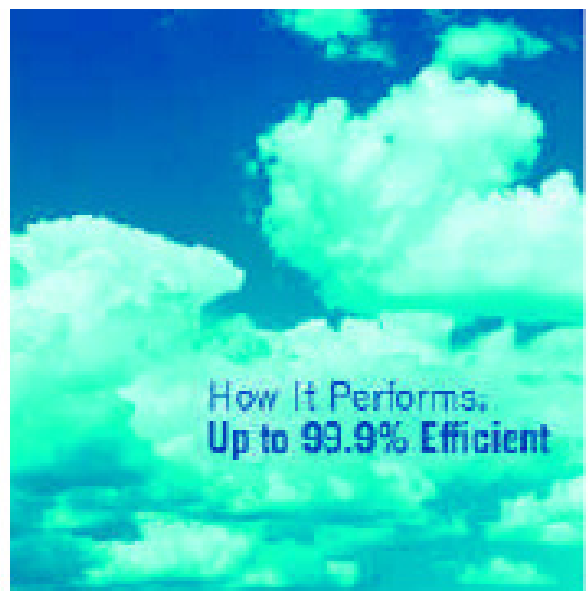

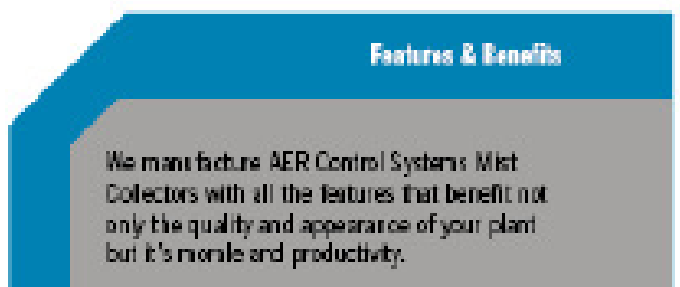

Bnile unis instito bur sarte of timition. Fist, and ineporave axy to replase, frst strege trowaway 1iter acts as a peventive barier, remmoirg the rajarty ofthe sald parieles in the colbeced mist. The secondstege primaty the is belind the throesway fliter and corsiste of a special high eificiency mecis designed to eficiently codexe ultra-fire nist partick. The first tro stapes ale housed is the retatirg drun essently. Atter eat ing the drum, ar passes through the thind stape fiber. then west through the burth-dage ahas at iter.

Minhal gap tatween the cover and adodfraric drum i rlat rinirias potartial bypars and enues that the maximam annurt of contamiantlacel ar pesses throuzh the dum fil tars. The perforated crun is havily reinicreed and cockod for d.ratilt/ and lorelite.

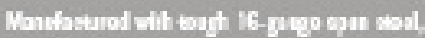
the poude-coated louing ntt ctaida rugi indistral arviroments.

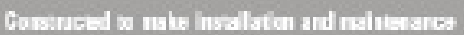
Whinaly efortan. Irits weigt from 74 to 124 los. Aor Centrol Bgatsme Met Coloctors are canpoct and exs y nachine rountes. Floor rounted podsetal atanda aro resilablo it masine mountiag is rt possibe

Anler oferstion. standard unt rdise biels rarge from 70 to $76 \mathrm{dEA}$ at 3 : *

Ondet nount cepabilly sares floo space, simplifes intellaior, redaces decting and the polential spledd d niestoukd of geiticn occut

Enargh Ealrge proide a rapid rotuin of intial investrenc. Cleated al paums back of te flait oxvirnment alminathg the nosd to eshaurt air outsice, the receseity for make-up ar incl.s. associared terang ando coolrge costs.

Mosiser orecolh Os:th roquirmsnts $s$ plast conpy wth the bugh dean alr tandarfs. The and reait, a clean, hashy plant axirannsint ath irpowed moraleand productioty.

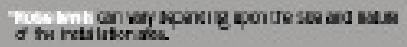




\section{Options. What separates us from the rest.}

\section{Prefilters}

Lntrgate a prefilicr to improve unit poformanx and reduce mainterance. Prefiliers remove larger solid paricles that may be suspended in the captured mis. To preverx chips, tumings and a majority of the fines from "sof" metals or grinding swaxf from entering and prematurely blocking off the dum filters, hoose 1 high-performance, add-on, mod.ular prefilter. The low cost, exy-to-replaxe, disposable fiter dises an be used in single or mulup le sages to cilor indiridual levels of pre-fltration.

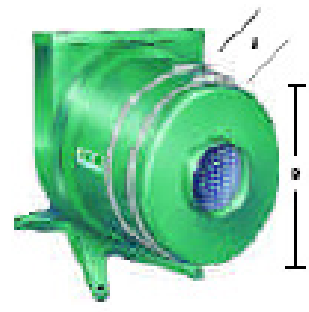

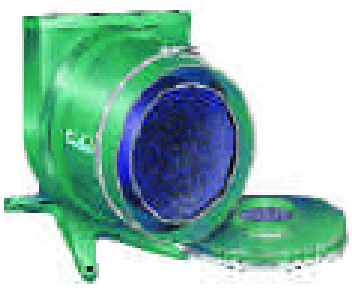

11-Cover Frefilter Trap

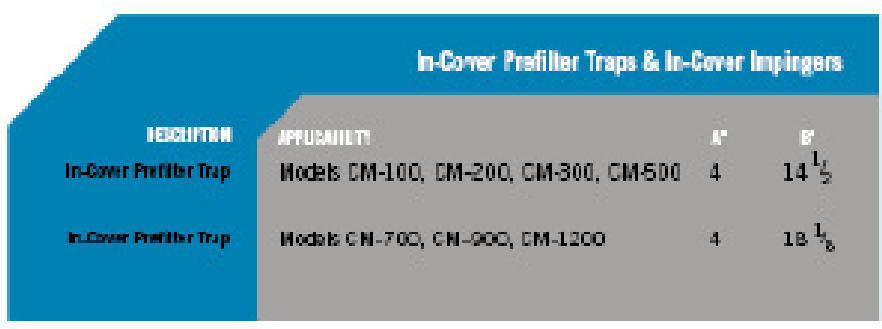

\section{HEPA Post Filters}

We understand that erery man facturing planr is dfferent - from ahat is produces o how it made, so we' Te desizned not just on mist collector model, but an entire modulur ine to support the variety of nerds in the martuctp lacc. A number of acd-on pre and post filter mod.ıles ure aralable albwing plants to custonize in-plant sys temr. Modules are exily adted and/or modified in the field, proxiding the ultimare in adapability.

Oil mist is not the coly contaminant producod in machining environments. Smoke is anober difficalt and typical byproduce from today's high-specd operations. If you preduxe both mist and smoke, then ou HEPA post fiter is the right choixe for your air filtration needs. Adding aHEPA filter to our standard unit licenses our mist oollector to handle the conbination of stb-micronic mist and snoke - a contuminart composition often asseciated with high spoed or heavy motal removal
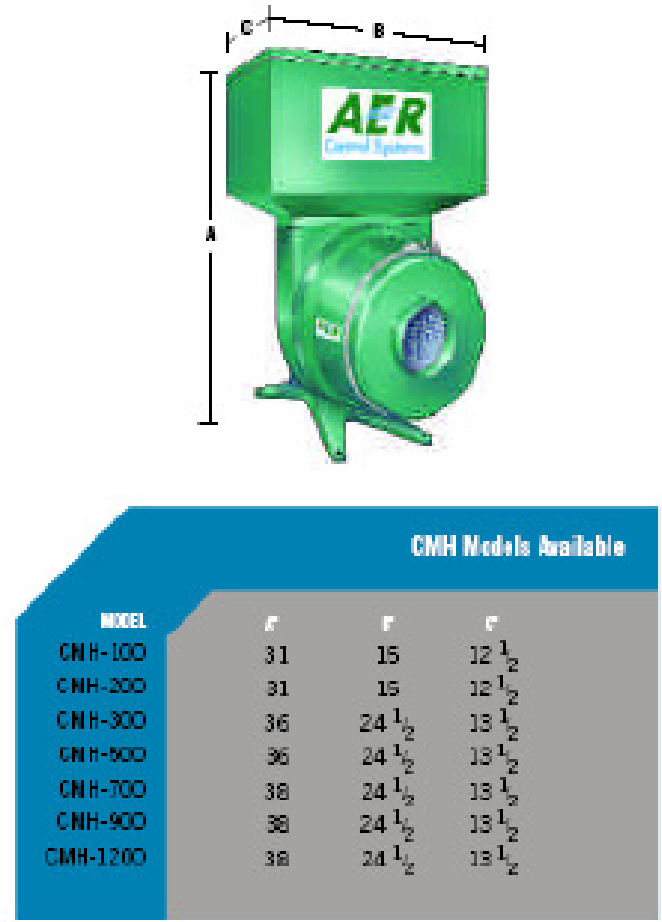

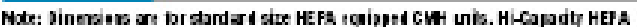
fiter nowies are aulale fer Mdiss 300 un tzon 
application and $\propto$ thermal processes like EDM. al; quenching orlube oil sump reserroirs. When equipped with a HEPA filter the partizulate efficiency rating increasss fom $98 \%$ efficiency at one ricron standard model rating - b $99.97 \%$ efficiency at 0.3 microms. Higher ifficendes wailable. Ou HE.PA filter assemblies are factory installed or field reticfited.

\section{Carbon \& Gas Vapor Filters}

Laddition to mist and smoke, som operations my genente gas/vapon or "odors" that require control vith gas/vipor files axh as caben A varisy of gasivapor fiters and/or filter modules are available for control of these contaminant. On most typicd applicaions ou standird, high capicity, refllable cabon filea module can be utilized. High quality, high capacty coconut shell cabos is itandardbut altemate media sach is treated or rextive carboas, potasium permanganxe/activacd aumina pellets, zedite or combinatiom of all three (CPL) can be provided for more dfficult application. 'The sandard carben noduks are availab $k$ for use wik the basic CM unit (Models CMC) or for units with HEPA past filten (Model CMHC) ar cas be field retrofited.

\section{Floor Mounted Pedestals \& Other Options}

For applicatious on mahines wherecher is limited acsess, nouxing space or where direct machine mounting is not advisable, optional Floor Moured Pedestal sunds are arailable. Standard Pedestals have predrilled, 12 "square top ad bottom mount/base plites and are arailable in $18^{\circ}$ or $6^{\prime} 6$ 'heigles (aher heights svailable). Other svailabl CM optioss ixlude machioe specific monnting brackets, boods, noa-sparkig drums, heaters, special motors, spray wash acezles and opecialized inlet and outbet filtings.
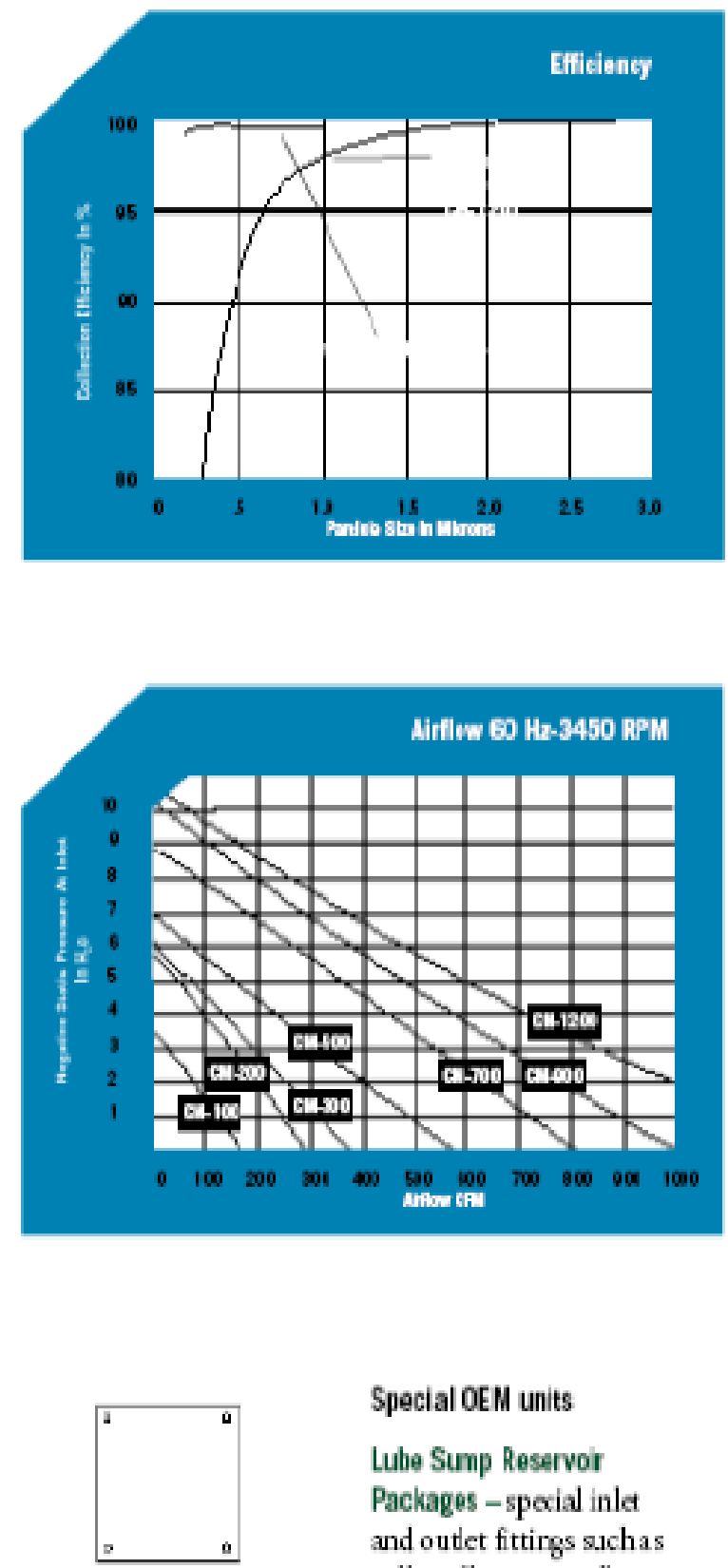

Special OEM units

Lube Sump Reservoir Packages - special inla and outet fittings s.chas collars, flanges, $150 \mathrm{lb}$. flanges ind NPT fittingss.

Full Factory Service and Refubishment progiam.

Optional Floer Mounted Padestal Stand

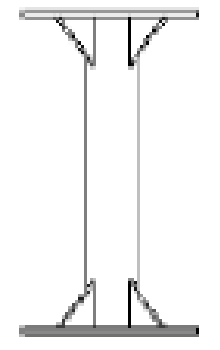

Technical suppoit, application and design engineering. 


\section{Performance. It's in the force.}

Weve integrated the law of centrifugal force into the design of our mist collectors.

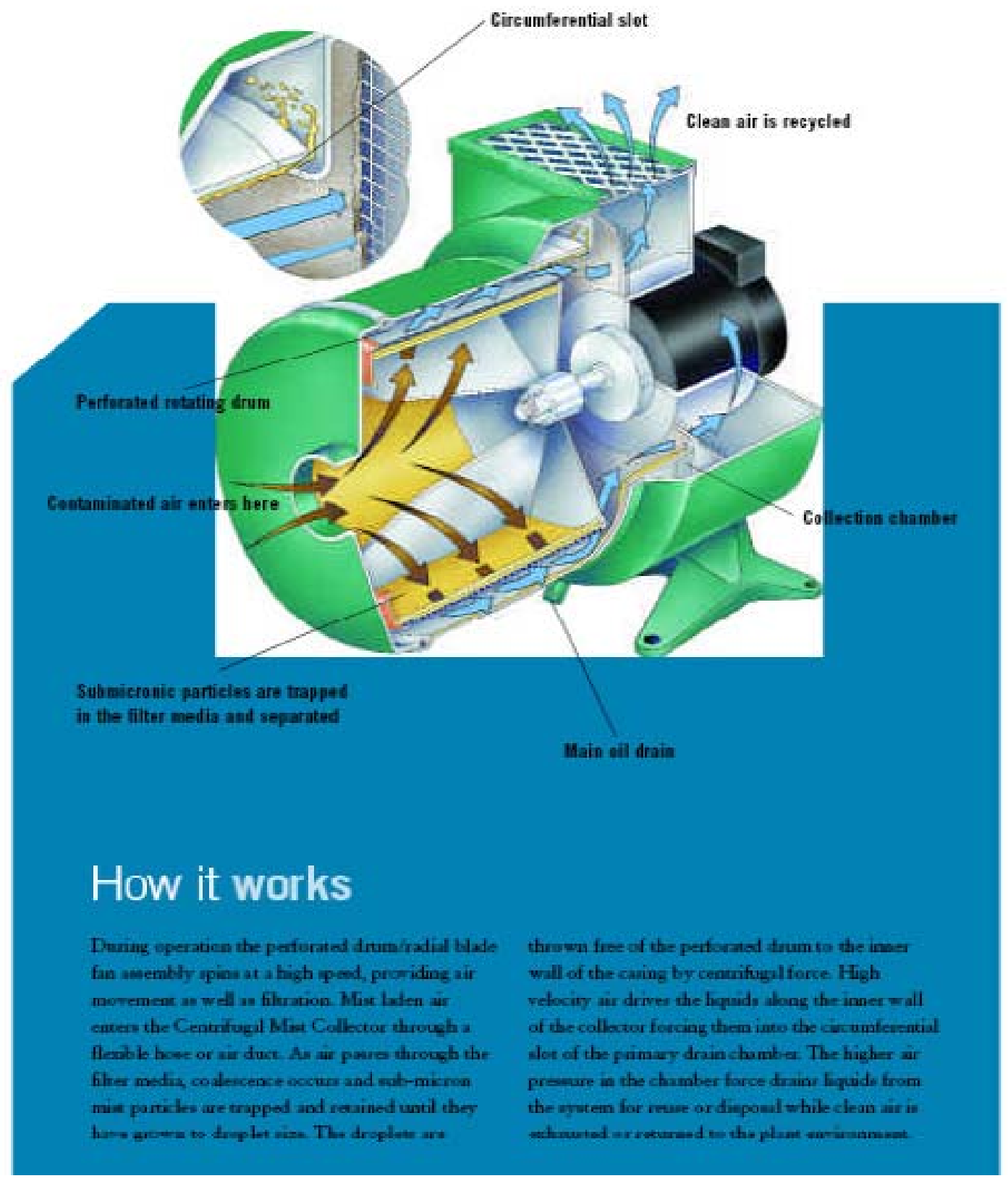




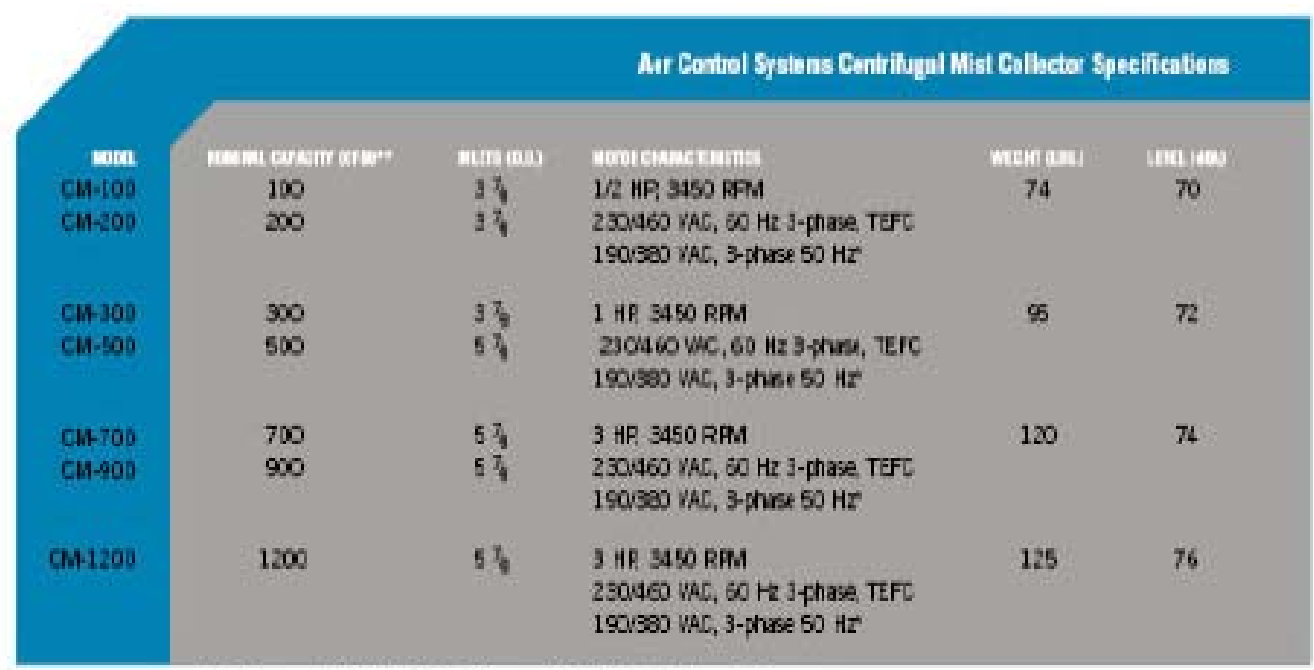

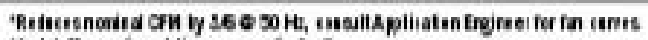

$*$ a 1. Oo negaive itaic prean $0 \mathrm{~b} / 20$

Moides CN-100 ani CM:200

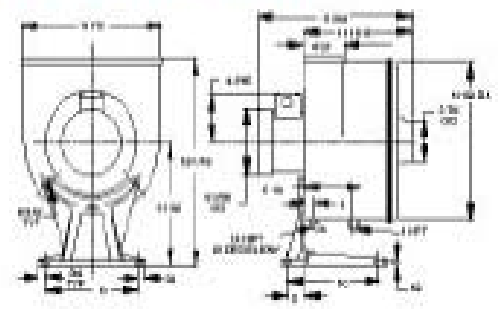

Modes CN-300 ant CM.500

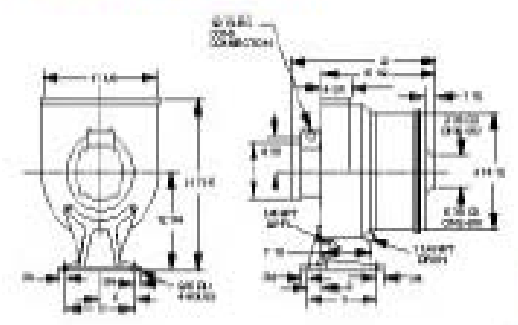

Mode's CN-300, CM-903 and CM-1200

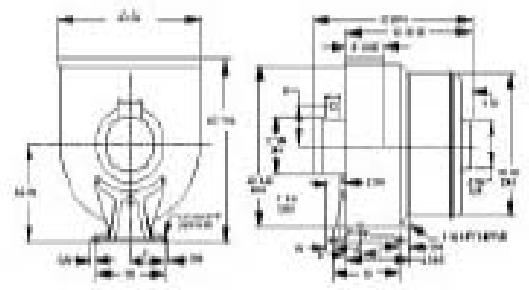

AER Control Syztriema, LUC 90 River 5 t.

New Haven, CT 06513

203-772-4700 Phone

203-772-0020 Fax

866-265-2372 Tol-free

www oercontolydtems.com

AER 


\section{ROYAL FILTERMIST FX Series}

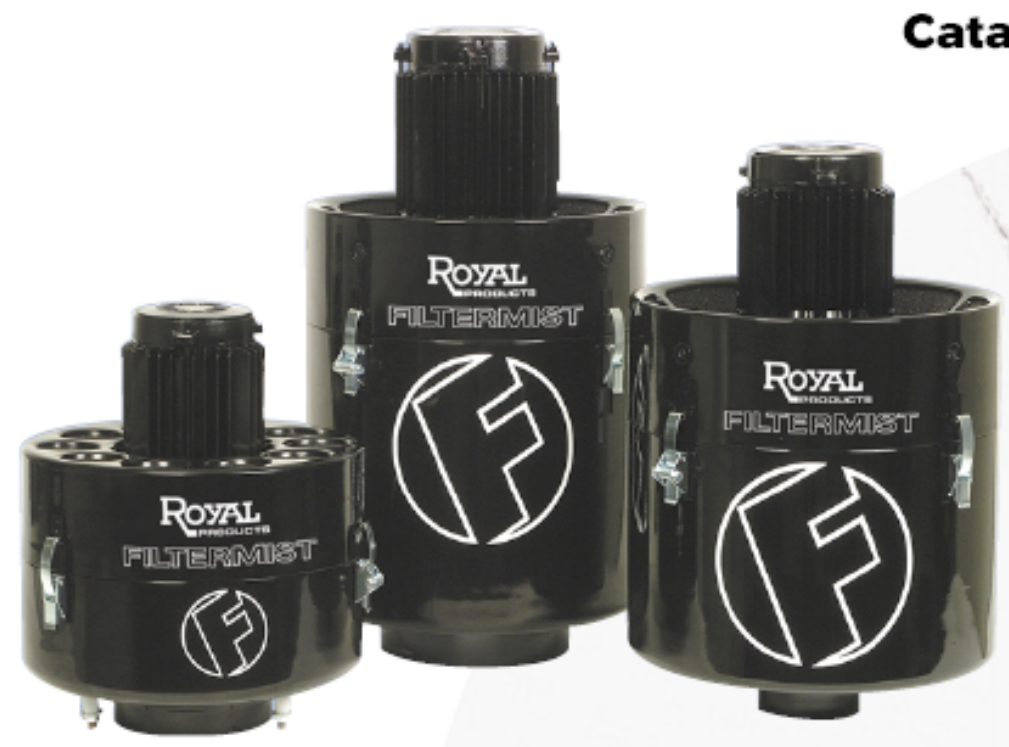

Low Cost, Highly

Efficient Mist

and Smoke

Collectors

Designed

Specifically

for the

Metalworking

Industry 


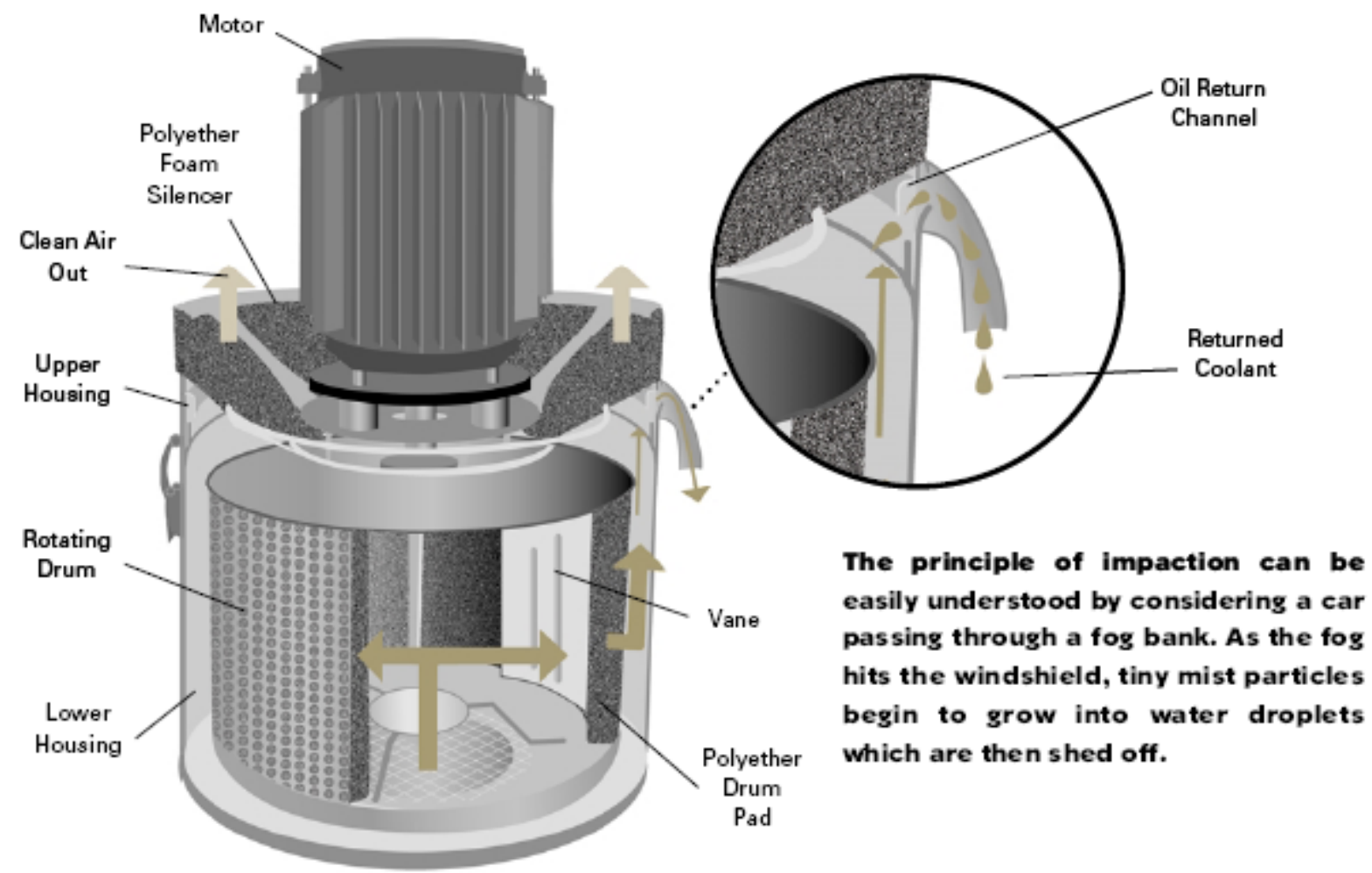

Dirty Air In

The Royal Filtermist uses the principle of centrifugal impaction to eliminate mist. With only three main components: a drum, a motor, and the housing, its operation is quite simple.

1. A three-phase motor rotates the internal drum at high speed, creating a vacuum which draws mist particles into the center of the drum.

2. The mist particles then collide with the rotating drum's vanes and are forced together with other particles, causing the $m$ to coalesce and form larger, droplet-sized particles.

3. As the particles grow into droplets, they pass through the perforations in the rotating drum and centrifugal force causes them to be thrown onto the inner wall of the housing.

4. The particles are then forced, under pressure, up the walls of the housing to the oil return channel, where they are subsequently drained back to the machine's coolant tank.
5. Clean, oil-free air blows past the motor and is returned to the shop.

6. Since this process relies on the mechanical principle of centrifugal impaction and the rotational speed remains constant, the Royal Filtermist maintains a continuous high efficiency.

7. For certain applications that produce smoke and/or very fine mist particles, an after filter may be required. This filter easily mounts to the top of the Filtermist unit by slipping over the motor and it is secured in place with two toggle clips. An after filter mounted to a Royal Filtermist typically enjoys a comparably long service life because most contaminants are removed by the impaction process prior to reaching the filter. 


\section{CHOOSING THE CORRECT FILTERMIST UNIT}

\section{Turning}

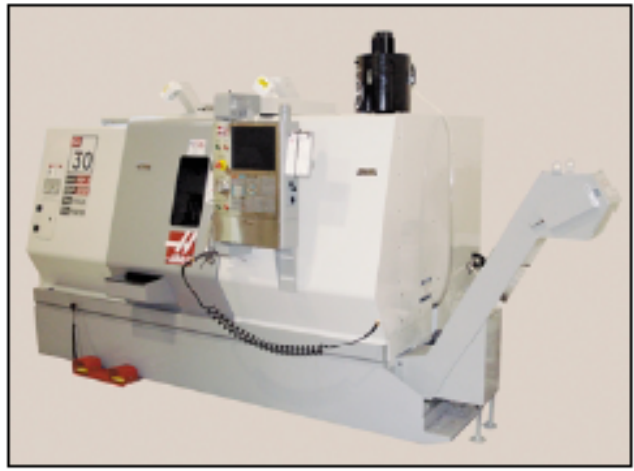

CNC lathes are relatively easy applications to tackle because the machines are usually well enclosed and direct mounting is often possible. On any well enclosed machine, it is recommended that the Filtermist intake point be located as far from the machining action as possible so that the mist is drawn from an area of heavy concentration to an area of lighter concentration. On CNC lathes, therefore, the ideal intake location is on the right side of the machine, near the tailstock. On subspindle lathes where the right-hand wall moves along the z-axis, it might be necessary for the Filtermist to have a more central location.

\section{Milling}

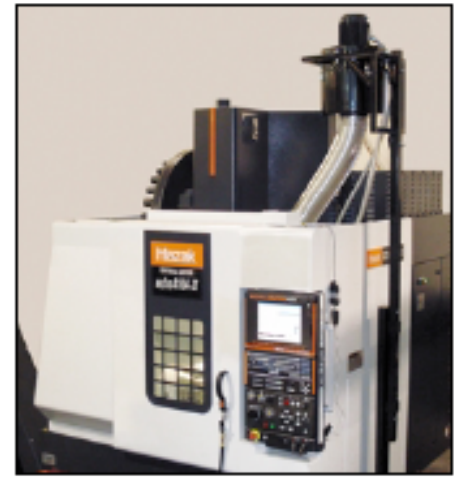

For enclosed machining centers, the Filtermist intake position should be located in an upper corner of the enclosure. Installation on open-top machines is not as clear-cut. If enclosing the machine is not possible, a successful installation can often be accomplished by suspending the Filtermist unit above the machine and running ducting down into the enclosure. It may be necessary to adjust the intake location so that it is close enough to the spindle to collect the mist, yet far enough away to keep chips from being drawn in. A Y-junction may be used to draw mist from both sides of the spindle, and a chip deflector may also come in handy.

\section{High-Pressure Coolant}

More and more machine tools today are equipped with high-pressure coolant systems. Machines running with high-pressure coolant tend to create more mist, and the particle size also tends to be smaller than normal. For most high-pressure coolant applications, the standard rules apply and Filtermist works very well. However, in some unique situations it may be necessary to take a different approach. Here are two ideas that may be worth considering:

- Downsize the Filtermist unit. On many high-pressure applications, we have seen the smaller models FX-275 and FX-550 work extremely well on large machines that would normally require a model FX-1200. Before downsizing, please speak to one of our applications engineers to ensure that this approach is the best one for your application.

- Add a cyclonic swarf separator. Although this device was designed for removing solid particles from the mist stream, it has proven itself to be quite adept as a pre-filter for high-pressure coolant applications. A large portion of the mist is actually removed by the cyclone, leaving the balance to be easily handled by the Filtermist unit. 
When evaluating the effectiveness of any mist collection system, two major aspects must be considered:

- The unit must be capable of handling the full volume of mist produced by the application.

- The unit must be efficient at capturing particles of all sizes.

Independent testing has proven the Royal Filtermist FX Series to be very effective at handling large volumes of mist and highly efficient at dealing with the full spectrum of particle sizes found in typical metalworking mist concentrations.

While a typical metalworking mist concentration is made up of many different-sized particles, $80-90 \%$ of these particles are larger than one micron in size. Fewer than $10 \%$ of the particles are smaller than 0.5 micron in size.

In order to effectively eliminate mist, the Royal Filtermist incorporates a two-phase process:

1. The first phase utilizes the mechanical process of centrifugal impaction. This centrifugal impaction process is the heart of the Filtermist's operating principle and it is highly effective at handling large volumes of mist.

The centrifugal impaction process is almost $100 \%$ efficient at handling particles larger than one micron, which make up the bulk of the mist. When considering a weighted average of the particle size in a typical metalworking mist concentration, overall efficiency of the impaction process is roughly $98 \%$.
2. Many may consider an efficiency of $98 \%$ to be adequate for their needs. However, if additional efficiency is required, the Royal Filtermist FX Series units may be equipped with an after filter to handle the small amount of residual mist that bypasses the impaction process. Royal after filters use a carefully selected grade of media that provides an effective balance between being fine enough to capture the smallest of particles while still allowing the filter to enjoy a comparatively long service life. Overall efficiency of a Royal Filtermist FX Series unit equipped with an after filter exceeds $99.5 \%$.

\section{OSHA and NIOSH Standards}

The OSHA and NIOSH limits on airborne mist particles are currently set at $5 \mathrm{mg} / \mathrm{m}^{2}$. It is believed that in the coming years this level will be reduced by a factor of ten to a new level of $0.5 \mathrm{mg} / \mathrm{m}^{2}$. The Royal Filtermist FX is so efficient that when equipped with an after filter, it easily meets not only the current limit, but even the stricter proposed limit.

\begin{tabular}{|c|c|}
\hline \multicolumn{1}{|c|}{ Lecetion } & Concentration $\left(\mathrm{mg} / \mathrm{m}^{2}\right)$ \\
\hline Ambient Shop Air & 0.75 \\
FX-1200 Inlet & $8.0-10.0$ \\
FX-1200 Exhaust & 0.18 \\
\hline
\end{tabular}

In a recent test carried out by an independent contractor, a Mori Seiki SL75ML was fitted with a model FX-1200 Filtermist unit and after filter. Particle counters were set up to monitor the air at three locations during machining - the ambient shop air, the Filtermist intake, and the Filtermist exhaust. The test results confirm that the Filtermist easily meets the challenge. Particle concentration levels at the Filtermist exhaust were well below $0.5 \mathrm{mg} / \mathrm{m}^{2}$. In fact, the air at the Filtermist exhaust was fourtimes cleaner than the ambient shop air!

IMPORTANT - The Royal Filtermist is designed to help your shop meet current and future air quality standards. It must be understood, however, that there are many variables involved in controlling shop pollution and we cannot guarantee that the Filtermist alone will prevent occupational diseases to workers. It is your responsibility to establish an effective overall industrial hygiene program designed to comply with OSHA and NIOSH standards. If you have any questions regarding this issue, please contact us at 1-800-645-4174. 


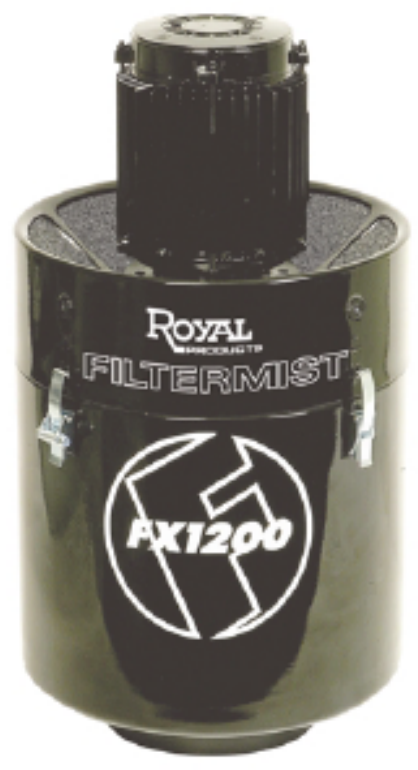

- For use on enclosed machines with an internal volume of $120 \mathrm{cu}$. ft. or larger.

- Popular for machines requiring Y-junction and two intake points.

- Excellent choice for large machining centers.

- Unit can be mounted directly to the machine, on stands, on brackets, or suspended. See pages 12-13 for mounting options.

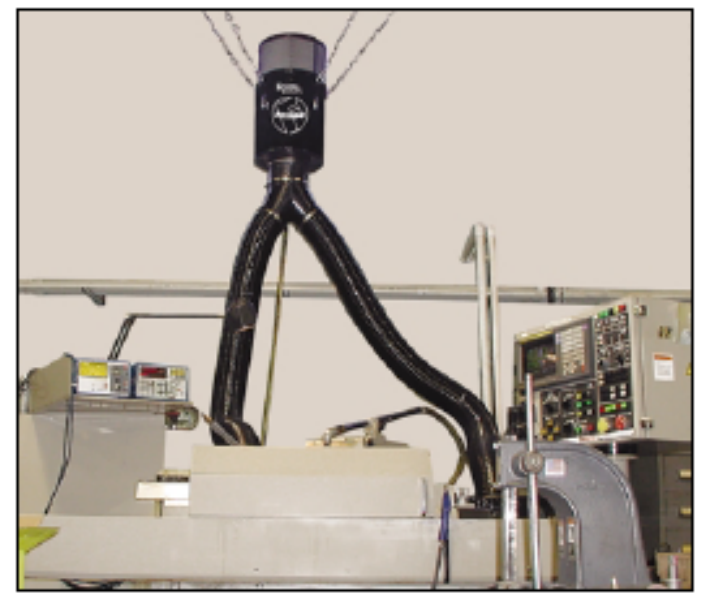

\begin{tabular}{|c|c|}
\hline Airflow & $1200 \mathrm{cfm}$ \\
\hline $\begin{array}{l}\text { Fits machines with } \\
\text { enclosure volume of: }\end{array}$ & 120 cubic feet or larger \\
\hline Motor & $\begin{array}{c}3 \mathrm{HP}, 3-\mathrm{Phase}, 50 / 60 \mathrm{~Hz} \\
\text { voltage \& Current } @ \Theta \mathrm{Hz} \text {. } \\
208 \mathrm{~V}-8.8 \mathrm{~A} \\
230 \mathrm{~V}-8.2 \mathrm{~A} \\
460 \mathrm{~V}-4.1 \mathrm{~A}\end{array}$ \\
\hline Weight & 64 Ibs. \\
\hline Noise Level & $72 \mathrm{dBA}$ \\
\hline Inlet Diameter & $8^{*}$ \\
\hline
\end{tabular}

\begin{tabular}{|c|c|}
\hline Direct Mount & use $30304-$ FX-1200 Direct Mount Kit \\
\hline Floor stand & use 30315 - Floor stand ' $B$ ' \\
\hline Machine Top Stand & use 30314 - Machine Stand " $\mathrm{B}^{N}$ \\
\hline Wall Mount & use $30320-$ Wall Bracket " $\mathrm{B}^{N}$ \\
\hline Machine side Mount & N/A \\
\hline suspended & use $30310-$ Suspension KIt ${ }^{\prime \prime} B^{N}$ \\
\hline
\end{tabular}
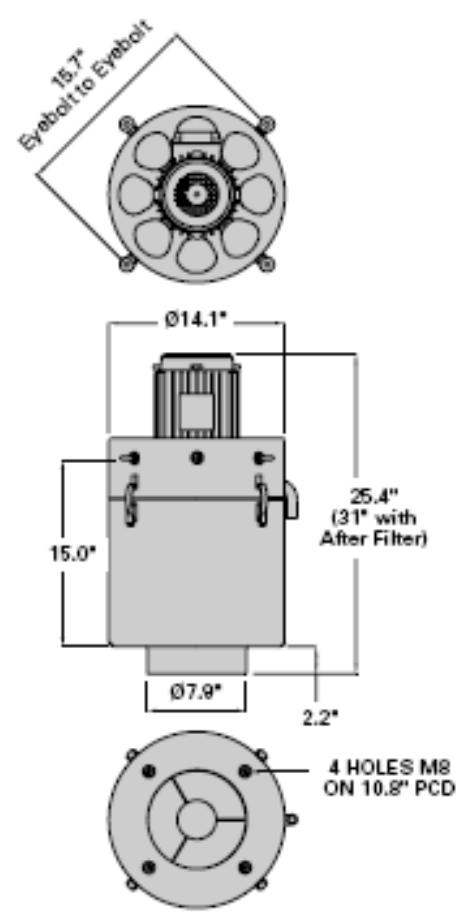


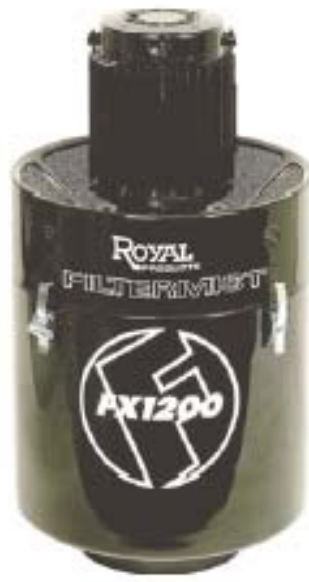

\section{Filtermist Units}

\begin{tabular}{|l|c|r|}
\hline Dascription & Cat. No. & Pulee \\
\hline $\begin{array}{l}\text { FX-1200 Flltermist Unit } \\
\text { Order performance and mounting } \\
\text { accessories separately. }\end{array}$ & 30130 & $\mathbf{\$ 2 , 3 9 6}$ \\
$\begin{array}{l}\text { FX-1200 Stalniess Steel Unit } \\
\text { See page 10 for additional infomation. }\end{array}$ & 30170 & $\mathbf{\$ 4 , 0 6 5}$ \\
\hline
\end{tabular}

\section{Performance Accessories}

\begin{tabular}{|c|c|c|}
\hline vescription & car wo. & Price \\
\hline $\begin{array}{l}\text { After Fliter " } \mathrm{B} \text { " } \\
\text { Used for collecting dry smoke } \\
\text { and very fine mist particles. }\end{array}$ & 30205 & $\$ 234$ \\
\hline $\begin{array}{l}\text { Cychnic Swart Separator } \\
\text { For use on applications such } \\
\text { as grinding and cast iron } \\
\text { machining where very nine } \\
\text { solid particles are entrained } \\
\text { in the mist stream. Also acts } \\
\text { as a great pre-fiter for high } \\
\text { pressure coolant appilcations. }\end{array}$ & 30210 & $\$ 643$ \\
\hline $\begin{array}{l}\text { Nolse Attenuator } \\
\text { Decresses the noise level by } \\
\text { approximately } 5 \mathrm{~dB} \text {. Cannot } \\
\text { be used in conjunction with } \\
\text { after niters. }\end{array}$ & 30215 & $\$ 483$ \\
\hline $\begin{array}{l}\text { Chlp Deflector } \\
\text { Protects intake from coolant } \\
\text { splash and chips. }\end{array}$ & 30220 & $\$ 44$ \\
\hline
\end{tabular}

\section{Mounting Accessories}

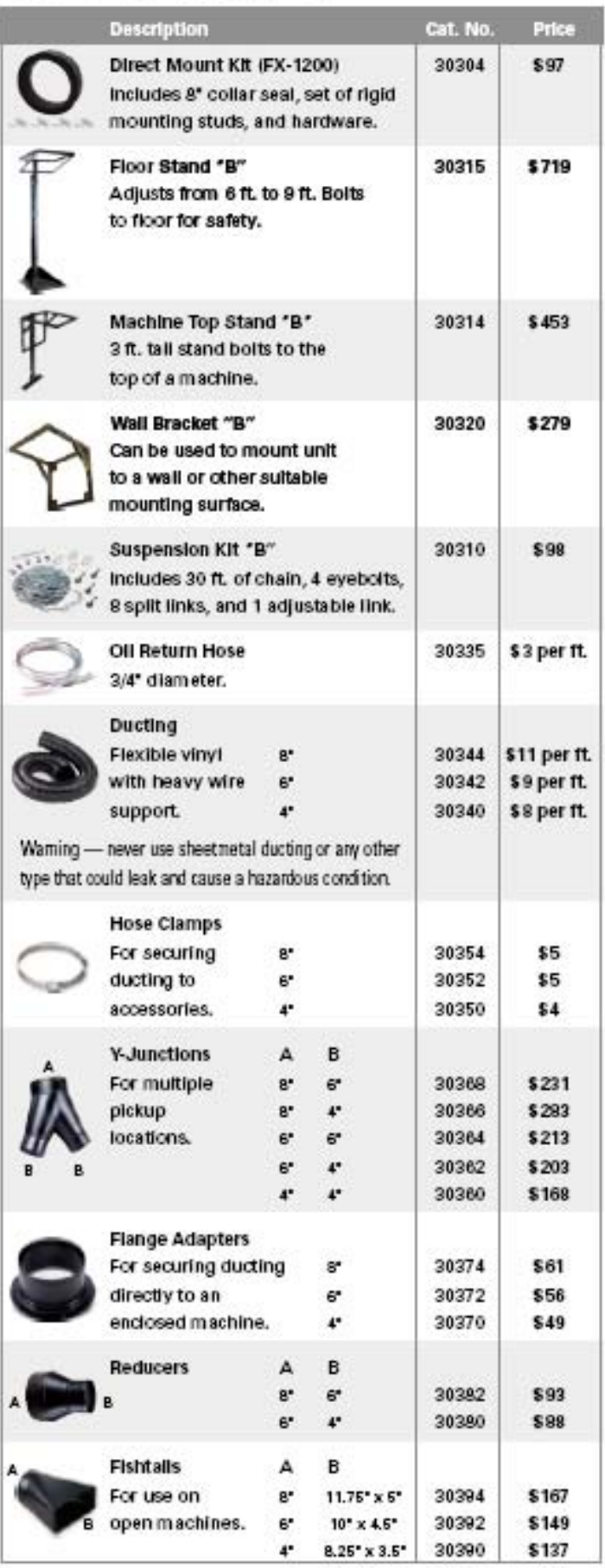


One of the most popular features of the Royal Filtermist is the fact that it requires minimal maintenance. Unlike media-type systems and electrostatic units, the Royal Filtermist works almost as well when it is dirty as it does when it is clean.

For safety purposes, it is necessary to periodically inspect the main components of the Royal Filtermist for wear or damage, especially if the unit is making loud noises or exhibiting vibration. Additionally, we recommend that these simple maintenance procedures be carried out every 2,000 operating hours, (every 1,000 hours for more demanding applications):

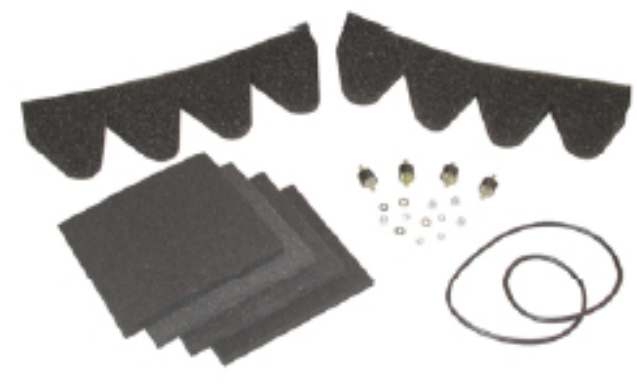

- Replace the drum pads. The pads that line the Filtermist drum are made from a specially manufactured foam containing thousands of tiny pores. These pores provide direct pathways from one side of the pad to the other for optimum airflow. They also assist in the coalescence of the mist particles for improved fluid collection. It is important that the pores of the drum pads be kept open for maximum flow.

- Inspect and replace the motor mounts and torque limiting straps if wom or damaged.

- Inspect silencer and replace if worn or damaged. If the silencer is saturated with oil, it is important to investigate the reason why. This could be the result of a clogged oil return channel or incorrect drum rotation. Important - the Filtermist will create suction regardless of which way the drum spins, but it will only properly collect and retum oil mist if the drum is spinning in the proper direction as indicated by the arrow on the housing.

- Inspect the housing seal and replace if necessary. This is especially important on older series units. The redesigned housing of the Filtermist FX Series virtually eliminates the chance of leakage around the seal area.

- Check all mounting fixtures such as stands and suspension kits for damage or signs of fatigue. Repair or replace as necessary.

- Check all other accessories for wear and/or damage (ducting. flange adapters, etc). Repair or replace as necessary.

- For your convenience, Royal Products offers complete maintenance kits for all Filtermist units. These value-priced kits include a drum pad set, a motor mount set, a silencer, and a housing seal. These items are also available separately.

Important - The recommended maintenance schedule and procedures outlined above are meant to serve as a guide for most common Filtermist applications. More detailed information is provided in the Royal Filtermist Installation and Maintenance Manual. When dealing with any equipment of this type, common sense must prevail. Any unsafe conditions pertaining to the Royal Filtermist must be immediately attended to. It is also important to understand that when Royal Filterm ist units are used in demanding applications such as grinding or cast iron machining, more frequent maintenance may be required. If you have any questions regarding the maintenance or operation of your Royal Filtermist units, please refer to the Royal Filtermist Installation and Maintenance Manual or contact one of our engineers at 1-800-645-4174.

\section{Maintenance Items}

\begin{tabular}{|c|c|c|c|c|c|c|c|c|}
\hline \multirow[b]{2}{*}{ Description } & \multicolumn{2}{|c|}{$P X-275$} & \multicolumn{2}{|c|}{ PX-550 } & \multicolumn{2}{|c|}{$P X-900$} & \multicolumn{2}{|c|}{$P X-1200$} \\
\hline & Cat No. & Price & Cat. No. & Price & Cat No. & Price & Cat. No. & Price \\
\hline $\begin{array}{l}\text { Complete Malntenance Kit } \\
\text { Complete kit provides a cost savings } \\
\text { over individual components. Includes } \\
\text { the following: drum pad set, silencer, } \\
\text { housing saal, and motor mount set. }\end{array}$ & 30400 & $\$ 110$ & 30406 & $\$ 129$ & 30402 & $\$ 158$ & 30404 & $\$ 167$ \\
\hline Drum Pad set & 30410 & $\$ 26$ & 30416 & $\$ 41$ & 30412 & $\$ 49$ & 30414 & $\$ 55$ \\
\hline sllencer & 30420 & $\$ 60$ & 30420 & $\$ 60$ & 30422 & $\$ 98$ & 30422 & $\$ 98$ \\
\hline Housing Seal & 30430 & $\$ 12$ & 30430 & $\$ 12$ & 30432 & $\$ 15$ & 30432 & $\$ 15$ \\
\hline Motor Mount Set & 30440 & $\$ 44$ & 30440 & $\$ 44$ & 30442 & $\$ 51$ & 30442 & $\$ 51$ \\
\hline
\end{tabular}

See page 28 for maintenance items for older series Filterm ist units. 


\section{ROYAL FILTERMIST FX Series}

\section{Catalog and Price List}

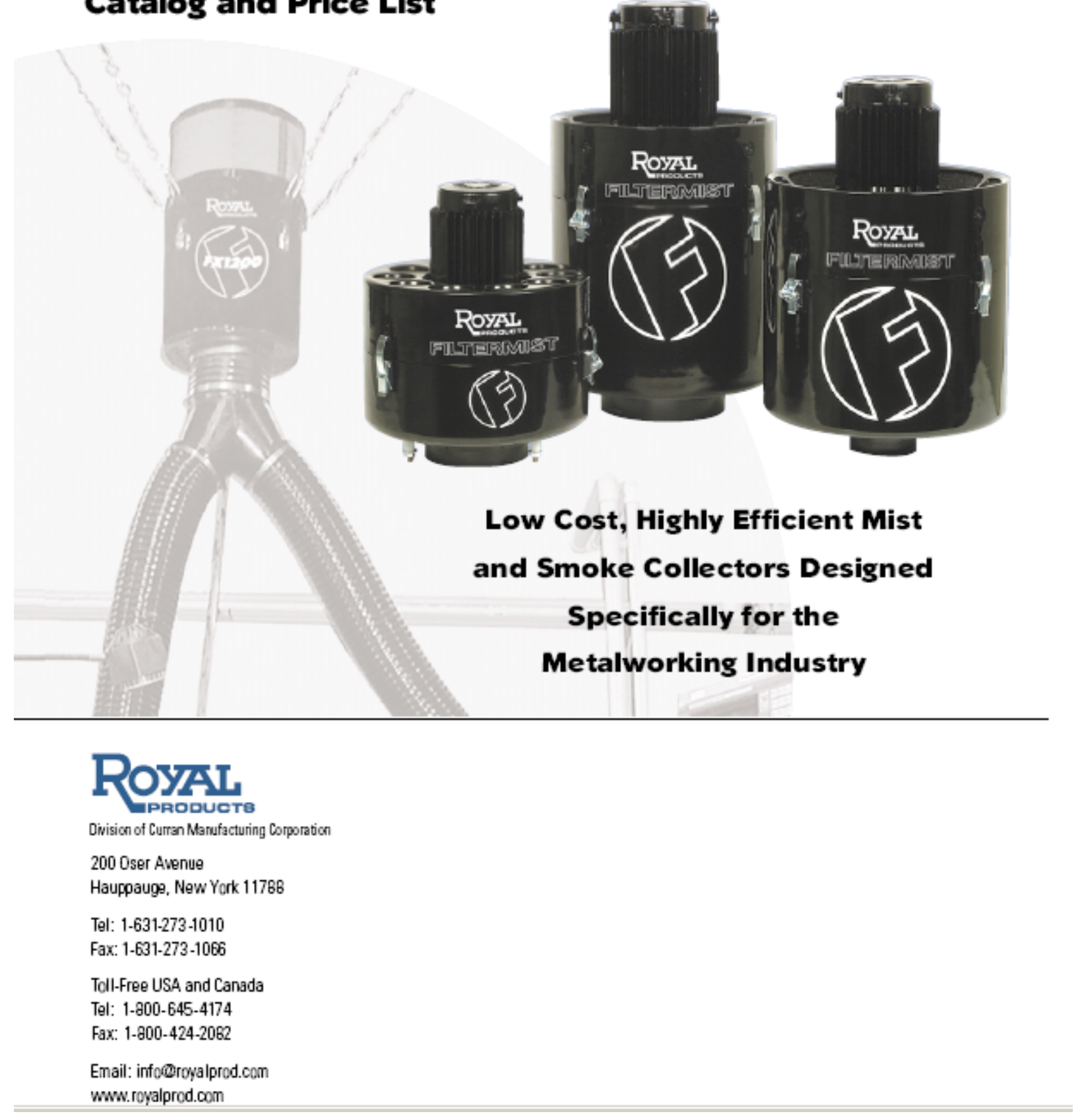




\section{ACE 73-200G} PORTABLE

\section{FUME EXTRACTOR}

$226 \mathrm{CFM}$, high vacuum fume extraction \& filtration capacity

Designed for field and bench work, this unit lightweight, portable, and easy to use

$10 \mathrm{ft}$. extraction hose $\mathrm{w} /$ flexible steel tube and nozzle assembly

Magnetic support base for hands free operation

Specialty filters available for odor and oil mist control

Heawy Duty steel construction Built in spark trap for fire safety

\section{Filter status LED light}

Optional two-operator feature available

\section{UL Listed}

Made in USA

Two year limited warranty

Dim. : $27^{\prime \prime} \mathrm{L} \times 12^{\prime \prime} \mathrm{H} \times 12^{\prime \prime W}$

Weight: 40 lbs
Oul' most

\section{versatile}

portable

extractoli, and the choice of welder's, mechanical contractor's, and rental fleets for over twenty year's

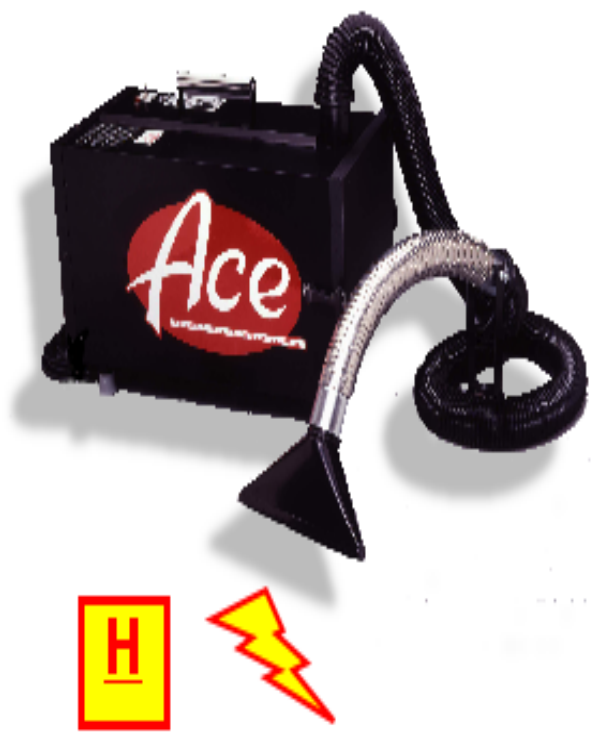

\begin{tabular}{|c|c|}
\hline DESCRIPTION & PART\# \\
\hline \multicolumn{2}{|l|}{ INAIII UIIT } \\
\hline \multicolumn{2}{|l|}{ 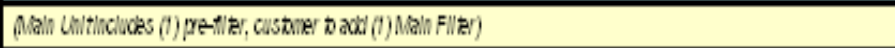 } \\
\hline 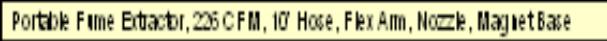 & $73-2006$ \\
\hline \multicolumn{2}{|l|}{ PRE-FLLTERS } \\
\hline \multicolumn{2}{|l|}{ 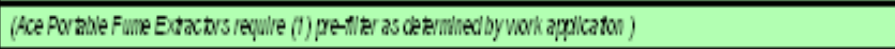 } \\
\hline 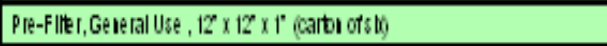 & 65011 \\
\hline Ple-Fllter, ExoraingGrakt, , $12 \times 12 \times 11^{\circ}$ & 6039 \\
\hline Pre-Fller, bul Wiap, 12 x 250 Yard & $91-963$ \\
\hline Ple-Fllter,Claroalodor Cortol, $12 \times 12 \times 10^{\circ}$ & 65037 \\
\hline 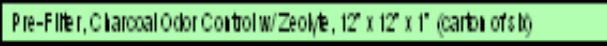 & 60044 \\
\hline Pre-Filter, Aluminim on inktCortol, $12 \times 12 \times 11^{\circ}$ & 65013 \\
\hline \multicolumn{2}{|l|}{ IIAIII FILTERS } \\
\hline \multicolumn{2}{|l|}{ 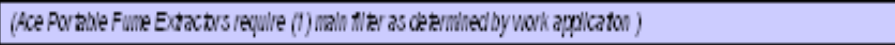 } \\
\hline 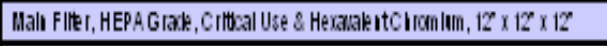 & 65010 \\
\hline 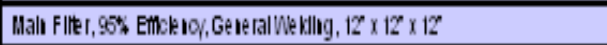 & 6509 \\
\hline 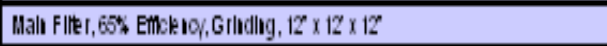 & 6500 \\
\hline \multicolumn{2}{|l|}{ PARTS } \\
\hline Hotr, Portale Fume Extacti & 6501 \\
\hline Hotr Gaket, Portule Fime Ertacti & 60002 \\
\hline 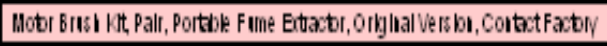 & 6507 \\
\hline 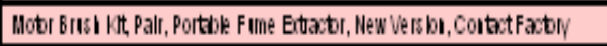 & 65077 \\
\hline Poner Sulti, Portale Fime Etactor & 6006 \\
\hline PowerCord, Portale Fine Eutactor & 6005 \\
\hline 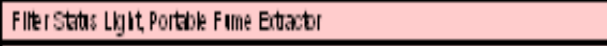 & 6504 \\
\hline 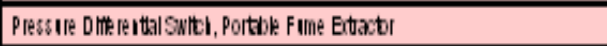 & 6506 \\
\hline 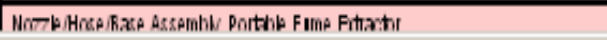 & 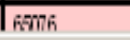 \\
\hline
\end{tabular}


ACE 73-601

MOBILE

\section{FUME EXTRACTOR}

$1200 \mathrm{cfm}$, high volume fume extraction \& filtration capacity

Designed for shopfloor use with the mobility to move from workstation to workstation

$10 \mathrm{ft}$. extraction arm with articulated joints designed to hold position for hands free use

Wide mouth source capture hood

Heavy Duty steel construction Built in spark trap for fire safety

Durable casters, two that swivel and lock for stability

Filter status gauge

Built in AC outlet to power other tools or accessories

Optional two-operator feature available

Optional automatic on/off feature available

\section{UL Listed}

Made in USA

Our' most

powerful mobille fume extractor also has $360^{\circ}$ arm rotation for' maximum reach and

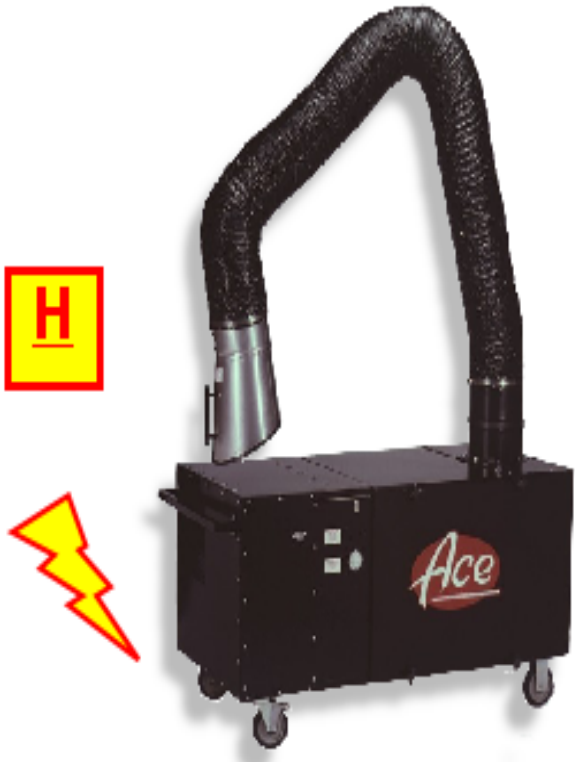

\begin{tabular}{|c|c|}
\hline DESCRIPTION & PART \# \\
\hline \multicolumn{2}{|l|}{ MAIN UNIT } \\
\hline \multicolumn{2}{|l|}{ (Main Unit DOES NOT include Fiters; select (1) Pre-Fitter and' (1) Main Fiter from below) } \\
\hline Mobile Air Cleaner, 1200 CFM, 10' Extraction Am, Horizontal Orientation & $73-601$ \\
\hline \multicolumn{2}{|l|}{ PRE FILTERS } \\
\hline \multicolumn{2}{|l|}{ (Main Unit requies 4 inches of pre-intration, (1) $4^{\prime}$ rither or (2) $2^{2}$ ritters) } \\
\hline Pre-Filter, General Use , 20" $\times 24 " \times 4 "$ & $91-956$ \\
\hline Pre-Fitter, General Use, 20 " $\times 24^{\prime \prime} \times 2$ " (use (1) with (1) 91.937 or (1) 91.958 ) & $91-955$ \\
\hline Pre-Filter, Bulk ioirap, 24 " $\times 250$ Yards & $91-962$ \\
\hline Pre-Filter, Charcoal Odor Control, 20" $\times 24^{\prime \prime} \times 2^{\prime \prime}$ (use w/ 91-955) & 91.937 \\
\hline Pre-Filter, Auminum Oil Mst Control, 20" 24" × 2 " (use w/91-955) & $91-958$ \\
\hline \multicolumn{2}{|l|}{ MAIIN FILTERS } \\
\hline \multicolumn{2}{|l|}{ (Main Unit requires (1) main fitter as determined by the work application) } \\
\hline Main Fitter, HEPA Grade, Stainless Steel / Hexavalent Chromium, $20 " \times 24^{\prime \prime} \times 12^{\prime \prime}$ & $91-999$ \\
\hline Main Fitter, 95\% Efficiency, General Wielding, $20^{\prime \prime} \times 24^{\prime \prime} \times 12^{\prime \prime}$ & $91-853$ \\
\hline Main Fitter, $65 \%$ Efficiency, Grinding, $20^{\prime \prime} \times 24^{\prime \prime} \times 12^{\prime \prime}$ & $91-854$ \\
\hline \multicolumn{2}{|l|}{ PARTS } \\
\hline Motor, 1 HP, Belt Drive, Mobile Fume Extractor & 65024 \\
\hline Blower Assembly, Mobile Fume Extractor & 65035 \\
\hline WBelt, Mobile Fume Extractor & 65056 \\
\hline Power Switch, Mobile Fume Extractor & 65026 \\
\hline Filter Status Gauge, Mobile Fume Extractor & 65027 \\
\hline Power Cord, Mobile Fume Extractor & 65055 \\
\hline Power Socket, Mobile Fume Extractor & 65025 \\
\hline Nozzle/Hose/Amm Assembly, Mobille Fume Extractor & 65028 \\
\hline 10' Renlan:ement Hnse Munhile Fume Fitrantor & Rinกวด्र \\
\hline
\end{tabular}

